Aus dem Institut für Neuro- und Sinnesphysiologie

(Prof. Dr. rer. nat. S. O. Rizzoli)

im Zentrum Physiologie und Pathophysiologie

der Medizinischen Fakultät der Universität Göttingen

\title{
Quantitative Anatomie zweier Formen von dendritischen Dornfortsätzen an hippocampalen Pyramidenzellen
}

\author{
INAUGURAL-DISSERTATION \\ zur Erlangung des Doktorgrades \\ für Zahnheilkunde \\ der Medizinischen Fakultät der \\ Georg-August-Universität Göttingen
}

vorgelegt von

Christina Koerbs

aus

Hannover

Göttingen 2017 
Dekan:

Prof. Dr. rer. nat. H. K. Kroemer

\section{Betreuungsausschuss:}

Betreuer:

Ko-Betreuer:

\section{Prüfungskommission:}

Referent/in:

Ko-Referent/in:

Drittreferent/in

Datum der mündlichen Prüfung: 11. März 2019
Prof. Dr. S. O. Rizzoli

PD Dr. M. Rickmann

Prof. Dr. O. S. Rizzoli

Prof. Dr. J. Staiger 
Ich versichere hiermit, dass ich die vorliegende Dissertation mit dem Titel

Quantitative Anatomie zweier Formen von dendritischen

Dornfortsätzen an hippocampalen Pyramidenzellen

selbständig verfasst und keine anderen als die angegebenen Quellen und Hilfsmittel benutzt habe.

Göttingen, den 15.02.2019

Christina Koerbs 


\section{Inhaltsverzeichnis}

Abbildungsverzeichnis III

Tabellenverzeichnis $\quad$ V

$\begin{array}{lll}\text { Abkürzungsverzeichnis } & \text { VI }\end{array}$

1 Einleitung $\quad 1$

1.1 Erregungsweiterleitung . . . . . . . . . . . . . . . . . 2

1.2 Morphologie der dendritischen Dornfortsätze . . . . . . . . . . . . . . . 4

1.2.1 Die postsynaptische Dichte . . . . . . . . . . . . 7

1.2.2 Neurotransmitterrezeptoren . . . . . . . . . . . . . . 9

1.2 .3 Ionenkanäle . . . . . . . . . . . . . . . . . . . . . . . 9 9 9

1.2.4 Endosomen . . . . . . . . . . . . . . . . . . . 10

1.2.5 Endoplasmatisches Retikulum und Golgi-Apparat . . . . . . . . 10

1.2.6 Ribosomen . . . . . . . . . . . . . . . . . . . . . 11

1.2.7 Mitochondrien . . . . . . . . . . . . . . . . . . . 11

1.3 Synaptische Plastizität . . . . . . . . . . . . . . . . . . . . 12

1.3.1 Kurzzeitplastizität . . . . . . . . . . . . 12

1.3.2 Langzeitplastizität . . . . . . . . . . . . . . . . . 13

1.4 Der Hippocampus . . . . . . . . . . . . . . . . . . . . . . . . . . . . . . 15

1.5 Ziel dieser Arbeit . . . . . . . . . . . . . . . . . . 15

2 Material und Methoden $\quad 17$

2.1 Sandwich-Zellkultur . . . . . . . . . . . . . . . . . . . . 17

2.1.1 Übersicht des Ablaufs . . . . . . . . . . . . . . . . . . . 19

2.1.2 Präparation und Wachstum der kortikalen Astroglia . . . . . . . 19

2.1.3 Präparation der Astrogliaschicht in 12-Well-Platten . . . . . . . 21

2.1.4 Vorbereitung der Saphirscheiben . . . . . . . . . . . . . . 21

2.1.5 Präparation der Neuronen und Anlegen der Sandwich-Kultur . . 22

2.1.6 Hochdruckgefrierung . . . . . . . . . . . . . . . 23

2.1.7 Gefriersubstitution ................. 24 
2.2 Konventionelle Zellkultur . . . . . . . . . . . . . . . . . . . . . 25

2.2.1 Vorbereitung der Deckgläser . . . . . . . . . . . . . 25

2.2.2 Neuronenpräparation . . . . . . . . . . . . . . 26

2.2.3 Einbettung der Zellsuspension . . . . . . . . . . . . . . . 27

2.3 Datenanalyse . . . . . . . . . . . . . . . . . . . . . . . . 28

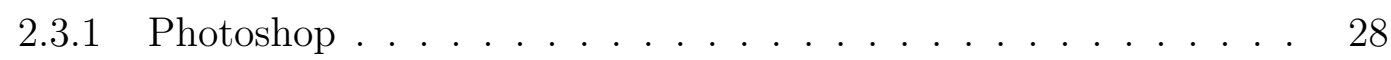

2.3.2 Matlab......................... 28

2.3.3 Statistik ......................... 33

2.3.3.1 Pearson-Korrelation . . . . . . . . . . . 33

2.3 .3 .2 t-Test . . . . . . . . . . . . . 34

3 Ergebnisse $\quad 35$

3.1 3D-Modelle der stumpfartigen dendritischen Dornfortsätze . . . . . . . 35

3.2 3D-Modelle der pilzförmigen dendritischen Dornfortsätze . . . . . . . . 35

3.3 Aktive Zone . . . . . . . . . . . . . . . . . . . . . . . . . . . . 38

3.4 Gesamtoberfläche . . . . . . . . . . . . . . . . 46

3.5 Volumen . . . . . . . . . . . . . . . . . . 47

3.6 Achsenverhältnis . . . . . . . . . . . . . . . . 50

3.7 Schnittvolumen . . . . . . . . . . . . . . . . . . . . 53

3.8 Schnittumfang . . . . . . . . . . . . . . . . . . 56

4 Diskussion $\quad 58$

4.1 Zusammenhang zwischen Form und Funktion . . . . . . . . . . . 58

4.2 Aktive Zone . . . . . . . . . . . . . . . . . . . . . . . . . . 59

4.2.1 Vergleich zwischen der aktiven Zone und der Gesamtoberfläche . 61

4.2.2 Vergleich zwischen der aktiven Zone und des Gesamtvolumens . 61

4.2.3 Formen und Lage der aktiven Zone . . . . . . . . . . . . . . . . 61

4.3 Abhängigkeit zwischen der Form der dendritischen Dornfortsätze und der Oberfläche der aktiven Zone . . . . . . . . . . . . . . . 63

4.4 Gesamtvolumen . . . . . . . . . . . . . . . . . . . . 64

4.5 Technische Aspekte und Modellkritik . . . . . . . . . . . . . . . 65

4.6 Schlussfolgerung . . . . . . . . . . . . . . . . 65

$\begin{array}{lll}5 & \text { Zusammenfassung } & 67\end{array}$

$\begin{array}{lll}6 & \text { Anhang } & 69\end{array}$

$\begin{array}{lll}7 & \text { Literaturverzeichnis } & 80\end{array}$ 


\section{Abbildungsverzeichnis}

1.1 Aufbau eines Neurons . . . . . . . . . . . . . . . . . . . . . 2

1.2 Unterschiedliche Formen der dendritischen Dornfortsätze . . . . . . . . 5

1.3 Aufbau und Organellen eines dendritischen Dornfortsatzes . . . . . . . 7

1.4 Teilungsvorgang eines dendritischen Dornfortsatzes mit den unterschiedlichen Strukturen der PSD . . . . . . . . . . . . . . . 8

1.5 Reproduziert von Sorra und Harris 2000 mit schriftlicher Einverständniserklärung des Autors: Vergleich der Weiterleitung bei den unterschiedlichen Formen der dendritischen Dornfortsätze . . . . . . . . . . . . . . . 16

2.1 Aufbau einer Sandwich-Kultur . . . . . . . . . . . . . . . . . . . 18

2.2 Elektronenmikroskopische Aufnahme eines Ultradünnschnitts . . . . . . 29

2.3 Die Schnitte eins bis sieben des dendritischen Dornfortsatzes (jeweils weiß markiert zur besseren Übersicht) . . . . . . . . . . . . . . . . . . . 30

2.4 Matlab: Schnitt eines Dornfortsatzes . . . . . . . . . . . . . . . 31

2.5 Matlab: Zweiter Schnitt eines Dornfortsatzes . . . . . . . . . . . . . 32

2.6 Matlab: Dritter Schnitt eines Dornfortsatzes . . . . . . . . . . . . . . . 32

2.7 3D-Modell einer Postsynapse . . . . . . . . . . . . . . . . . . . . . 33

3.1 3D-Modelle der stumpfartigen dendritischen Dornfortsätze . . . . . . . 36

3.2 3D-Modelle der pilzförmigen dendritischen Dornfortsätze . . . . . . . . 37

3.3 Durchschnittliche Oberfläche der aktiven Zonen . . . . . . . . . . . . 38

3.4 Anzahl der Dornfortsätze in Relation zu festgelegten Größen der aktiven Zone (Intervallbildung) . . . . . . . . . . . . . . . . . . 40

3.5 Oberfläche der aktiven Zone vs. Gesamtvolumen . . . . . . . . . . . . . 41

3.6 Oberfläche der aktiven Zone vs. Gesamtoberfläche . . . . . . . . . . . . 42

3.7 Relativer Anteil der aktiven Zone an der Gesamtoberfläche . . . . . . . 43

3.8 Hauptachse vs. Oberfläche der aktiven Zone . . . . . . . . . . . . . . . 44

3.9 Distanzen vom Zentrum der aktiven Zone zur Membran . . . . . . . . . 45

3.10 Distanzen vom Zentrum der aktiven Zone zum Zentrum des Dornfortsatzes 46

3.11 Gesamtoberfläche der Dornfortsätze . . . . . . . . . . . . . . . . . . . 47

3.12 Volumen der Dornfortsätze . . . . . . . . . . . . . . . . . . . . 48 
3.13 Volumenverteilung der Dornfortsätze . . . . . . . . . . . . . 50

3.14 Achsenverhältnis schematisch . . . . . . . . . . . . . . 51

3.15 Achsenverhältnisse der dendritischen Dornfortsätze . . . . . . . . . . 51

3.16 Standardabweichungen der Achsenverhältnisse . . . . . . . . . . . . . . 52

3.17 Haupt- vs. Nebenachsenlänge . . . . . . . . . . . . . . . . . . . 53

3.18 Schnittvolumina . . . . . . . . . . . . . . . . . 54

3.19 Schnittvolumen vs. Oberfläche der aktiven Zone . . . . . . . . . . . . . 55

3.20 Schnittumfänge . . . . . . . . . . . . . . . . . 56

3.21 Schnittumfang vs. Oberfläche der aktiven Zone . . . . . . . . . . . . . . 57

4.1 Form der aktiven Zone . . . . . . . . . . . . . . . . . . . . . 62 


\section{Tabellenverzeichnis}

1.1 Ionenkonzentrationen . . . . . . . . . . . . . . . . . . . . 3

2.1 Übersicht Sandwich-Kultur . . . . . . . . . . . . . . . . . . . . . . . . . 19

3.1 Volumina der Dornfortsätze (Intervallbildung) . . . . . . . . . . . . . . 49

6.1 Oberfläche der aktiven Zonen . . . . . . . . . . . . . . . 69

6.2 Gesamtoberflächen aller dendritischen Dornfortsätze . . . . . . . . . . . 70

6.3 Volumina aller dendritischen Dornfortsätze . . . . . . . . . . . . . . . . 71

6.4 Achsenverhältnisse aller dendritischen Dornfortsätze . . . . . . . . . . . 72

6.5 Haupt- und Nebenachsenlängen der Dornfortsätze . . . . . . . . . . . . 73

6.6 Schnittvolumina der dendritischen Dornfortsätze . . . . . . . . . . . . . 74

6.7 Schnittumfänge der dendritischen Dornfortsätze . . . . . . . . . . . . . 75 


\section{Abkürzungsverzeichnis}

AMPA ...........Alpha-Amino-3-hydroxy-5-methyl-4-isoxazol-Propionsäure

AP $\ldots \ldots \ldots \ldots \ldots$ Aktionspotenzial

APP ............. Amyloid-Vorläuferprotein (amyloid precursor protein)

ATP ............. Adenosintriphosphat

BDNF ........... Brain derived neutrophic factor

BSS .............. Bikarbonatfreie Hanks' gepufferte Salzlösung

cAMP ........... Zyklisches Adenosinmonophosphat

CMF-HBSS ........ Kalzium-, Magnesium- und Bikarbonat-freie Hanks' gepufferte Salzlösung mit $10 \mathrm{mM}$ HEPES

DNA ............. Desoxyribonukleinsäure

EDTA ........... Ethylendiamintetraessigsäure

EM $\ldots \ldots \ldots \ldots \ldots$ Elektronenmikroskop

EPSP ............. Erregendes postsynaptisches Potenzial

ER .............. Endoplasmatisches Retikulum

FCS .............. Fetales Kälberserum (fetal calf serum)

FIB-SEM..........Focused ion beam-scanning electron microscopy

FIT ............ Regressionsgerade

FUDR ...........5-Fluoro-2'-Deoxyuridin

GABA ........... Gamma-Amino-Buttersäure

GluR-2 ......... Glutamatrezeptor 2 
HBSS ............Hanks' gepufferte Salzlösung (Hank's Balanced Salt Solution)

HEPES ........... 2-(4-(2-Hydroxyethyl)-1-piperazinyl)-ethansulfonsäure

HPF ............. Hochdruckgefrierung (high pressure freezing)

IPSP $\ldots \ldots \ldots \ldots$ Inhibierendes postsynaptisches Potenzial

$\mathbf{K}_{\mathrm{ez}} \ldots \ldots \ldots \ldots \ldots$ Konzentration Extrazellulärraum

$\mathbf{K}_{\mathbf{i z}} \ldots \ldots \ldots \ldots \ldots$ Konzentration Intrazellulärraum

LTD ............. Langzeitdepression (long-term depression)

LTP ............... Langzeitpotenzierung (long-term potentiation)

MEM .............Minimal essential medium

mRNA ........... Messenger-Ribonukleinsäure

NMDA .......... N-Methyl-D-Aspartat

PBS ........... Phosphatgepufferte Salzlösung (phosphate buffered saline)

PLL ............. Poly-L-Lysin

PSD ........... Postsynaptische Dichte

PVP ............ Polyvinylpyrrolidon

RMP ........... Ruhemembranpotenzial

RNA ............ Ribonukleinsäure

rRNA ............Ribosomale Ribonukleinsäure

TEM............ Transmissionselektronenmikroskop

ZNS ........... Zentralnervensystem 


\section{Einleitung}

Erstmals wurden die dendritischen Dornfortsätze 1888 von Ramón y Cajal beschrieben. Sie sollen für die Gedächtnisfunktion von besonderes großer Bedeutung sein, da mit ihrer Hilfe Eindrücke und Informationen aus der Umwelt verarbeitet, neue Dinge erlernt und gegebenenfalls später wieder abgerufen werden können. Die Darstellung dieser dendritischen Dornfortsätze gelang erstmals 1959 mithilfe eines Elektronenmikroskops. So war es möglich, ihre Existenz endgültig nachzuweisen (Gray 1959). Die dendritischen Dornfortsätze werden auch als Postsynapse bezeichnet und sind Ausstülpungen des Dendriten, die unterschiedliche Formen annehmen können. Sie werden häufig als Kompartimentierungen angesehen, da sie ihr eigenes Mikroenvironment bilden. Dieser dendritische Dornfortsatz bildet zusammen mit der Präsynapse (axonaler Bouton) und dem dazwischenliegenden synaptischen Spalt eine Synapse. Sie verbindet Neurone miteinander und ermöglich ihnen somit die Kommunikation. Das menschliche Gehirn besteht Schätzungen zufolge aus $10^{13}$ Neuronen, die mithilfe von Synapsen ein großes Netzwerk bilden (Azevedo et al. 2009). Dieses Netzwerk zeigt unterschiedliche Anpassungsmechanismen bei veränderter Stimulation, die in ihrer Gesamtheit als synaptische Plastizität bezeichnet werden. In Abbildung 1.1 ist der Aufbau eines Neurons schematisch dargestellt.

Ein wichtiger Bestandteil von den dendritischen Dornfortsätzen ist die postsynaptische Dichte an der Membran des Endköpfchens, die sich aus einer Vielzahl an Neurotransmittern, Rezeptoren, Ionenkanälen, Proteinkinasen und -phosphatasen sowie aus Strukturproteinen (scaffold proteins) und anderen Molekülen zusammensetzt.

Unbekannt ist der genaue Vorgang, wie die Informationen gespeichert werden. Um diesen Prozess, der sich innerhalb der Synapsen abspielt, verstehen zu können, ist es wichtig, die genaue Anatomie der dendritischen Dornfortsätze zu untersuchen. Die bisherigen Studien der Anatomie der dendritischen Dornfortsätze erfolgten überwiegend an Gewebeschnitten (Harris und Stevens 1989; Parnass et al. 2000; Bourne und Harris 2007). 


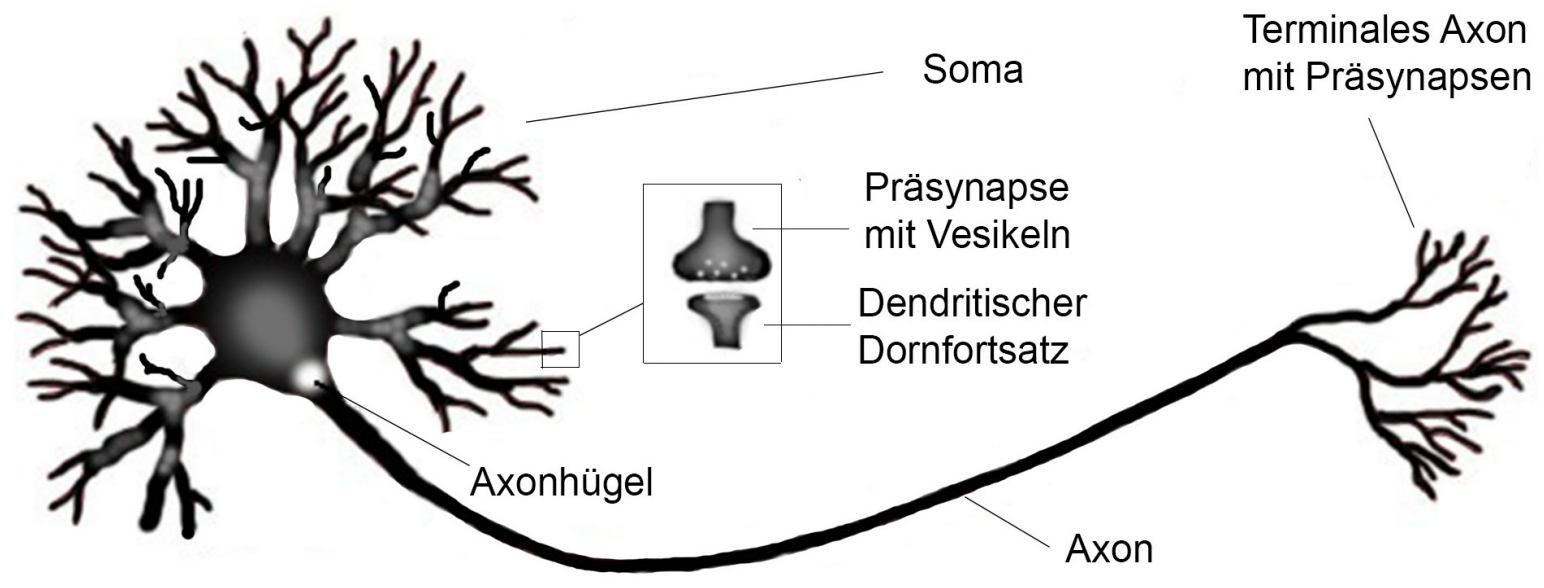

Abbildung 1.1: Aufbau eines Neurons

\subsection{Erregungsweiterleitung}

In den Neuronen herrscht im unerregten Zustand ein sogenanntes Ruhemembranpotential (RMP) von etwa $-70 \mathrm{mV}$. In anderen Zellen sind niedrigere RMP möglich: In den Skelettmuskelzellen beträgt es $-80 \mathrm{mV}$, im Arbeitsmyokard und in den Gliazellen sogar -90 mV (Rassow et al. 2012). Alle bislang analysierten Zellen haben ein negatives Ruhemembranpotential. Als Referenzwert wird das extrazelluläre Potential mit 0 $\mathrm{mV}$ definiert. Gemessen wird die Potentialdifferenz zum Intrazellulärraum. Entscheidend für die Ausbildung der Potenziale sind Transportvorgänge von Natrium- und Kaliumionen durch die Zellmembran. Durch zusätzlich unterschiedlich hohe Membranpermeabilitäten (selektive Membranpermeabilität) für die Ionen können verschiedene Konzentrationen zwischen dem Intra- und Extrazellulärraum aufgebaut werden. Der wichtigste Transporter für das Aufrechterhalten des Ruhemembranpotentials ist die Natrium-Kalium-ATPase ( $\mathrm{Na}^{+}-\mathrm{K}^{+}$-ATPase), die pro Durchgang drei Natriumionen in den Extrazellulärraum pumpt und zwei Kaliumionen in den Intrazellulärraum transportiert. Dafür wird Energie in Form von ATP (Adenosintriphosphat) benötigt, welches in der Zelle produziert wird. Die Zellmembran ist für Kaliumionen, anders als für Natriumionen, durchlässig. Aufgrund der Natrium-Kalium-ATPase wird ein Konzentrationsgradient für Kalium erzeugt, der diese positiv geladenen Ionen wieder in den Extrazellulärraum strömen lässt. Dieser chemischen Triebkraft steht dann die elektrische Triebkraft entgegen, da der Extrazellulärraum durch die nach außen strömenden Kaliumionen positiver geladen wird und die Kationen wieder in den Intrazellulärraum gezogen werden. So wird das RMP von -90 mV aufgebaut. Da im Neuron zusätzlich Natriumleckströme (Natriumionen strömen nach innen) vorhanden sind, verschiebt sich das RMP auf -70 mV (Rassow et al. 2012). Sind die chemische und die elektrische 
Triebkraft im Gleichgewicht, so ist der Nettostrom der Ionen gleich null. Die grobe Ionenverteilung zwischen Intra- und Extrazellulärraum ist in Tabelle 1.1 zusammengefasst. Natrium und Chlorid sind vor allem im Extrazellulärraum vorhanden, während Kalium aufgrund der elektrischen Triebkraft hauptsächlich im Intrazellulärraum zu finden ist.

Tabelle 1.1: Ionenkonzentration in dem Extra- $\left(\mathrm{K}_{\mathrm{ez}}\right)$ und Intrazellulärraum $\left(\mathrm{K}_{\mathrm{iz}}\right)$

\begin{tabular}{lll}
\hline Ion & $\mathrm{K}_{\text {ez }}[\mathrm{mM}]$ & $\mathrm{K}_{\text {iz }}[\mathrm{mM}]$ \\
\hline $\mathrm{K}^{+}$ & 4 & 120 \\
$\mathrm{Na}^{+}$ & 150 & 15 \\
$\mathrm{Ca}^{2+}$ & 2,5 & 0,0001 \\
$\mathrm{Cl}^{+}$ & 120 & 6 \\
\hline
\end{tabular}

Die Bildung eines Aktionspotentials (AP) ist nur auf Basis des RMP möglich. Wird aufgrund einer Erregung das RMP auf etwa -60 mV verschoben, so kommt es zur Ausbildung eines AP. Durch das Öffnen von schnellen spannungsabhängigen Natriumkanälen wird eine Depolarisation auf etwa $+20 \mathrm{mV}$ erreicht (Rassow et al. 2012). Das Membranpotential ist kurze Zeit im positiven Bereich. Dies wird als overshoot bezeichnet. Die Repolarisation wird durch das Öffnen langsamer spannungsabhängiger Kaliumkanäle eingeleitet. Zum Schluss des AP gibt es ein sogenanntes Nachpotential, welches eine leichte Hyperpolarisation der Zellen darstellt. Während dieser Hyperpolarisation kann - aufgrund des deutlich negativen Potentials in der Zelle und der Inaktivierung der schnellen spannungsgesteuerten Natriumkanäle - kein neues AP generiert werden. Diese Zeit wird Refraktärzeit genannt. Die Stärke einer Erregung wird durch die APFrequenz codiert. Die Dauer eines APs ist von Zelle zu Zelle unterschiedlich. In den Neuronen dauert es lediglich 1-2 ms, in der Skelettmuskulatur benötigt es $20 \mathrm{~ms}$ und im Arbeitsmyokard 400 ms.

Erreicht ein am Axonhügel (Übergang Neuronenzellkörper zum Axon) generiertes AP die Präsynapse, so folgt ein Einstrom von Kalzium in diese. Dadurch kommt es zu einer Verschmelzung von präsynaptischen Vesikeln an der präsynaptischen Membran und die darin enthaltenen Neurotransmitter werden in den synaptischen Spalt entlassen. Diese diffundieren durch den synaptischen Spalt zu den Neurotransmitterrezeptoren an der Postsynapse. Dadurch werden die Kanäle, die sich in den Neurotransmitterrezeptoren befinden, für bestimmte Ionen permeabel, und es entstehen erregendeoder inhibierende postsynaptische Potenziale (EPSP und IPSP). Die Gesamtheit aller postsynaptischen Potenziale (von allen Synapsen aller Dendriten eines Neurons) wird 
zum Zellkörper geleitet und dort verrechnet. Ist die Erregung aller postsynaptischen Potenziale groß genug, so werden erneut AP an dem Axon des Neurons generiert und weitergeleitet. Ist die Erregung unterhalb eines Schwellenwertes, geschieht nichts. Dieses Prinzip wird als Alles-oder-nichts-Prinzip bezeichnet (Rassow et al. 2012).

\subsection{Morphologie der dendritischen Dornfortsätze}

Die dendritischen Dornfortsätze kommunizieren mit einem Axon (Gray 1959). Das Volumen des Fortsatzes liegt zwischen $0,01 \mu \mathrm{m}^{3}$ und $0,8 \mu \mathrm{m}^{3}$. Pro $\mu \mathrm{m}$ Schaft eines Neurons können bis zu zehn dendritische Dornfortsätze vorhanden sein (Chicurel und Harris 1992; Harris 1999; Sorra und Harris 2000).

Die dendritischen Dornfortsätze werden anhand ihres Aussehens in verschiedene Typen unterteilt (Abbildung 1.2). Hierbei muss beachtet werden, dass die verschiedenen Formen fließend ineinander übergehen können, indem sie ihre eigene Morphologie vor allem während ihrer Entwicklung ändern.

Die Filopodien sind sehr lange und fadenförmige Dornfortsätze ohne erkennbaren Kopf. Dem gegenüber stehen sehr dünne Dornfortsätze (thin spines) mit einem ebenfalls dünnen Hals, jedoch mit einem deutlich sichtbaren Kopf. Die stumpfartigen dendritischen Dornfortsätze (stumpy spines) sind kurz und können als verzweigte Dornenfortsätze autreten. Der Hals und der Kopf stellen bei dieser Form kaum einen Unterschied dar. Bei den pilzförmigen Dornfortsätzen (mushroom spines) ist ein schmaler Hals mit einem voluminösen Kopf am Ende des Dornfortsatzes zu sehen, an welchem sich die aktive Zone befindet (Harris et al. 1992). In dieser Arbeit werden die stumpfartigen (Abbildung 1.2 d) und die pilzförmigen dendritischen Dornfortsätze (Abbildung 1.2 b) untersucht und miteinander verglichen. Es wurde sich auf diese beiden Formen beschränkt, da sie über 80 Prozent aller Dornfortsatzformen in den untersuchten Neuronenkulturen ausmachen. 
a

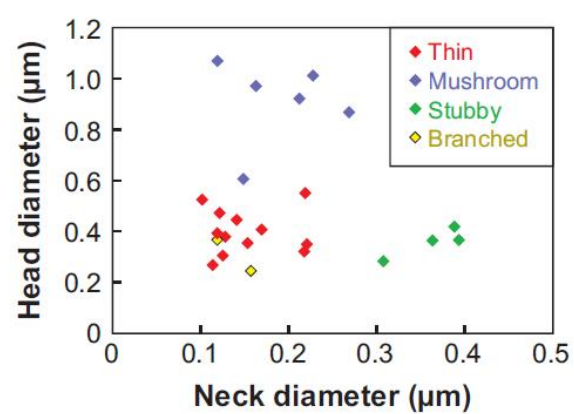

Thin spine

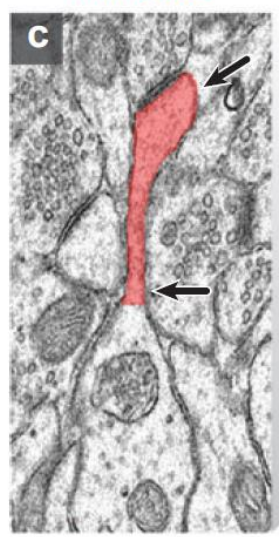

Stubby spine

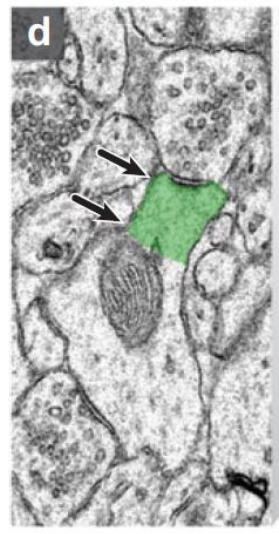

Mushroom spine

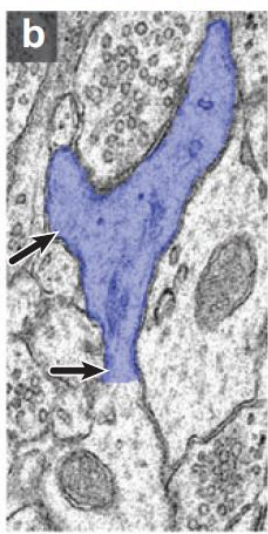

Branched spine

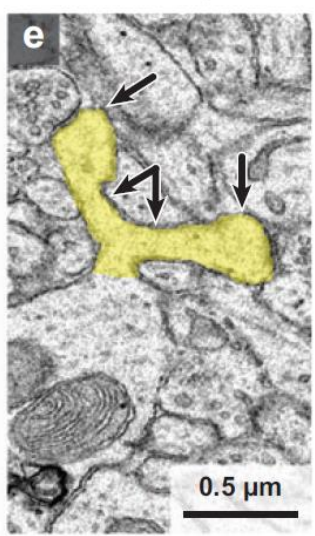

Abbildung 1.2: Reproduziert von Bourne und Harris 2008 mit schriftlicher Einverständniserklärung des Autors

Unterschiedliche Formen der dendritischen Dornfortsätze

b: pilzförmige Dornfortsätze

c: dünne Dornfortsätze (Filopodien)

d: stumpfartige Dornfortsätze

e: verzweigte Dornfortsätze 
Diese verschiedenen Formen entstehen vor allem während der Entwicklung der dendritischen Dornfortsätze mithilfe ihres Aktingerüsts. Verschiedene Proteine, die mit dem Aktingerüst interagieren beeinflussen dieses. Dem aktinbindenen Protein Drebrin wird dabei eine immer größer werdende Rolle zugeordnet (Hayashi 2017). Das Aktingerüst kann auf verschiedene Stimuli reagieren und ermöglicht daraufhin die Veränderung der Morphologie (Hering und Sheng 2001). Bei vermehrter Stimulation und somit auch vermehrtem Kalziumeinstrom in das Endköpfchen ist zu beobachten, dass dieses eine eher runde Form annimmt und das Aktingerüst des dendritischen Dornfortsatzes stabilisiert wird (Fischer et al. 2000; Lendvai et al. 2000; Schiffelholz und Aldenhoff 2002; Korkotian et al. 2004;). Im Dendriten selbst befinden sich zahlreiche Microtubuli sowie Intermediärfilamente. Sie bilden zusammen mit den Mikrofilamenten die Grundlage für das Zytoskelett der eukaryotischen Zelle. Im dendritischen Dornfortsatz findet man hingegen selten Mikrotubuli (Chicurel und Harris 1992). Je größer die dendritischen Dornfortsätze sind, desto vielfältiger ist die Zusammensetzung der vorhandenen Proteine und Organellen. Der Aufbau und die Organellen der dendritischen Dornfortsätze werden in Abbildung 1.3 schematisch dargestellt. Insbesondere Fortsätze mit sehr großen Endköpfchen und langen, schmalen Hälsen generieren unabhängig vom dendritischen Schaft ihr eigenes Mikroenvironment. Dies ist besonders beim Kalziumeinstrom nach der Stimulation zu beobachten, da bei einem geringeren Volumen des Endköpfchens ein geringerer Kalziumeinstrom eine deutlich höhere Konzentrationsänderung bewirkt (Abschnitt 1.2.3). Es ist von besonderer Bedeutung, da sich lediglich bis zu zwanzig Kalziumkanäle am Endköpfchen befinden (Sabatini und Svoboda 2000). Auch die Antwort des dendritischen Dornfortsatzes auf den Kalziumein- und -ausstrom soll von der Form, vor allem bei dünnen Hälsen, beeinflusst werden (Sabatini et al. 2001). Es könnte also sein, dass die Form der Synapsen der Funktion angepasst wird. Eine weitere Möglichkeit besteht jedoch darin, dass die unterschiedlichen Formen lediglich entstehen, um die Präsynapsen räumlich zu erreichen. 


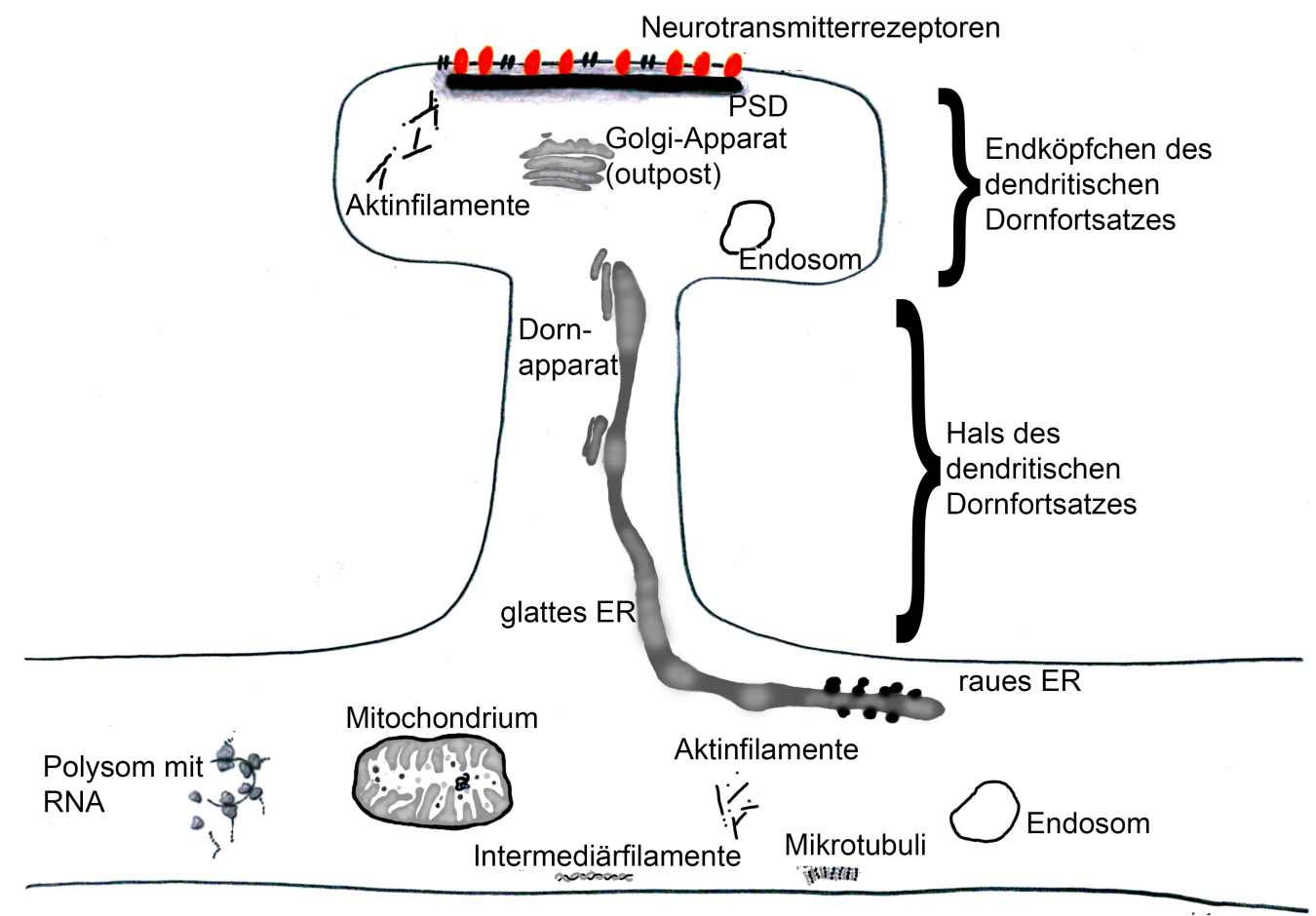

Abbildung 1.3: Aufbau und Organellen eines dendritischen Dornfortsatzes

\subsubsection{Die postsynaptische Dichte}

Die postsynaptische Dichte (PSD) stellt sich im Elektronenmikroskop als besonders elektronendichter Bereich direkt unterhalb eines postsynaptischen Membranabschnitts dar, welcher sich gegenüber der präsynaptischen Membran befindet. Stimulierte Postsynapsen besitzen eine besonders augewachsene PSD mit vielen Rezeptoren und weiteren Molekülen (Toni et al. 2001). Untersuchte Neuronen in Gewebeschnitten zeigten, dass zwischen der Höhe der PSD, dem Volumen, der Anzahl der Organellen des dendritischen Dornfortsatzes und der Anzahl der präsynaptischen Vesikel eine lineare Korrelation besteht (Harris et al. 1992; Spacek und Harris 1997). Das bedeutet, dass große dendritische Dornfortsätze eine hohe PSD und viele verschiedene Organellen aufweisen. Abgesehen von der Dicke und Größe der PSD lassen sich auch verschiedene Formen unterscheiden. Diese können neben kontinuierlichen auch diskontinuierliche Strukturen aufweisen oder sogar komplett perforiert sein (Abbildung 1.5). Die perforierten Strukturen lassen sich weiter unterteilen in fenestrierte, segmentierte oder hufeisenähnliche Formen (Hering und Sheng 2001). Vor allem während Teilungsvorgängen der dendritischen Dornfortsätze und bei ansteigender Rezeptorsynthese nach einer plastizitätsinduzierenden Stimulation weist die PSD eine perforierte Struktur auf (Sorra und 


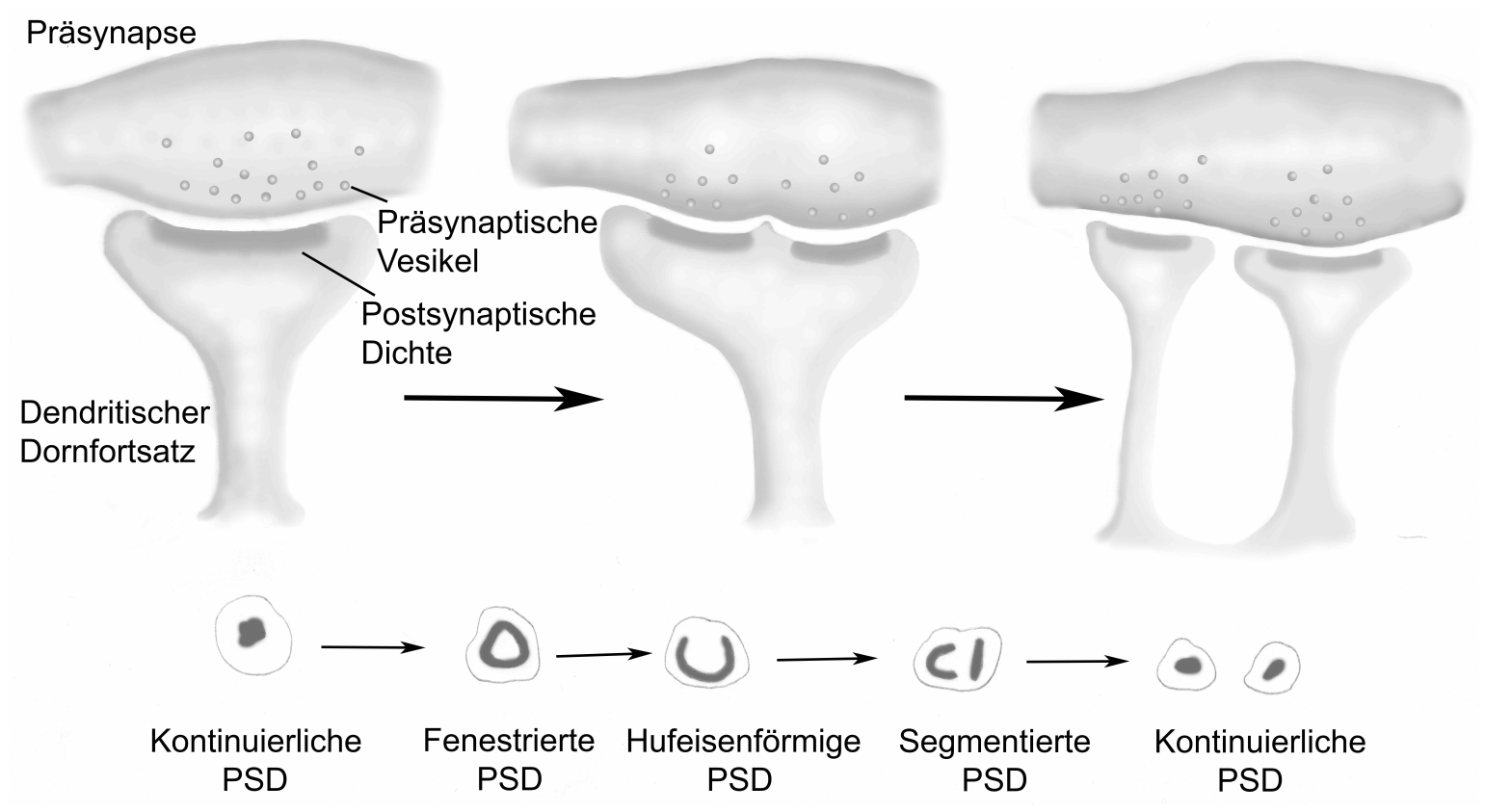

Abbildung 1.4: Teilungsvorgang eines dendritischen Dornfortsatzes mit den unterschiedlichen Strukturen der PSD

Harris 1998; Toni et al. 2001). Die oben beschriebenen morphologischen Veränderungen gehen immer auch mit einer molekularen Veränderung der PSD einher.

In der PSD befinden sich vor allem Neurotransmitterrezeptoren und Ionenkanäle sowie viele verschiedene Proteine, die eine Interaktion ermöglichen und zur Stabilisierung beitragen. Ein sehr wichtiger Bestandteil der PSD sind die Strukturproteine (scaffold proteins). Sie bestehen aus verschiedenen Domänen, interagieren mit verschiedenen Proteinen und organisieren die PSD. Die Interaktion dieser Proteine wird durch ihre PDZ-Domäne ermöglicht. Das bereits um 1990 beschriebene PSD 95 (post synaptic density-95) ist ein gut untersuchtes Strukturprotein (Cho et al. 1992; Kistner et al. 1993), welches in der PDZ-Domäne gefunden wurde. Es bindet an den N-Methyl-DAspartat-Rezeptor (NMDA) und an den Alpha-Amino-3-hydroxy-5-methyl-4-isoxazolPropionsäure-Rezeptor (AMPA) und verbindet diese über verschiedene Proteininteraktionen mit dem Zytoskelett und der Membran sowie mit anderen Rezeptorfamilien und Signaltransduktionsmolekülen. Das PSD-95 wird durch Phosphorylierung reguliert (Wu et al. 2017). Die PDZ-Domäne hat ihren Namen aufgrund von drei verschiedenen Proteinen, die in ihr gefunden wurden, bekommen: Das PSD95/SAP90 Protein, das seperate junction protein discs-large aus Drosophila melanogaster und das tight junction-protein zonula occludens. 


\subsubsection{Neurotransmitterrezeptoren}

Die Neurotransmitterrezeptoren lassen sich in verschiedene Klassen unterteilen. Eine Einteilung bezieht sich auf deren Wirkungsweise: Es wird unterschieden zwischen exzitatorischen (erregende) und inhibitorischen (hemmende) Rezeptoren.

Exzitatorische Rezeptoren wie Acetylcholin- und Glutamatrezeptoren sind im Gegensatz zu den inhibitorischen Rezeptoren, wie Gamma-Amino-Buttersäure- (GABA) oder Glycinrezeptoren, an dendritischen Dornfortsätzen zu finden. Die inhibitorischen Rezeptoren befinden sich ausschließlich am Schaft oder direkt am Zellkörper der Dendriten (Choquet und Triller 2013).

Die ionotropen (wirken auf den Ionen- bzw. Elektrolythaushalt) Glutamatrezeptoren lassen sich nochmal in drei verschiedene Rezeptoren unterteilen. Diese Unterteilung ist abhängig von der Sensitivität der verschiedenen Rezeptoren gegenüber verschiedenen Glutamat-Antagonisten: AMPA, NMDA und Kainat. Der AMPA-Rezeptor ist ein tetramerer Ionenkanal, welcher durch verschiedene Zusammensetzungen der Proteinuntereinheiten für unterschiedliche Ionen permeabel ist. Der Kanal ist für Natrium-, Kalzium- und Kaliumionen bei Aktivierung permeabel, wobei die Permeabilität von Kalzium jedoch bei der Anwesenheit der GluR2-Proteinuntereinheit (Glutamatrezeptor 2) vermindert wird (Nakanishi und Masu 1994; Kim et al. 2001). Der NMDARezeptor ist ebenfalls ein tetramerer aber nichtselektiver Kationenkanal. Im Bereich des Ruhemembranpotentials ist der Kanal durch extrazelluläres Magnesium verschlossen. Dies bedeutet, dass zusätzlich zur Bindung von Glutamat (Ligandenabhängigkeit) das Verdrängen des Magnesiums (Spannungsabhängigkeit) notwendig ist, um eine Permeabilität für Kationen zu erreichen. Hierfür ist eine Depolarisation von etwa $-80 \mathrm{mV}$ auf mindestens $-30 \mathrm{mV}$ notwendig (Nikolaev et al. 2012). Die Kainat-Rezeptoren sind vor allem Kalium- und Natriumdurchlässige tetramere Ionenkanäle. Die Kalizumleitfähigkeit hängt von der Zusammensetzung der Proteinuntereinheiten ab, ist jedoch meist geringer als die Leitfähigkeit von Kalium und Natrium (Nakanishi und Masu 1994).

Diese Rezeptoren können in der PSD, in den perisynaptischen Membranen oder innerhalb der dendritischen Dornfortsätze in Vesikeln lokalisiert sein (Malenka 2003).

\subsubsection{Ionenkanäle}

Ionenkanäle sind Transmembranproteine, die durch Porenbildung geladenen Teilchen die Möglichkeit bieten, die Membranen zu durchqueren. Im geöffneten Zustand stellen sie das schnellste Membrantransportmittel dar. In den dendritischen Dornfortsätzen sind sie durch eine Vielzahl von Strukturproteinen gebunden. Spannungsabhängige Ionenkanäle sind von großer Bedeutung bei der De- und Repolarisation eines Neurons. 
Ein Aktionspotential kann nur in einem Axon und nicht in einem Dendriten ausgelöst werden. Grund dafür ist, dass im Dendriten viele Kalium- und Kalziumkanäle, jedoch deutlich weniger Natriumkanäle vorhanden sind (Caldwell et al. 2000; Lorincz und Nusser 2010). Somit ist der für ein Aktionspotenial notwendige hohe Natriumstrom im Dendriten nicht zu generieren. Die Ionenkanäle befinden sich nicht nur auf den äußeren Membrananteilen, sondern sind auch in den Membranen der Zellorganellen vorhanden.

\subsubsection{Endosomen}

Die Endosomen entstehen durch Endozytose mithilfe von Clathrin. Sie bestehen aus Membranen und weiteren Membranbestandteilen, wie Ionenkanälen oder Neurotransmitter-Rezeptoren, die bei einem Wachstum des dendritischen Dornfortsatzes eingebaut werden können (Bourne und Harris 2008).

\subsubsection{Endoplasmatisches Retikulum und Golgi-Apparat}

Das glatte endoplasmatische Retikulum (ER) ist der wichtigste intrazelluläre Kalziumspeicher. Es erstreckt sich gelegentlich bis nahe der PSD (Spacek und Harris 1997). Die Ausprägung korreliert mit der Größe der dendritischen Dornfortsätze, sodass mehr ER in größeren Dornen gefunden werden als in kleineren (Gray 1959). In ungefähr $5 \%$ der Fortsätze ist das ER als sogenannter Dornapparat im Endköpfchen organisiert. Die Funktion dieser Dornapparate war lange Zeit ungewiss. Es wird vermutet, dass sie neben der Regulation des Kalziumhaushalts und der Proteinsynthese (Sorra und Harris 2000) einen wichtigen Beitrag zur synaptischen Plastizität leisten (Deller et al. 2003). Zur Ausbildung des Dornapparates wird das zytoplasmatische Synaptopodin aus verschiedenen Großhirnregionen (Neocortex, Hippocampus, Striatum und Bulbus olfactorius) benötigt (Segal et al. 2010). Es wird von Neuronen mit dendritischen Dornfortsätzen exprimiert und kommt ebenfalls in der Niere vor. Es verbindet das ER mit dem Aktinzytoskelett (Deller et al. 2000). Fehlt dieses Protein, so kommt es nicht zur Ausbildung von Dornapparaten. Die Folgen sind Lern- und Gedächtnisdefizite bei betroffenen Personen (Deller et al. 2003).

Vor knapp 20 Jahren wurden spezialisierte Ausläufer des Golgi-Apparates, sogenannte Golgi outposts, in den dendritischen Dornfortsätzen wie auch im eigentlichen dendritischen Schaft entdeckt (Gardiol et al. 1999; Pierce et al. 2001; Horton und Ehlers 2003). Sie besitzen ähnliche molekulare Marker, obwohl sie vollständig von Golgi-Apparaten getrennt sind (Horton und Ehlers 2003; Bisbal et al. 2016). Die Funktion der Golgi outposts ist noch weitgehend ungeklärt, jedoch geht man davon aus, dass sie für eine posttranslationale Modifikation (unter anderem für die Glykolysierung) bestimmter 
Proteine verantwortlich sind. Außerdem beeinflussen sie zusammen mit anderen Proteinen (N-acetyl-D-glucosamin Kinase und Dynein) das Wachstum von Dendriten (Islam et al. 2015).

\subsubsection{Ribosomen}

Ribosomen bestehen zu etwa zwei Drittel aus ribosomaler Ribonukleinsäure (rRNA) sowie zu einem Drittel aus ribosomalen Proteinen und besitzen einen Durchmesser von 20-25 nm. Sie sind aus einer kleinen und einer großen Untereinheit zusammengesetzt. Die eukaryotischen Ribosomen (80S-Ribosomen) werden aus einer 60S- und einer 40SUntereinheit gebildet, die prokaryotischen (70S-Ribosomen) aus einer 50S- und einer 30S-Untereinheit. Das S steht für die Svedberg-Konstante und ist ein Sedimentationskoeffizient. Die große Untereinheit der Ribosomen besitzt eine Peptidyltransferaseaktivität (ermöglicht die Verkettung der Aminosäuren während der Translation), wohingegen die kleine Untereinheit die Bindung der mRNA ermöglicht. Häufig sind bis zu 30 Ribosomen zu sogenannten Polyribosomen zusammengeschlossen. Meist sind Ribosomen in den Zellkörpern der Neuronen zu finden. Im Gegensatz zu den Dendriten fehlen sie in den Axonen jedoch vollständig. Nach Stimulation der dendritischen Dornfortsätze sind Ribosomen auch in den Dornfortsätzen nachzuweisen (Ostroff et al. 2002).

Mit dem rauen endoplasmatischen Retikulum, der vorhandenen mRNA und den Golgi outposts ist eine Synthese und eine notwendige posttranslationale Modifikation der Membranproteine in den dendritischen Dornfortsätzen möglich (Cajigas et al. 2012). Diese schnelle und lokale Produktion von Proteinen kann auch bei der synaptischen Plastizität von Bedeutung sein (Mameli et al. 2007).

\subsubsection{Mitochondrien}

Mitochondrien befinden sich ausschließlich in den größten dendritischen Dornfortsätzen der hippocampalen Neuronen (Chicurel und Harris 1992). Da die Diffusion von ATP (Adenosintriphosphat) durch den Hals des dendritischen Dornfortsatzes nur sehr eingeschränkt möglich ist und die in den Dornfortsätzen selten auftretenden Mitochondrien nicht ausreichend ATP für die PSD produzieren können, muss der Energiebedarf auf einem anderen Weg gedeckt werden. Es wurde nachgewiesen, dass in der PSD alle Enzyme vorhanden sind, die für eine eigene Glykolyse notwendig sind (Wu et al. 1997). Diese lokale Glykolyse deckt den ATP-Bedarf des dendritischen Endköpfchens. 


\subsection{Synaptische Plastizität}

Synapsen unterliegen einer ständigen aktivitätsabhängigen Anpassung. Die Gesamtheit der verschiedenen morphologischen und physiologischen Anpassungsmechanismen, die zu einer Schwächung oder einer Stärkung der Synapse führen, wird als synaptische Plastizität bezeichnet. Dies und die Möglichkeit der Signalübertragung stehen wahrscheinlich direkt mit der Lern- und Gedächtnisfunktion im Zusammenhang. Man unterscheidet eine Kurzzeit- (short-term plasticity) von einer Langzeitplastizität (long-term plasticity). Der am weitesten erforschte Mechanismus der synaptischen Plastizität ist die Langzeitpotenzierung (long-term potentiation, LTP), die eine verstärkte Ausprägung der Synapse bewirkt und hauptsächlich an der Postsynapse, aber auch an der Präsynapse stattfindet. Bereits 1949 wurde von Hebb die Hypothese aufgestellt, dass wenn ein Neuron wiederholt ein anderes Neuron in der Umgebung aktiviert, ihre synaptische Verbindung verstärkt wird, um so bei einer späteren Aktivierung eine verstärkte Erregungsübertragung zu erreichen. Die gesteigerte Effizienz der Erregung dieser Neurone untereinander wird durch Wachstumsprozesse und Stoffwechseländerungen in beiden Neuronen ermöglicht (Hebb 2002).

\subsubsection{Kurzzeitplastizität}

Eine Synapse kann auf zwei kurz aufeinander folgenden Impulsen mit einer Depression (Abschwächung) oder einer Potenzierung (Stärkung) der Erregung reagieren (Zucker und Regehr 2002). Dies ist hauptsächlich auf eine Modulation bei der Freisetzung der präsynaptischen Vesikel zurückzuführen, die durch Kalzium- und Natriumkanäle ermöglicht wird (Citri und Malenka 2008). Ob eine Despression oder eine Potenzierung erfolgt, ist vorwiegend von der Aktivität des Neurons und von dem zeitlichen Abstand der beiden (oder mehrerer) Impulse abhängig.

Wenn zwei stimulierende Impulse mit einem zeitlichen Abstand von bis zu $20 \mathrm{~ms}$ auf eine Synapse treffen, erfolgt eine Depression und somit eine verminderte Ausschüttung von Vesikeln an der Präsynapse, da die Natrium- und Kalziumkanäle noch inaktiviert sind (Refraktärzeit). Beträgt der zeitliche Abstand aber zwischen 20 ms und $500 \mathrm{~ms}$, so folgt eine vermehrte Ausschüttung von Neurotransmittern durch die präsynaptischen Vesikel und somit eine Potenzierung (Rosahl et al. 1993; Zucker und Regehr 2002; Citri und Malenka 2008).

Viele aufeinander folgende Stimuli (von $200 \mathrm{~ms}$ bis 5 s lang andauernde Stimulation mit $10 \mathrm{~Hz}$ bis $200 \mathrm{~Hz}$ ) können ebenfalls entweder zu einer Depression oder zu einer Potenzierung führen, die Sekunden bis Minuten andauert (Zucker und Regehr 2002; Citri und Malenka 2008). Aufgrund der hohen Kalziumkonzentration in der Präsynapse 
durch die vielen AP kommt es zu einer Verstärkung über die gesamte Erregungszeit. Dies erhöht die Wahrscheinlichkeit für das Generieren eines weiteren Aktionspotenzials in der darauffolgenden Nervenzelle. Bei einem so langanhaltenden Stimulus kann ebenso eine Depression entstehen. Grund hierfür kann eine Reduktion des Pools der präsynaptischen Vesikel sein, die durch deren plötzlich massiv vermehrte Verschmelzung mit der präsynaptischen Membran zustande kommt. Wichtig ist vor allem die Lokalisation der Vesikel. Quantitativ sind ausreichend Vesikel in der Präsynapse vorhanden, um eine lange Ausschüttung von Transmittern zu ermöglichen. Befinden sich jedoch nur wenige Vesikel in der Nähe der Membran, so ist der Pool an synaptischen Vesikel frühzeitig erschöpft.

Es wird ebenfalls ein retrograder Einfluss von der Postsynapse auf die Präsynapse diskutiert. Bei starker Stimulation schüttet die Postsynapse Signalstoffe aus (Citri und Malenka 2008). Durch kalziumgesteuerte Exozytose werden Stoffe wie Stickstoffmonoxid, Glutamat, Dopamin oder auch ein Wachstumsfaktor (brain-derived neurotrophic factor, BDNF) freigesetzt, die eine Veränderung der präsynaptischen Aktivität bewirken (Chevaleyre et al. 2006).

Die Neurone können bereits bei ankommenden Signalen ein effektiver Filter sein, indem sie die Weiterleitung fördern (Kurzzeitpotenzierung), oder sie hemmen (Kurzzeitdepression). Auch benachbarte Neurone können durch Botenstoffe die Aktivität der Neurone beeinflussen. Die Kurzzeitplastizität wird als einer der wichtigsten Faktoren bei der Signalmodulation angesehen.

Weitere Formen der Kurzzeitplastizität sind an der Postsynapse zu finden. Die Rezeptoren der Postsynapse können durch häufigen Zustrom von Neurotransmittern desensibilisiert werden. Eine verminderte Signaltransduktion durch Toleranzentwicklung ist die Folge (Constals et al. 2015).

\subsubsection{Langzeitplastizität}

Die Langzeitplastiziät an der Präsynapse wurde hauptsächlich an Moosfaser-Synapsen untersucht. Es handelt sich hierbei um eine Langzeitpotenzierung, die durch Kalziumeinstrom in die Präsynapse gesteuert wird. Das Kalzium aktiviert durch einen erhöhten cAMP-Spiegel die Proteinkinase A. Die Phosphorylierung der Kinase bewirkt eine stärkere und langanhaltendere Freisetzung von Neurotransmittern in den synaptischen Spalt (Citri und Maleka 2008).

In den dendritischen Dornforstätzen wird sowohl die LTP als auch die Langzeitdepression (long-term depression, LTD) beobachtet, wobei sich sowohl die Morphologie als auch die molekulare Zusammensetzung der Dornfortsätze ändert. 
Die LTP kann durch die AMPA- und NMDA-Rezeptoren erfolgen. Die AMPARezeptoren sind für Natrium- und Kaliumionen permeabel. Die NMDA-Rezeptoren sind in der Regel durch extrazelluläres Magnesium geblockt, welches erst bei einer deutlichen Depolarisierung dissoziiert (Mayer et al. 1984). Erst dann wird der Kanal geöffnet und lässt neben Natrium- und Kaliumionen auch Kalziumionen hindurchströmen. So wird bei einer starken Depolarisation der Zelle die intrazelluläre Kalziumkonzentration erhöht. Dieser erhöhte Kalziumspiegel kann weitere biochemische Mechanismen der LTP zur Folge haben (Malenka 1991; Malenka und Nicoll 1993).

Eine weitere gut verstandene Möglichkeit der LTP und der LTD ist der Ein- oder Abbau der AMPA-Rezeptoren in die postsynaptische Membran (Bredt und Nicoll 2003; Citri und Malenka 2008).

Bei der LTP zeigten sich unterschiedliche Ergebnisse in verschiedenen Studien. Ein Größenwachstum zeichnete sich lediglich in einer Studie im Jahr 1981 ab (Fifková und Anderson 1981), wohingegen andere Studien keinerlei morphologische Veränderungen nachweisen konnten (Lee et al. 1980; Chang und Greenough 1984). Widersprüchliche Ergebnisse lieferten auch die Untersuchungen zur Zunahme der Anzahl der postsynaptischen Dornfortsätze. Es konnte eine Zunahme der dendritischen Dornfortsätze nachgewiesen werden (Engert und Bonhoeffer 1999; Maletic-Savatic et al. 1999), die jedoch in einer anderen Studie nicht gezeigt werden konnte (Sorra und Harris 1998). Das Problem dieser Studien ist, dass zwei unterschiedliche Kulturen (eine stimuliert, die andere nicht-stimuliert), miteinander verglichen wurden, die jedoch von Beginn an eine große strukturelle Heterogenität aufwiesen. Erschwerend kommt hinzu, dass nur wenige der stimulierten Neurone einer Potenzierung unterlagen und zusätzlich nicht genau identifiziert werden konnte, bei welchen dies der Fall gewesen war. Erst die Kalziumniederschlag-Technik (calcium precipitation method) ermöglichte es mithilfe der Elektronenmikroskopie die Zunahme der Anzahl und der Größe der dendritischen Dornfortsätze zu beweisen (Toni et al. 1999; 2001). Bei dieser Technik wird zu der Osmiumlösung für die Fixation $\mathrm{K}_{3} \mathrm{Cr}\left(\mathrm{C}_{2} \mathrm{O}_{4}\right)_{3}$ (Kaliumtrioxalatochro-mat(III)-Trihydrat) zugefügt (Buchs et al. 1994). Im Elektronenmikroskop kann man elektronendichte Präzipitate nachweisen, die sich vor allem bei Kontakt mit Kalzium bilden, welches notwendig ist für die LTP. Zusätzlich konnte mit dieser Methode ein Zusammenhang zwischen der Veränderung der PSD und der Potenzierung der Dornfortsätze erkannt werden. Bei einer hohen Potenzierung war die PSD deutlicher ausgeprägt und besaß meist eine perforierte Struktur (Toni et al. 1999; 2001). Ihre Zunahme steht langfristig im Zusammenhang mit der Erweiterung der aktiven Zone. 


\subsection{Der Hippocampus}

Der Hippocampus liegt im Temporallappen des Gehirns und ist Teil des limbischen Systems. Er ist von besonderer Bedeutung für die Gedächtnisfunktion. Ohne den Hippocampus können die Informationen nicht von dem Kurzzeit- in das Langzeitgedächtnis gelangen. Die Afferenzen stammen aus verschiedenen Hirnregionen, wie dem Thalamus, dem Septum, dem Corpus amygdaloideum, den Neocortexarealen und dem Gyrus cinguli. Über die Area entorhinalis gelangen Afferenzen ebenfalls aus dem Riechhirn in den Hippocampus. Die Efferenzen verlaufen zunächst im Fornix zum Septum sowie zur Amygdala, zum Hypothalamus und zu den Corpora mamillaria.

Der Hippocampus gehört zum Allocortex. Der Allocortex ist aus mindestens drei Schichten aufgebaut, in wenigen Arealen können zusätzliche Schichten auftreten. Die äußerste Schicht ist die Lamina molecularis. Dort sind hauptsächlich Interneurone und wenige Gliazellen (zum Beispiel Astrozyten) zu finden. Interneurone sind ein Teil des neuronalen Netzwerks die von exzitatorischen Pyramidenzelen gebildet werden und der Kontrolle und Regulierung dieser Netzwerke dienen. Gliazellen bilden das Stützgewebe des gesamten Nervensystems. In den tieferen Schichten können myelinisierte Fasern vorhanden sein. Die mittlere Schicht des Allocortex ist die Lamina pyramidalis. Hier liegen die Pyramidenzellen, die in dieser Arbeit kultiviert und untersucht wurden. Die innerste Schicht ist die Lamina multiformis. Hier liegen meist spindelförmige Zellen.

Dieser - verglichen mit den übrigen Hirnregionen - einfache Aufbau ermöglicht eine gute Kultivierung der Pyramidenzellen. Sie sind gut abgrenzbar gegenüber den übrigen Zellen des Allocortex.

\subsection{Ziel dieser Arbeit}

Bislang ist ungeklärt, weshalb die unterschiedlichen Formen der dendritischen Dornfortsätze entstehen. Es wird diskutiert, ob sie je nach Form auch unterschiedliche Funktionen besitzen, denn die unterschiedlichen Formen der dendritischen Dornfortsätze führen nach Stimulation zu unterschiedlich hohen Kalziumkonzentrationsänderungen innerhalb des Dendriten. Während pilzförmige Dornfortsätze mit einem langen und schmalen Hals bei starkem Kalziumanstieg wenig zur Erhöhung der intrazellulären Kalziumkonzentration im Dendriten und somit in den benachbarten dendritischen Dornfortsätzen beitragen, ist es bei den stumpfartigen Dornfortsätzen einfacher eine Veränderung der Kalziumkonzentration in ihrer Umgebung zu erreichen (Abbildung 1.5) (Sorra und Harris 2000). Eine weitere Theorie ist, dass die Formen durch unterschiedliches Wachstum bedingt sind und im Allgemeinen einen ähnlichen Aufbau des 


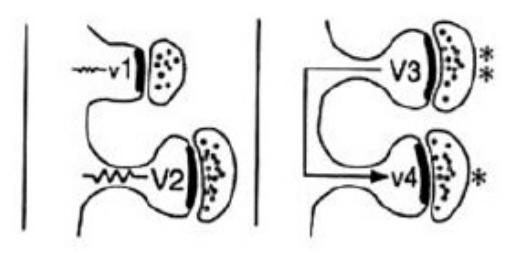

\begin{abstract}
Abbildung 1.5: Reproduziert von Sorra und Harris 2000 mit schriftlicher Einverständniserklärung des Autors:

Vergleich der Weiterleitung bei den unterschiedlichen Formen der dendritischen Dornfortsätze
\end{abstract}

Endköpfchens besitzen. Liegt eine Präsynapse weiter entfernt von einem Dendriten, so wäre es möglich, dass sich eine eher pilzförmige Synapse bildet, damit die Distanz mithilfe des Halses überbrückt wird.

Um die Funktion der verschiedenen dendritischen Dornfortsätze zu verstehen, ist es zunächst notwendig, die genaue Anatomie zu bestimmen. Die meisten bislang durchgeführten Untersuchungen erfolgten an Gewebeschnitten. In dieser Arbeit wurden konventionelle hippocampale Neuronenkulturen (Abschnitt 3.2) genutzt, da auf ihrer Grundlage seit fast 30 Jahren die Arbeitsmechanismen der Synapsen untersucht werden, während die quantitative Anatomie der dendritischen Dornfortsätze weiterhin unbekannt bleibt. Es wurden die Oberflächen der aktiven Zonen, die Achsenverhältnisse (Abschnitt 3.6), die Gesamtoberflächen, sowie die Gesamtvolumina der dendritischen Dornfortsätze und die Schnittvolumina und -umfänge berechnet und analysiert. Für die beiden Formen der dendritischen Dornfortsätze (pilzförmig und stumpfartig) wurde untersucht, ob die einzelnen Merkmale miteinander korrelieren. Diese zwei Formen wurden ausgewählt, da sie über 80 Prozent der vorhandenen Dornfortsätze in den hippocampalen Neuronenkulturen ausmachen. Somit konnten Unterschiede herausgestellt und Gleichheiten beschrieben werden. Ebenfalls wurde ermittelt wie sich einzelne Merkmale der stumpfartigen und der pilzförmigen dendritischen Dornfortsätze zueinander verhalten. Das gemeinsame Ziel der Arbeitsgruppe Rizzoli ist zunächst die Erstellung eines detaillierten Models einer Synapse, um später die Funktionen, Dysfunktionen und Arbeitsweisen nachvollziehen und darstellen zu können. Dafür werden zunächst die genaue Untersuchungen der Morphologie der Postsynapse benötigt, um das bereits vorhandene Modell des präsynaptischen Köpfchens zu ergänzen. 


\section{Material und Methoden}

Ursprünglich war die Darstellung der Neurone mithilfe des FIB-SEM (focused ion beamscanning electron miscroscope) geplant, um so besonders dünne Schnitte (bis maximal $15 \mathrm{~nm}$ ) und eine möglichst genaue anatomische Darstellung zu erreichen. Dazu musste zunächst eine Sandwich-Zell angelegt werden, um somit eine möglichst geringe Dichte von Neuronen und damit eine gute Bildgebung zu erreichen. Die Präparation und die genaue Vorgehensweise werden weiter unten beschrieben. Es war ein Hochdruckgefrieren (High Pressure Freezing; Abschnitt 2.1.6) und anschließend eine Gefriersubstitution (Abschnitt 2.1.7) notwendig. Trotz der genauen Arbeitsweise waren die Ergebnisse aufgrund des geringen Kontrastes und der zu geringen Neuronendichte, die anfangs angestrebt wurde, qualitativ nicht zufriedenstellend.

Aufgrund dessen wurde eine konventionelle Zellkultur von hippocampalen Rattenneuronen angelegt und diese mit einem Elektronenmikroskop (Zeiss EM902) dargestellt. Die Schnittdicke betrug $70 \mathrm{~nm}$ und ermöglichte somit ebenfalls eine gute Darstellung und Analyse der quantitativen anatomischen Strukturen der dendritischen Dornfortsätze.

\subsection{Sandwich-Zellkultur}

Für das ursprünglich durchgeführte Anlegen der Sandwich-Zellkulturen wurde ein modifiziertes Protokoll nach Kaech und Banker (Kaech und Banker 2006) verwendet. Der schematische Aufbau ist in Abbildung 2.1 dargestellt.

Eine Astrogliaschicht (monolayer) befand sich am Boden einer 12-Well-Platte. Diese Gliazellen ernähren und schützen die Neuronen während der Entwicklung. Die Neurone waren auf der Unterseite der Saphirscheiben (cover slips). Dort befanden sich ebenfalls Paraffinwachstropfen, welche die Neuronen von der Astrozytenschicht soweit trennen sollten, dass sie sich nicht berührten. Eine Ernährung der Neuronen durch die Astrozyten konnte dennoch erfolgen konnte. Diese Sandwich-Zellkulturen ermöglichten zum einen das leichte Trennen der Neurone von den Gliazellen (Astrozyten) beim Abnehmen der Saphirscheibe und zum anderen das Anlegen einer Neuronenkultur mit geringer Dichte. 


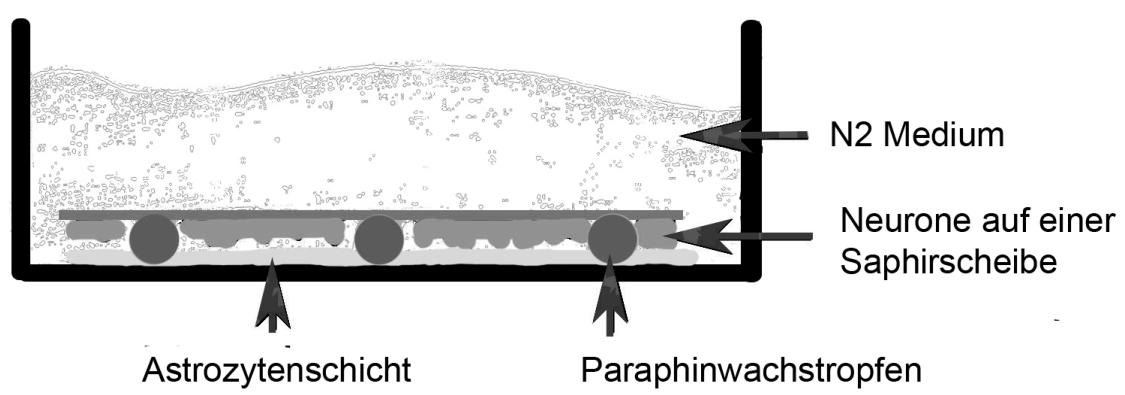

Abbildung 2.1: Aufbau einer Sandwich-Kultur

Dieses Protokoll sollte die Voraussetzungen für eine genaue Untersuchung der quantitativen Anatomie der dendritischen Dornfortsätze schaffen. Die hippocampalen Neurone wurden genutzt, da der Hippocampus, verglichen mit anderen Regionen des ZNS, relativ einfach strukturiert ist (Abschnitt 1.4). Die Pyramidenneurone (= Pyramidenzellen) sind hier der vorherrschende Zelltyp. Die zahlreich vorhandenen Interneurone konnten später in den Zellkulturen durch ihre typische Morphologie von anderen Zelltypen unterschieden werden. Ein weiterer Grund für die Verwendung von Pyramidenzellen war, dass sie sich in Zellkulturen sehr gut entwickeln und große Netzwerke mit vielen dendritischen Dornfortsätzen ausbilden.

Bei der Präparation war darauf zu achten, dass die Ratten sich in einem späten embryonalen Stadium befanden. Zu diesem Zeitpunkt ist die Entwicklung der Pyramidenzellen fast abgeschlossen, während viele Interneurone noch nicht gebildet worden sind. Des Weiteren sind die Gliazellen nicht vollständig entwickelt, sodass die Gefahr einer Verunreinigung der Zellkulturen minimiert wurde.

Am 18. Gestationstag hatten die Embryos eine ungefähre Länge von $25 \mathrm{~mm}$ und ein ausreichendes Entwicklungsstadium erreicht, um mit der Präparation der hippocampalen Neurone zu beginnen.

Zwei Wochen vor Präparation der Neurone und vor dem Anlegen der sogenannten Sandwich-Kulturen in 12-Well-Platten wurde zunächst die Astrogliaschicht angelegt. Die Astrozyten konnten sich in der Zwischenzeit vermehren und eine ausreichend hohe Dichte entwickeln, um die Neuronen in der Zellkultur zu ernähren und zu schützen. Fünf Tage vor Präparation der hippocampalen Neurone mussten die Saphirscheiben vorbereitet werden, damit neuronales Wachstum an der Unterseite stattfinden konnte. Nach dem Anlegen der Sandwich-Kulturen bildete sich zwischen der Saphirscheibe und der 12-Well-Platte ein Mikroenvironment. Der notwendige Abstand zwischen den beiden Oberflächen wurde, wie oben beschrieben, durch Paraffinwachstropfen gewährleistet. Der grobe Ablauf des Protokolls ist in Tabelle 2.1 aufgeführt. 


\subsection{1 Übersicht des Ablaufs}

Tabelle 2.1: Übersicht über den Ablauf zum Anlegen einer Sandwich-Kultur

\begin{tabular}{ll}
\hline Schritt & Zeitpunkt \\
\hline $\begin{array}{l}\text { Präparation und Wachstum } \\
\text { der kortikalen Astroglia }\end{array}$ & $\begin{array}{l}\text { ca. 3 Wochen vor Anlegen } \\
\text { der Sandwich-Kultur }\end{array}$ \\
$\begin{array}{l}\text { Präparation der Astrogliaschicht } \\
\text { in 12-Well-Platten }\end{array}$ & $\begin{array}{l}\text { ca. 1 Woche vor Anlegen } \\
\text { der Sandwich-Kultur }\end{array}$ \\
Vorbereitung der Saphirscheiben & $\begin{array}{l}\text { 2 Tage vor Anlegen } \\
\text { der Sandwich-Kultur }\end{array}$ \\
Austausch des Gliamediums gegen & $\begin{array}{l}\text { 1-2 Tage vor Anlegen } \\
\text { der Sandwich-Kultur }\end{array}$ \\
Präparation der Neurone & $\begin{array}{l}\text { 2-3 Stunden vor Anlegen } \\
\text { der Sandwich-Kultur }\end{array}$ \\
Wachstum der Neurone & $\begin{array}{l}\text { Bis 3 Wochen nach Anlegen } \\
\text { der Sandwich-Kultur }\end{array}$ \\
\hline
\end{tabular}

\subsubsection{Präparation und Wachstum der kortikalen Astroglia}

Für die Präparation der Astroglia wurden die Kortizes der Ratten mithilfe eines Skalpells und einer Pinzette auf ungefähr $1 \mathrm{~mm}$ große Stücke geteilt, um dem Puffer (HBSS) eine bessere Angriffsfläche zu bieten. Durch das darauffolgende, dreimalige Waschen mit HBSS wurden größere Gewebestücke herausgefiltert, da diese toxisch auf die Neurone gewirkt hätten. Im Verlauf eines Waschvorgangs wurde die Lösung geschwenkt und anschließend das Medium abgenommen und durch frisches ersetzt (7-8 ml pro Waschdurchgang). Das Selektieren der größeren Gewebeteilchen war durch die unterschiedlich schnelle Sedimentation möglich.

Das Medium (HBSS) konnte nun entfernt werden. Das restliche Gewebe wurde mithilfe einer mit Puffer benetzten 10-ml-Pipette in ein 15-ml-Zentrifugenröhrchen umgefüllt. Die Benetzung der Pipette sorgte dafür, dass Gewebeanhaftung an der Wand vermieden wurde. In dem Zentrifugenröhrchen wurde bereits vorher ein warmer Puffer $\left(37^{\circ} \mathrm{C}\right)$ vorbereitet, welcher aus $12 \mathrm{ml}$ HBSS, 1,5 ml einer $1 \%$ igen DNase und 1,5 ml 2,5\%igem Trypsin bestand. Die DNase und das Trypsin wurden zuvor aus Pulver angemischt und bei $20{ }^{\circ} \mathrm{C}$ gelagert. Dies bedeutet, dass der Puffer nicht steril war und ein 
erster Filtervorgang bereits vor dessen Benutzung notwendig wurde. Die Wärme des Puffers gewährleistete eine optimale Enzymaktivität, um die Zellen aus dem Gewebe zu lösen. Extrazelluläres Gewebe und DNA sollten entfernt werden (DNase) und die Zell-Zell-Kontakte sollten gelöst werden (Trypsinisierung). Nach diesen Schritten kam die fertige Lösung mit dem Gewebe für 15 Minuten unter Rotation in den Inkubator. Es folgte die Entfernung des Überstandes und die erneute dreimalige Waschung mit Gliamedium (6-7 ml pro Durchgang) um den Aufschluss der Zellen zu stoppen. Während dieser Waschvorgänge musste darauf geachtet werden, dass die Lösung nicht suspendiert wurde. Sie musste trotzdem vorsichtig gedreht werden, um ein vollständiges Entfernen der Enzyme zu ermöglichen. Nachdem dies erfolgt war, wurde die Lösung auf $10 \mathrm{ml}$ mit frischem Gliamedium ergänzt und in ein 50-ml-Falcon-Röhrchen umgefüllt, in welchem mithilfe einer Pipette eine zehnmalige Suspension erfolgte.

Durch den beim Suspendieren aufgebauten Druck wurden die größeren Gewebeteile aufgelöst. Die Lösung wurde trüb und es waren lediglich kleinste Gewebereste zu erkennen. Durch das darauffolgende Sieben wurden diese herausgefiltert (Siebgröße $100 \mu \mathrm{m}$ ). Es folgte das Zentrifugieren der erhaltenen Lösung für 5 Minuten mit $120 \mathrm{~g}$ (entsprach 800 Umdrehungen pro Minute). Beim Herausnehmen waren Erschütterungen zu vermeiden, da sich das abgesetzte Sediment leicht lösen konnte. Der Überstand, in dem sich viele Mikroglia befanden, wurde entfernt und die sich abgesetzten Astrozyten in $10 \mathrm{ml}$ frischem Gliamedium suspendiert.

Je 2,5 ml von der Zellsuspension wurden in eine Kulturflasche (flask) gegeben und mit je 12,5 ml frischem Gliamedium aufgefüllt, sodass man viermal je $15 \mathrm{ml}$ Zellsuspension (etwa 7,5 × 106 Zellen) erhielt. Ein leichtes Schwenken der Flaschen ermöglichte eine gleichmäßige Zellverteilung.

Ein kompletter Austausch des Gliamediums erfolgte am nächsten Tag. Vor dem Austausch wurde die Kulturflasche leicht gegen die Hand geklopft, damit alle losen Zellen aus der Suspension entfernt wurden. Diese losen, nicht am Boden haftenden Zellen waren zum Großteil Mikroglia, die toxisch auf andere Zellen und vor allem auf die Neurone wirken können. Zweimal wöchentlich, montags und freitags, wurde das Gliamedium ausgewechselt.

Um die Astrozyten nach ungefähr zwei Wochen von dem Boden der Kulturflaschen zu lösen, wurden sie vorsichtig mit 3-5 ml Trypsin/EDTA gewaschen und anschließend mit 2-3 ml Trypsin/EDTA in einen $37^{\circ} \mathrm{C}$ warmen Inkubator gestellt, bis sich die Zellen ablösten (ungefähr 2-3 Minuten). Um die Trypsinisierung zu stoppen wurden anschließend $5 \mathrm{ml}$ Gliamedium hinzugefügt und wiederholt mehrere Male pipettiert. Nach diesem Schritt war es möglich, die Zellsuspension in die 12-Well-Platten zu bringen. Angestrebt war eine Dichte von ungefähr 1000 Zellen pro Well. 


\subsubsection{Präparation der Astrogliaschicht in 12-Well-Platten}

Ungefähr eine Woche vor Anlegen der Sandwich-Kulturen wurde die in Abschnitt 2.1.2 vorbereitete Gliazellsuspension auf die 12-Well-Platten gegeben. Ebenso wie in den Kulturflaschen wurde auch hier das Gliamedium zweimal wöchentlich, montags und freitags, ausgetauscht. Hatten die Astrozyten eine Dichte von 40-70\% erreicht, konnte diese Gliakultur mit den Neuronen zusammengeführt werden. Spätestens ein bis zwei Tage vor dem Einsetzen der Saphirscheiben mit den Neuronen musste das Gliamedium gegen das N2-Medium ausgetauscht werden, damit ein optimales Neuronenwachstum möglich war. Das N2-Medium gewährleistete ein Überleben der Astroglia einerseits und das der Neuronen andererseits.

\subsubsection{Vorbereitung der Saphirscheiben}

Anstelle von Deckgläsern wurden Saphirscheiben (6 mm Durchmesser und $120 \mu \mathrm{m}$ stark) genutzt. Saphirscheiben haben während des Hochdruckgefrierens mit flüssigem Stickstoff einen höheren Wärmeleitkoeffizienten als Deckgläser. Saphirscheiben wurden erstmals von Schwarb genutzt (Schwarb 1900). Diese Saphirscheiben wurden zunächst mit einer Kohlenstoffschicht benetzt, um eine bessere Neuronenbesiedlung erreichen zu können. Um zu sehen, welche Seite beschichtet war, wurde der asymmetrische Buchstabe „F" hineingeschnitzt.

Nun wurden Wachstropfen auf der Unterseite der Saphirscheiben platziert, welche einen definierten Abstand für die Aufhängung der Neuronen über der Astrozytenschicht ermöglichten. Die Größe dieser Wachstropfen war vorgeschrieben, um den optimalen Abstand der beiden Schichten gewährleisten zu können (ca. 0,5 mm hoch und $2 \mathrm{~mm}$ breit).

Mindestens zwei Tage vor der Neuronenpräparation wurden die Saphirscheiben mit Poly-L-Lysin (PLL) bedeckt. Nachdem die Scheiben eine halbe Stunde unter ultraviolettem Licht sterilisiert worden waren (Jiménez et al. 2006), waren sie hydrophil, und das Poly-L-Lysin verteilte sich gleichmäßig dünn auf der Oberfläche. Da die Petrischalen, in welchen sich die Saphirscheiben befanden, hydrophob waren, wurden sie nicht mit Poly-L-Lysin benetzt. Anschließend mussten sie 12-24 Stunden abgedeckt bei Raumtemperatur gelagert werden. Nach dieser Zeit wurde die Poly-L-Lysinlösung mit sterilem Wasser 2 Stunden lang abgespült. Während des gesamten Vorgangs durfte die Scheibe nicht trocknen.

Nach Entfernung des sterilen Wassers wurden $6 \mathrm{ml} \mathrm{N} \mathrm{N}_{2}$-Medium in eine Petrischale gegeben und diese mit den vorbehandelten Saphirscheiben in den $\mathrm{CO}_{2}$-Inkubator gestellt. Auf diese Weise konnten sie einige Tage vor Verwendung gelagert werden. 


\subsubsection{Präparation der Neuronen und Anlegen der Sandwich-Kultur}

Am 18. Gestationstag wurden die Ratten dekapitiert, ihre Uteri herauspräpariert und in eine sterile Petrischale platziert. Unter dem laminaren Abzug wurden die Föten aus dem Uterus entfernt. Ihre Gehirne wurden herauspräpariert und in eine mit CMF-HBSS (Kalzium-, Magnesium-, und Bikarbonat-freie Hank's Balanced Salt Solution mit $10 \mathrm{mM}$ 2-(4-(2-Hydroxyethyl)-1-piperazinyl)-ethansulfonsäure) gefüllte Petrischale platziert. Es war darauf zu achten, dass die Gehirne jederzeit vollständig mit der Lösung bedeckt waren. Unter einem Präparationsmikroskop wurden die Meningen der medialen Seite der Hemisphären abgetrennt und die zwei Hippocampi herauspräpariert. Diese wurden sofort in einer weiteren Petrischale mit CMF-HBSS platziert. Nachdem alle Hippocampi erfolgreich entfernt worden waren, wurden sie in ein konisches Zentrifugenröhrchen gelegt und das Volumen auf 4,5 ml mit CMF-HBSS aufgefüllt. Danach wurden 0,5 ml von 2,5\% igem Trypsin hinzugefügt und die Lösung für 15 Minuten in ein $37^{\circ} \mathrm{C}$ warmes Wasserbad gestellt. Das Hinzufügen von Trypsin ist notwendig, um die Dissoziierung der Zellen zu gewährleisten (Trypsinisierung). Um es anschließend aus dem Gewebe zu entfernen, wurde die Lösung zunächst abgesaugt und die Hippocampi am Boden des Röhrchens belassen. Es wurden wieder $5 \mathrm{ml}$ der CMF-HBSS-Lösung hinzugefügt und 5 Minuten bei Raumtemperatur belassen. Dieser Vorgang wurde dreimal wiederholt, um das vollständige Herausdiffundieren des restlichen Trypsins aus dem Gewebe zu gewährleisten. Nach Abschluss dieses Vorgangs musste das Volumen 2-3 ml betragen.

Die Suspensierung der Hippocampi erfolgte durch das fünf- bis zehnmalige Pipettieren mit einer normalen 10-ml-Pipette. Für diese weiteren fünf- bis zehn Pipettiervorgänge wurde eine Pasteur-Pipette benutzt, deren Durchmesser unmittelbar zuvor mithilfe von Wärmeeinwirkung in etwa halbiert worden war (flame polished). Es musste darauf geachtet werden, dass der Durchmesser nicht zu klein gestaltet wurde, um eine Schädigung der Zellen auszuschließen. Ein zu großer Durchmesser hätte jedoch die spätere Homogenität der Lösung nicht gewährleisten können.

Nun musste die Dichte der Zellsuspension bestimmt werden. Es wurden etwa 150.000 Zellen gleichmäßig auf eine 60-mm-Saphirscheibe gepflanzt. Die Zellen, die sich nicht auf der Saphirscheibe befanden, gingen unter. Eine Kontrolle nach drei bis vier Stunden zeigte, ob die Zellen an den Saphirscheiben hafteten. War dies der Fall, wurden die Scheiben mit den Wachstropfen und den anhaftenden Zellen nach unten in die 12Well-Platten zu den Astroglia und dem $\mathrm{N}_{2}$-Medium gelegt.

Drei Tage nach dem Anlegen der Sandwich-Kulturen wurde 5-Fluoro-2'Deoxyuridin bis zu einer Konzentration von $5 \mu \mathrm{M}$ hinzugegeben, um die Proliferation der Gliazellen zu bremsen. 
Für die Ernährung der Kulturen wurde wöchentlich ein Drittel des $\mathrm{N}_{2}$-Mediums ausgetauscht. Das Medium durfte nie ganz ersetzt werden, da die Konditionierung des Mediums durch die Gliazellen für ein Überleben der Zellen wichtig war.

Die Fortsätze der Neuronen wuchsen und entwickelten ihre Polarität (Differenzierung des Axons und der Dendriten). Die längeren Fortsätze entwickelten axonale Charakteristika, die kürzeren entwickelten sich zu Dendriten. Nach und nach entstand ein neuronales Netzwerk. Die Dendriten entwickelten sich, verzweigten stärker und die synaptische Entwicklung schritt weiter voran. Die Spitze des Wachstums der Dendriten und Synapsen war nach zwei bis drei Wochen erreicht. Ungefähr Anfang der dritten Wochen bildeten sich die dendritischen Dornfortsätze. Der Zelltod begann in der Regel am Ende der dritten oder vierten Woche.

Nach drei Wochen Wachstum wurde deshalb das Hochdruckgefrieren (high pressure freezing, HPF) durchgeführt.

\subsubsection{Hochdruckgefrierung}

Das HPF wurde mit flüssigem Stickstoff $\left(\mathrm{LN}_{2}\right)$ durchgeführt. Der Druck lag bei 2045 bar, die Temperatur bei $-160{ }^{\circ} \mathrm{C}$. Der hohe Druck war erforderlich, um eine Ausdehnung des Wassers bei der Abkühlung zu verhindern. So wurde eine Kristallisation des Wassers unterbunden, es entstand keine Kristallisationswärme, die beim Abkühlen hätte frei werden können. Das so entstandene Eis hat eine höhere Dichte als flüssiges Wasser. Beim Gefrieren mit atmosphärischem Druck wäre lediglich das Einfrieren von Schichtendicken bis maximal 10-20 $\mu \mathrm{m}$ möglich. Die Kryofixierung ermöglichte das Einfrieren von Proben mit 100-200 $\mu \mathrm{m}$ Dicke (Mulisch und Welsch 2015).

Am Morgen des HPF wurden die angelegten Neuronenkulturen kontrolliert und zusätzlich 20 mM HEPES hinzugefügt, um den pH-Wert während des Transports zum Gerät (Leica HPM100) konstant halten zu können. Dort wurden die Neuronenkulturen wieder inkubiert.

Zunächst wurde die Plunchette, in welche die Saphirscheibe gesetzt wurde, so präpariert, dass nach Entnahme der Saphirscheiben aus der Sandwich-Kultur das HPF schnellstmöglich folgen konnte. Ein carrier Typ A (6 mm Durchmesser) mit einer 0,1 mm großen Kavität wurde mit der Öffnung nach oben in die Plunchette gesetzt. Nun wurde ein kleiner Tropfen Phosphatgepufferte Salzlösung (PBS) mit $20 \%$ Polyvinylpyrrolidone (PVP) als Druckübertragungsmedium eingefüllt. Selbst wenn der Probenhalter möglichst passgenau zugeschnitten wurde, entstanden Leerräume die aufgefüllt werden mussten um eine gute Druckübertragung von Probenträger zur Probe gewährleisten zu können. Dies wurde durch das Druckübertragungsmittel gewährleistet. Nun wurde die Zellkultur aus dem Inkubator genommen, die Saphirscheibe entfernt 
und möglichst schnell (nicht länger als 30 Sekunden) mit den Neuronen nach unten in die untere Plunchette platziert, wobei die Wachspunkte zuvor mit einem Skalpell abgelöst wurden. Zwei 200- $\mu$ m-Platzhalter (spacer) aus Nickel wurden auf die Saphirscheibe gelegt und der entstandene Leerraum erneut mit dem Druckübertragungsmittel aufgefüllt. Nun wurde es in die Leica HPM100 geladen. Das HPF der Saphirscheiben wurde durchgeführt, nachdem zwei Probeläufe erfolgreich waren. Die Abkühlrate und die Haltezeit waren während des HPF korrekt.

Anschließend wurden das $\mathrm{LN}_{2}$ Dewar und die Plunchette herausgenommen. Die Plunchette wurde zusammen mit den Saphirscheiben bis zu der Gefriersubstitution in $\mathrm{LN}_{2}$ gelagert.

\subsubsection{Gefriersubstitution}

Das gefrorene Wasser musste im Rahmen der Gefriersubstitution unter Ersatz von Lösungsmittel aus der Probe entfernt werden. Nachdem dies geschehen war, konnte die Einbettung und Polymerisation der Probe bei Raumtemperatur in Epoxidharz durchgeführt werden.

Es wurde die Gefriersubstitution nach Kent McDonald (McDonald und Webb 2011) durchgeführt.

Zunächst wurde ein Metallblock in flüssigem Stickstoff gekühlt. Dieser besaß zwei Aussparungen für Eppendorfgefäße. Sobald der Metallblock kühl genug war, wurde er aus dem $\mathrm{LN}_{2}$ herausgenommen und zwei Eppendorfgefäße, die mit einer vorbereiteten und ebenfalls durch $\mathrm{LN}_{2}$-gekühlten Lösung $\left(1 \% \mathrm{OsO}_{4}, 1 \%\right.$ Glutaraldehyd, $1 \%$ $\mathrm{H}_{2} \mathrm{O}$, Lösungsmittel Aceton) gefüllt waren, in die dafür vorgesehenen Löcher eingesetzt (Jiménez et al. 2006). Auf ein Eppendorfgefäß kam je eine in $\mathrm{LN}_{2}$ gelagerte Plunchette mit einer Saphirscheibe. Der Metallblock sollte nun leicht gekippt in eine Styroporbox gestellt werden, die sich auf einem beweglichen Untergrund befand. Nun wurde alles für 4 Stunden bei Raumtemperatur bei ständiger Bewegung aufgewärmt. Das allmähliche Aufwärmen führte zur langsamen Herauslösung des Wassers. Ab $-90{ }^{\circ} \mathrm{C}$ wurde das Aceton flüssig und das Wasser substituiert. Das Osmiumoxid und das Glutaraldehyd wurden zur Fixierung von Zellmembranen und Proteinen benötigt. Da diese Substanzen toxisch sind, mussten sie anschließend durch mehrmaliges Waschen (fünfmal 12 Minuten) mit Aceton herausgelöst werden.

Nun wurde die Plunchette mit der Saphirscheiben in ein mit Epon (ein aliphatisches Epoxidharz) gefülltes Gefäß gelegt. Um eine langsame und gleichmäßige Eponverteilung über die gesamte Saphirscheibe zu gewährleisten, wurde der prozentuale Eponanteil der Epon-Aceton-Lösung im 30-Minutentakt um jeweils 25\% erhöht. Angefangen wurde mit einer 25 \%igen Lösung. Die Saphirscheiben mussten anschließend über Nacht in 
$100 \%$ igem, hochviskosem Epon bei Raumtemperatur gelagert werden. Am nächsten Morgen wurden die Saphirscheiben aus der Plunchette gelöst, mithilfe eines Skalpells in vier Teile geschnitten und in Gelatinekapseln oder in Silikonformen mit Epon gefüllt. Die Polymerisation des Epoxidharzes wurde für 72 Stunden bei $60{ }^{\circ} \mathrm{C}$ durchgeführt, um eine erforderliche, besonders hohe Härte für das FIB-SEM zu erreichen.

Bevor das FIB-SEM genutzt wurde, mussten die Zellkulturen unter dem TEM (Transmissionselektronenmikroskop) kontrolliert werden.

Die Ergebnisse waren qualitativ nicht ausreichend. Die Dichte der Neuronen war zu niedrig, und der Kontrast war zu gering. Es wäre nicht möglich gewesen, ausreichend dendritische Dornfortsätze zu untersuchen. Es wurden anschließend konventionelle Zellkulturen gezüchtet. Zur Bildgebung wurde ein Elektronenmikroskop (Zeiss EM902) genutzt.

\subsection{Konventionelle Zellkultur}

Für die konventionelle Zellkultur wurden nur die Neuronen des Hippocampus benötigt. Die Astrozyten, die bei der Sandwich-Kultur die Neuronen in ihrer Entwicklung unterstützt hatten, waren hier nicht notwendig. Zunächst wurden die Deckgläser vorbereitet, um den Neuronen die Möglichkeit zu geben, auf ihnen zu haften. Anschließend konnten die Neuronen aus den Hippocampi präpariert werden. Nach dem Aufbringen der Neurone auf die Deckgläser, musste mindestens zwei Wochen gewartet werden, um eine ausreichende Differenzierung der Neurone zu erreichen. Während dieser Zeit musste alle zwei Tage ein Teil des Neurobasal-A-Mediums ausgetauscht werden, um genügend Nährstoffe bereitzustellen.

\subsubsection{Vorbereitung der Deckgläser}

Zunächst wurden die Deckgläser (Durchmesser $18 \mathrm{~mm}$ ) über Nacht in Salpetersäure gelegt, um eine grobe Reinigung zu erreichen. Am nächsten Morgen mussten sie, bis ein $\mathrm{pH}$ von 7 erreicht wurde, in einem großen Becher mit Reinstwasser einige Male gewaschen werden, um sicher zu gehen, dass die Salpetersäure und verbliebene Verunreinigungen vollständig entfernt waren. Zum Trocknen wurden sie zunächst mit einem weichen Tuch abgewischt und bei $37{ }^{\circ} \mathrm{C}$ für eine halbe Stunde gelagert. Die Trocknung ist wichtig, um anschließend eine gute Beschichtung mit PLL erreichen zu können. Anschließend wurden sie in einem Becherglas mit Alufolie bedeckt in den Autoklaven gegeben. Durch den Schutz des Becherglases mit der Alufolie wurde versucht, die Deckgläser möglichst trocken zu belassen. 
Anschließend wurde eine Lösung von PLL mit Borat-Puffer angelegt. Dazu wurde $1 \mathrm{mg}$ PLL in Pulverform benötigt, welches in $1 \mathrm{ml}$ Borat-Puffer gelöst wurde. Um Lösung zu sparen, wurden die Deckgläser nach dem Sterilisieren nicht in die 12-WellPlatte gegeben, sondern in ein großes Gefäß gelegt, in welchem mehrere Deckgläser parallel Platz hatten. Hier war es einfacher, die PLL-Lösung aufzubringen. Sie wurden berührungsfrei in das Gefäß gelegt. Sie durften die Ränder des Gefäßes nicht berühren und sollten untereinander ebenfalls keinen Kontakt aufweisen. Mit einer 1-ml-Pipette wurde nun $1 \mathrm{ml}$ PLL-Lösung auf ein Deckglas gegeben. Da lediglich eine dünne Schicht auf den Deckgläsern notwendig war, konnte die überschüssige Lösung nun abpipettiert und weiterverwendet werden. Deshalb war bei dieser Methode $1 \mathrm{ml}$ PLL-Lösung für drei bis vier Deckgläser ausreichend. Nun wurden die vollständig bedeckten Deckgläser mit Alufolie abgedeckt und über Nacht in den $36{ }^{\circ} \mathrm{C}$ warmen Inkubator gestellt.

Am nächsten Morgen wurde das PLL entfernt, die Deckgläser mit Reinstwasser bedeckt und in 12-Well-Platten umgesetzt. Anschließend wurden sie noch dreimal mit Reinstwasser gewaschen. In der Regel reichten hier $1 \mathrm{ml}$ Wasser pro Well aus. Dieser Vorgang stellte sicher, dass überschüssiges PLL entfernt wurde. Es haftete nun lediglich in den Rauigkeiten der Glasoberfläche.

Nachdem dies erfolgt war, wurde das Wasser verworfen und $1 \mathrm{ml}$ Plating Medium auf die Deckgläser gegeben. Die 12-Well-Platte wurde nun für mindestens drei Tage bei $37^{\circ} \mathrm{C}$ inkubiert. Das Plating Medium enthielt Pferdeserum, welches ebenso wie das PLL wichtig für die Anhaftung der Neuronen ist.

Nach diesen Arbeitsschritten konnte die Präparation der Neurone aus den Hippocampi beginnen.

\subsubsection{Neuronenpräparation}

Vierundzwanzig Stunden nach der Geburt wurden die Ratten dekapitiert. Die folgenden Vorgänge waren unter laminarem Abzug vorzunehmen.

Zunächst wurde die Kopfhaut der Ratte entfernt und der Schädel mit Sorgfalt eröffnet. Nach Herausnehmen des Gehirns wurde dieses sofort in eine Petrischale mit HBSS-Puffer gelegt. Es war darauf zu achten, dass das Gehirn vollständig von dem Puffer bedeckt wurde. Es wurde umgekehrt in die Petrischale platziert, sodass der Hypothalamus nach oben zeigte. Im nächsten Schritt mussten die Meningen entfernt werden, sodass die Gliazellen trotz eventueller Verwachsungen nicht beschädigt wurden. Um die Meningen vollständig abtragen zu können, war es notwendig, die Hemisphären zu trennen. Dafür wurden die Pinzetten zwischen Hirnstamm/Kleinhirnregion und den beiden großen zerebralen Kortizes platziert und die Hemisphären vorsichtig mit einem Skalpell getrennt und die Hippocampi entfernt. 
Nach der Trennung wurden nun die Hippocampi für 60 Minuten in eine sterile Enzymlösung gelegt, wobei darauf geachtet werden musste, dass die Lösung in Bewegung blieb, um sicherzustellen, dass der Puffer überall angreifen konnte.

Nach den 60 Minuten wurde eine Inaktivierungslösung (25 mg Albumin, $25 \mathrm{mg}$ Trypsin-Inhibitor, $5 \mathrm{ml} 10 \%$ FCS-Medium) hinzugegeben. Diese musste 15 Minuten einwirken und wurde anschließend verworfen. Daraufhin wurden die Zellen dreimal mit $5 \mathrm{ml}$ Neurobasal-A-Medium gewaschen, um sicherzustellen, dass alle Rückstände der Inaktivierungslösung entfernt wurden.

Mit einer 10-ml-Pipette wurden anschließend $3 \mathrm{ml}$ Neurobasal-A-Medium zu der Lösung hinzugefügt. Durch wiederholtes Pipettieren lösten sich die Zellen aus dem Gewebe. Dabei sollte sich die Pipettenspitze immer am Boden des Gefäßes befinden.

Abschließend wurden erneut $2 \mathrm{ml}$ Neurobasal-A-Medium hinzugefügt und die Zellen in einer Neubauer-Zählkammer gezählt. Pro Well wurden 80.000 Zellen platziert, in welchem sich Plating Medium befand. Die Zellen kamen für mindestens zwei Stunden mit dem Plating Medium in den Inkubator. Danach wurde das Medium komplett entfernt und 1,25 ml Neurobasal-A-Medium zu den Zellen gegeben. Nach zwei Tagen erneuerte man $1 \mathrm{ml}$ Neurobasal-A-Medium.

Wenn zu viele Mikroglia in der Zellsuspension vorhanden waren, mussten diese nach vier bis fünf Tagen aufgrund ihrer neurotoxischen Wirkung durch Zugabe von $20 \mu \mathrm{l}$ FUDR pro Well, inhibiert werden.

\subsubsection{Einbettung der Zellsuspension}

Zunächst wurden die Zellen für eine Stunde bei Raumtemperatur mit $2 \%$ igem Glutaraldehyd fixiert und anschließend mit 1\%igem Osmiumtetroxid behandelt, um die Neurone für die Transmissionselektronenmikroskopie anzufärben. Anschließend wurde es mit einer stetig ansteigenden Menge von Ethanol und Propylenoxid dehydriert. Die Proben wurden nun in 50 \%iges Epon (in Propylenoxid) gegeben. Die Inkubation dauerte 12-18 Stunden. Es musste darauf geachtet werden, dass sich die Proben in leichter Bewegung befanden, damit das Epon überall hingelangen konnte. Es schloss sich eine mindestens 8 Stunden lange Inkubationszeit in $100 \%$ igem Epon an, die in einem offenen Gefäß stattfand, um die Verdunstung von Propylenoxid zu ermöglichen. Die vorherige Behandlung mit 50 \% igem Epon ist erforderlich, da das $100 \%$ ige für den Start zu viskos ist. Zum Abschluss wurden die Präparationen erneut für 36 Stunden bei $60{ }^{\circ}$ Celsius inkubiert (Denker et al. 2011).

Von dem so hergestellten Resin-Block wurden mithilfe eines Diamantmessers $70 \mathrm{~nm}$ dicke Querschnitte genommen. Die Bildgebung erfolgte mithilfe des Elektronenmikro- 
skops ( serial sectioning electron microscopy) von Zeiss (EM902A) mit einem 1024x1024CCD-Detektor (Proscan CCD HSS 512/1024; Proscan Electronic Systems).

Die Präparate und die Bilder wurden von Prof. Dr. Thomas Schikorski (Universidad Central Del Caribe, Bayamon, PR, USA) angefertigt.

\subsection{Datenanalyse}

\subsubsection{Photoshop}

Mit Photoshop konnten die einzelnen eingescannten, elektronenmikroskopischen Schnitte der Synapsen korrekt übereinandergelegt werden.

Zunächst wurde ein geeigneter dendritischer Dornfortsatz aus den EM-Bildern gewählt (Abbildung 2.2) und in Photoshop bearbeitet, indem jeder Schnitt des Dornfortsatzes durch die notwendigen Rotationen über den vorherigen Schnitt gelegt wurde (Abbildung 2.3). Für jeden dendritischen Dornfortsatz musste so eine Bildreihenfolge erstellt werden. Diese Reihenfolge war wichtig, damit der jeweils ausgewählte Dornfortsatz immer exakt an der richtigen Position zu finden war. Dies erfolgte für die Rekonstruktion und die Analyse mithilfe von Matlab.

\subsubsection{Matlab}

Für die Bildanalyse und die Erstellung der 3D-Modelle wurde eine spezielle, von Prof. Dr. Silvio O. Rizzoli, programmierte Software in Matlab verwendet.

Die eingescannten dendritischen Dornfortsätze wurden auf einem Monitor mit der Hand nachgezeichnet. Der erste Schritt war das Einzeichnen der aktiven Zone, wenn sie auf dem jeweils aktuellen Schnitt vorhanden war. Die Kennzeichnung erfolgte anhand einer roten Linie. Anschließend wurde die Membran der Synapse mit einer gelben Linie nachgezogen, um so die äußere Form festzulegen. Der nächste Schritt war beim Vorhandensein von Vakuolen die Umzeichnung dieser. Sie wurden mit einem grünen Kreis markiert. Die vorhandenen und nachgezeichneten Vesikel zeigten sich als gelbe Punkte, welche mit hellem Türkis umrandet waren. Die Morphologie der Vesikel erlaubt keine Rückschlüsse auf deren Funktion. Jedoch gehören sie mit hoher Wahrscheinlichkeit dem endosomalen sekretorischen System an. Alle Mitochondrien wurden blau nachgezeichnet (Abbildungen 2.4-2.5).

Mit den so erstellten Daten konnten mithilfe der programmierten Matlab Software 3D-Modelle (Abbildung 2.7) erstellt werden. Die äußere Membran der dendritischen Dornfortsätze wird hellbraun dargestellt. Die aktive Zone erscheint in Rot. Die Vesikel waren hellgrau bis grau, die Mitochondrien dunkel-lila. 


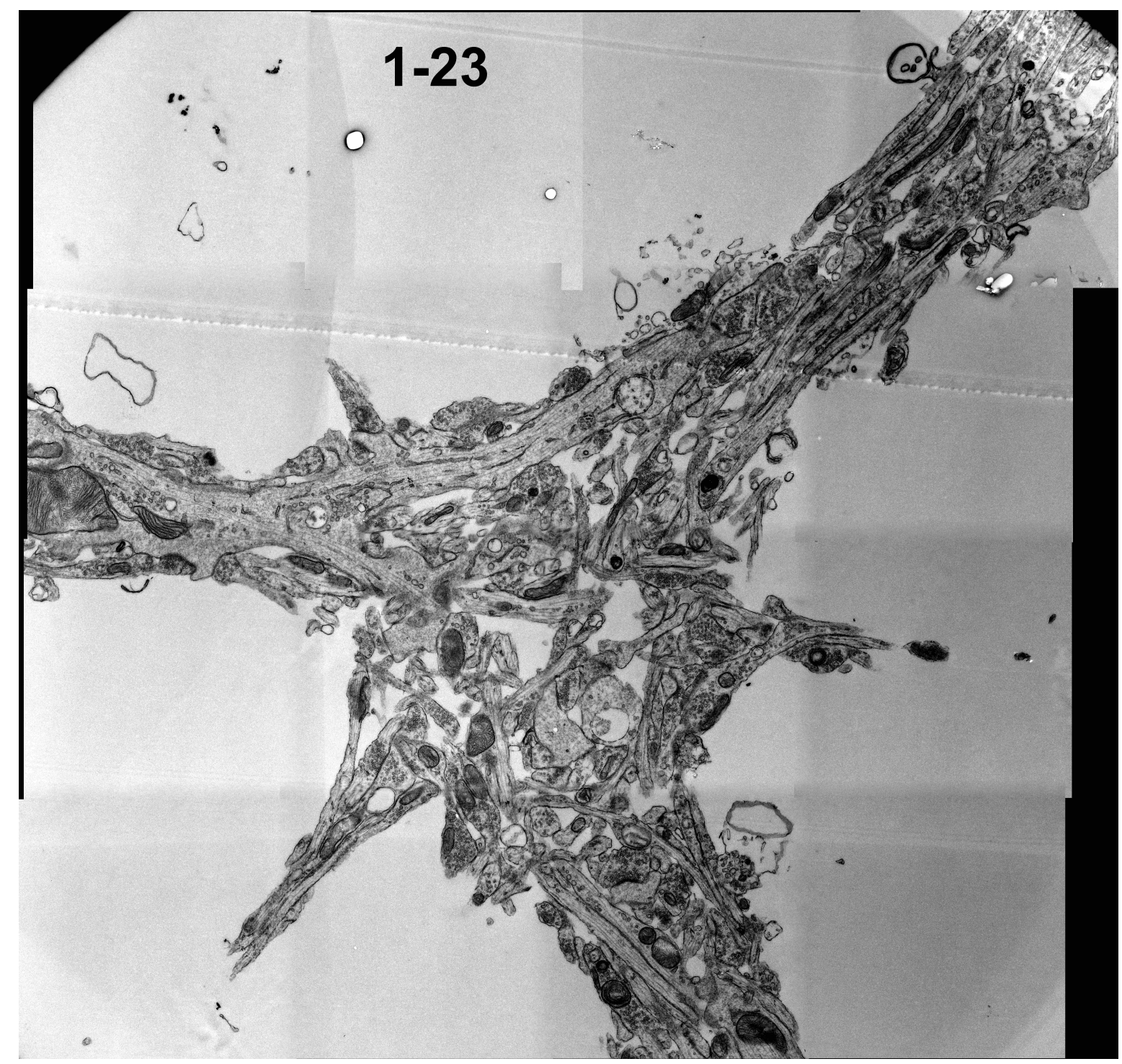

Abbildung 2.2: Elektronenmikroskopische Aufnahme eines Ultradünnschnitts 


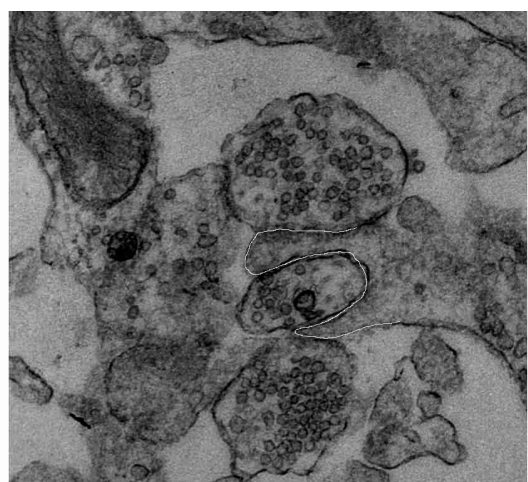

(a) Erster Schnitt

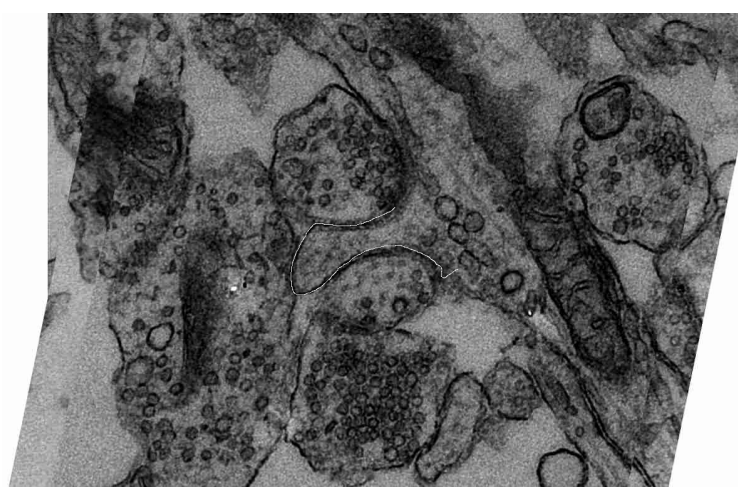

(c) Dritter Schnitt

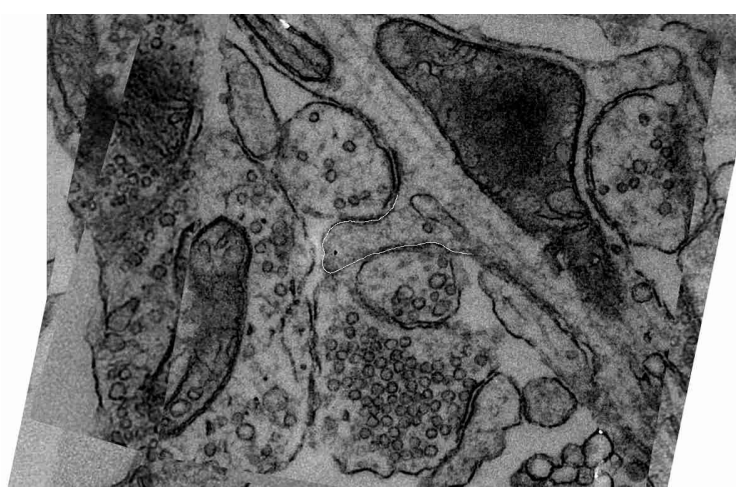

(e) Fünfter Schnitt

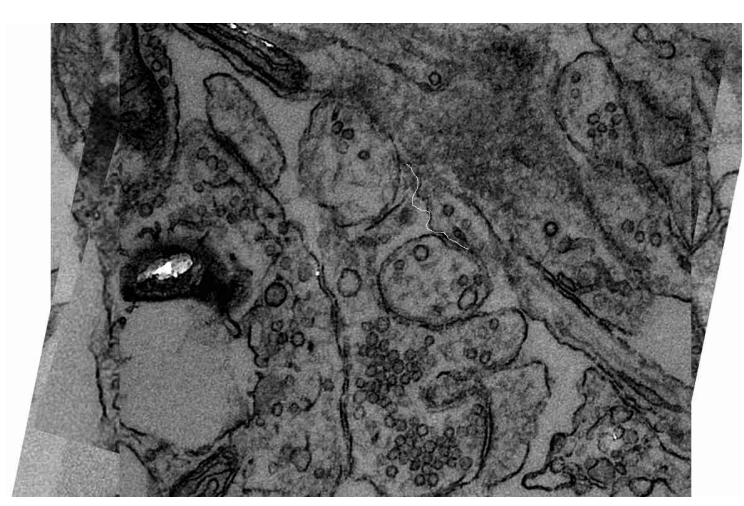

(g) Siebter Schnitt

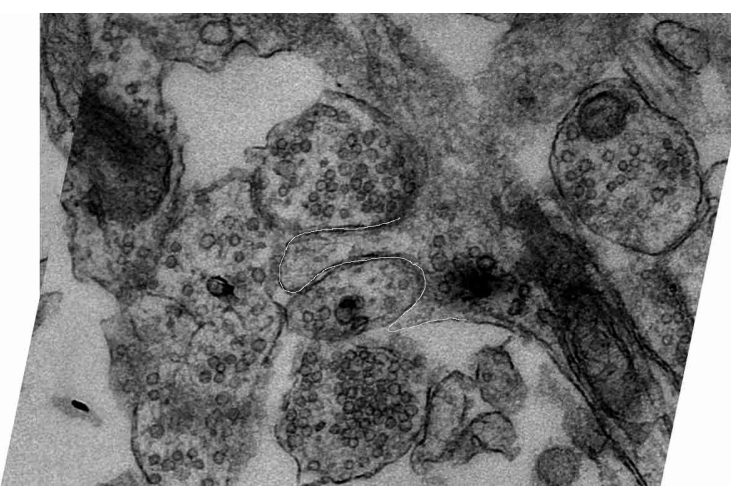

(b) Zweiter Schnitt

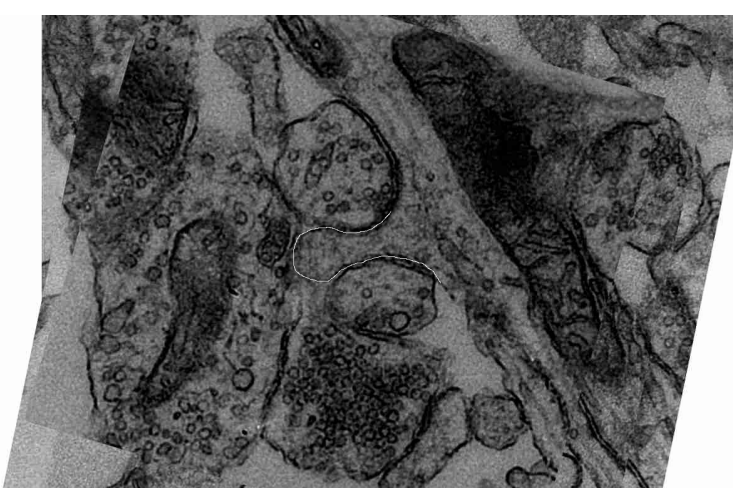

(d) Vierter Schnitt

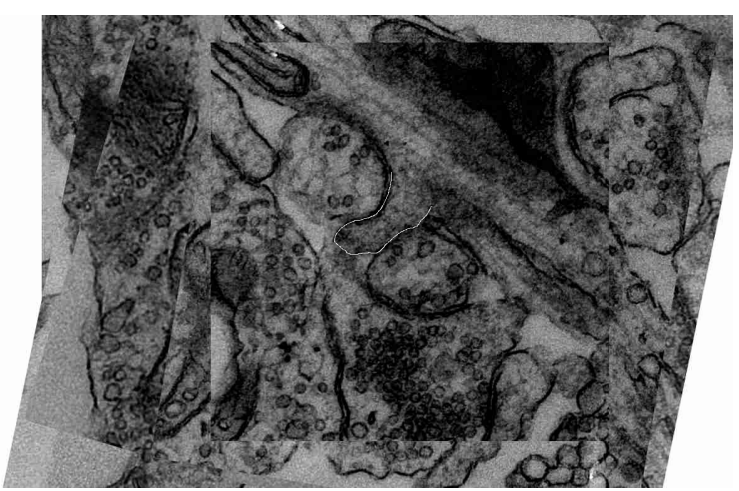

(f) Sechster Schnitt 


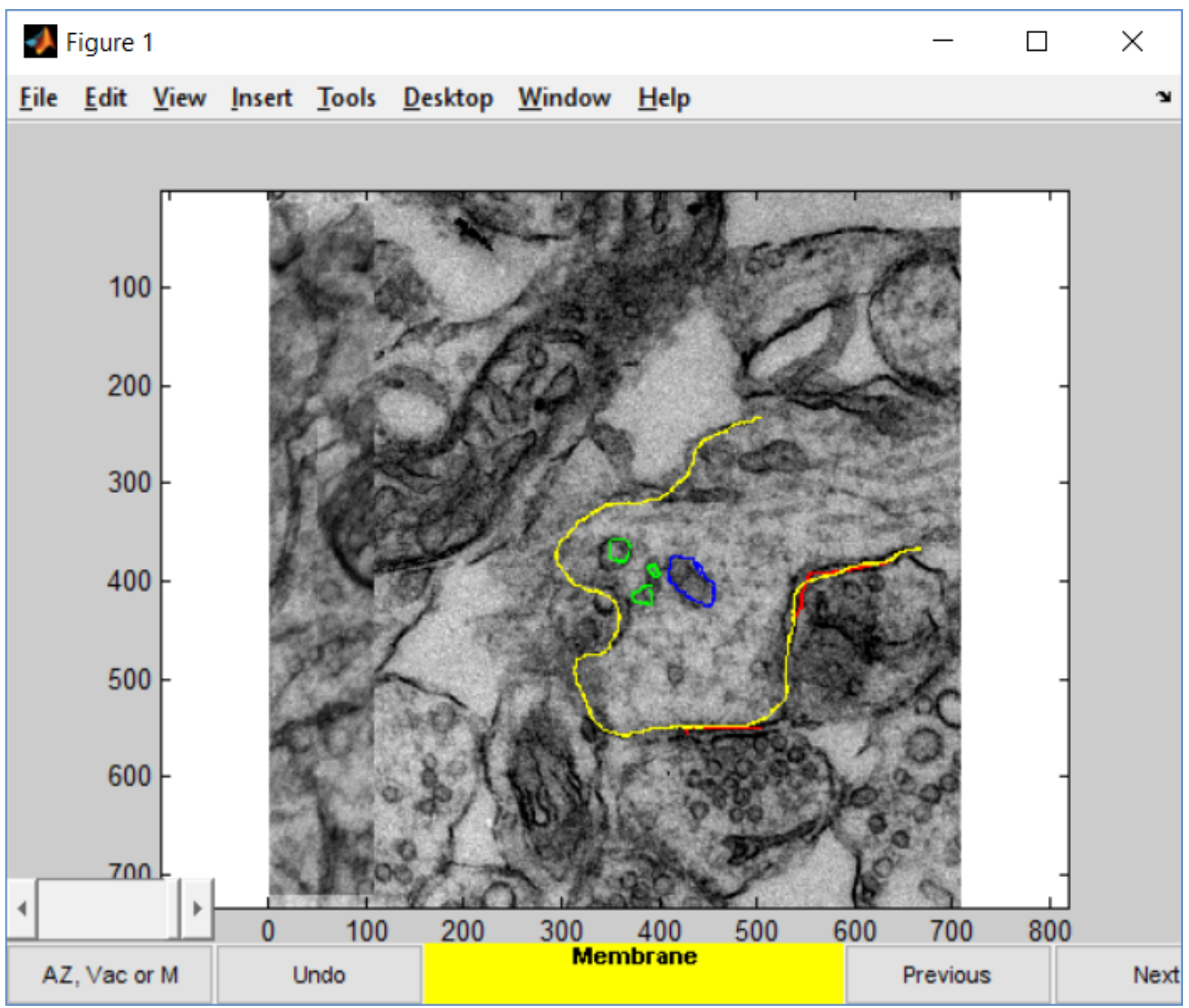

Abbildung 2.4: Matlab 1 - Schnitt eines dendritischen Dornfortsatzes. Umrandung der Membran der Postsynapse (gelb), Umrandung der Vakuolen (grün), Umrandung des Mitochondriums (blau). 


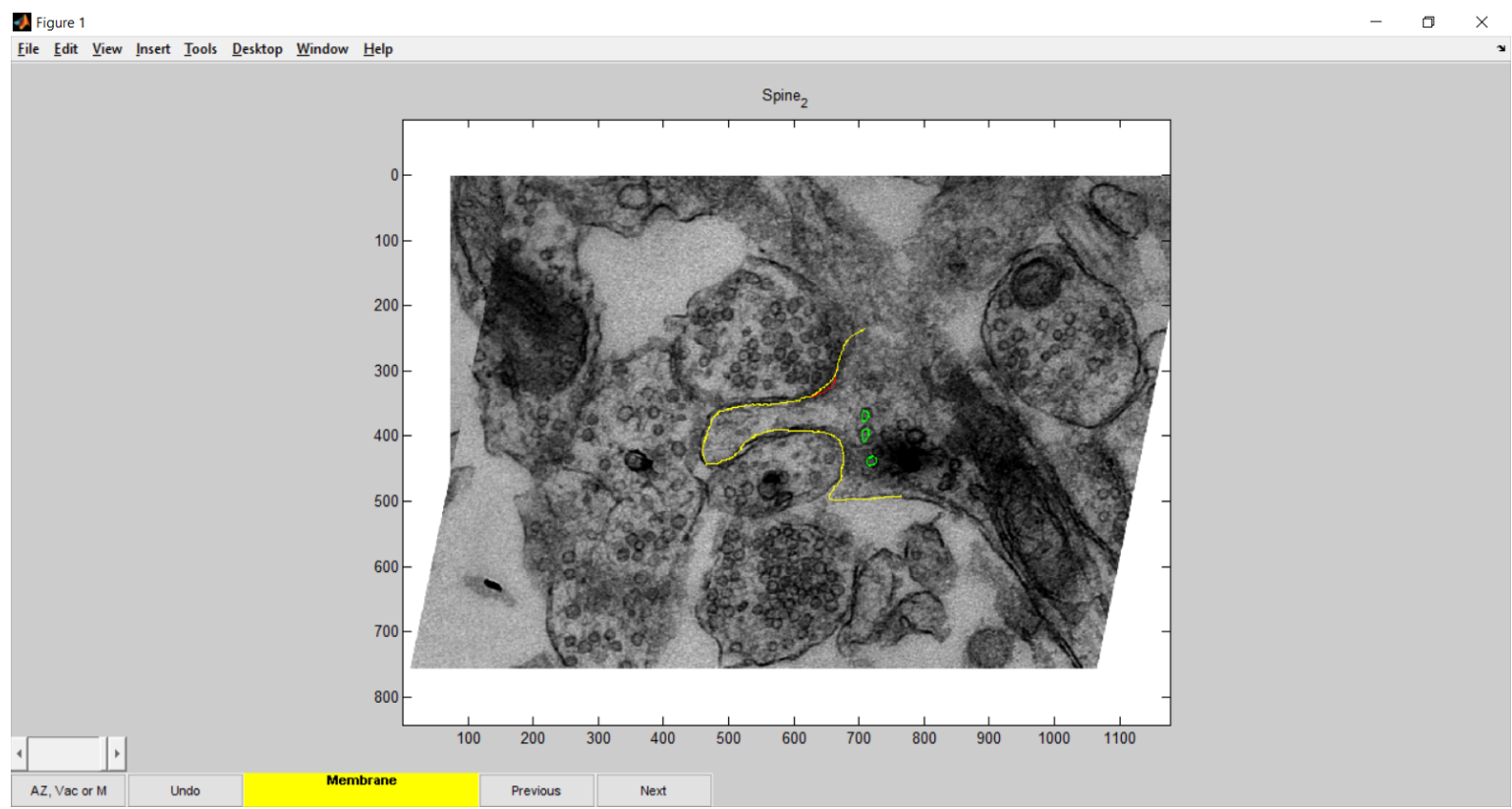

Abbildung 2.5: Matlab 2 - zweiter Schnitt des dendritischen Dornfortsatzes (Abb. 2.3(b)). Umrandung der Membran der Postsynapse (gelb), Umrandung der Vakuolen (grün).

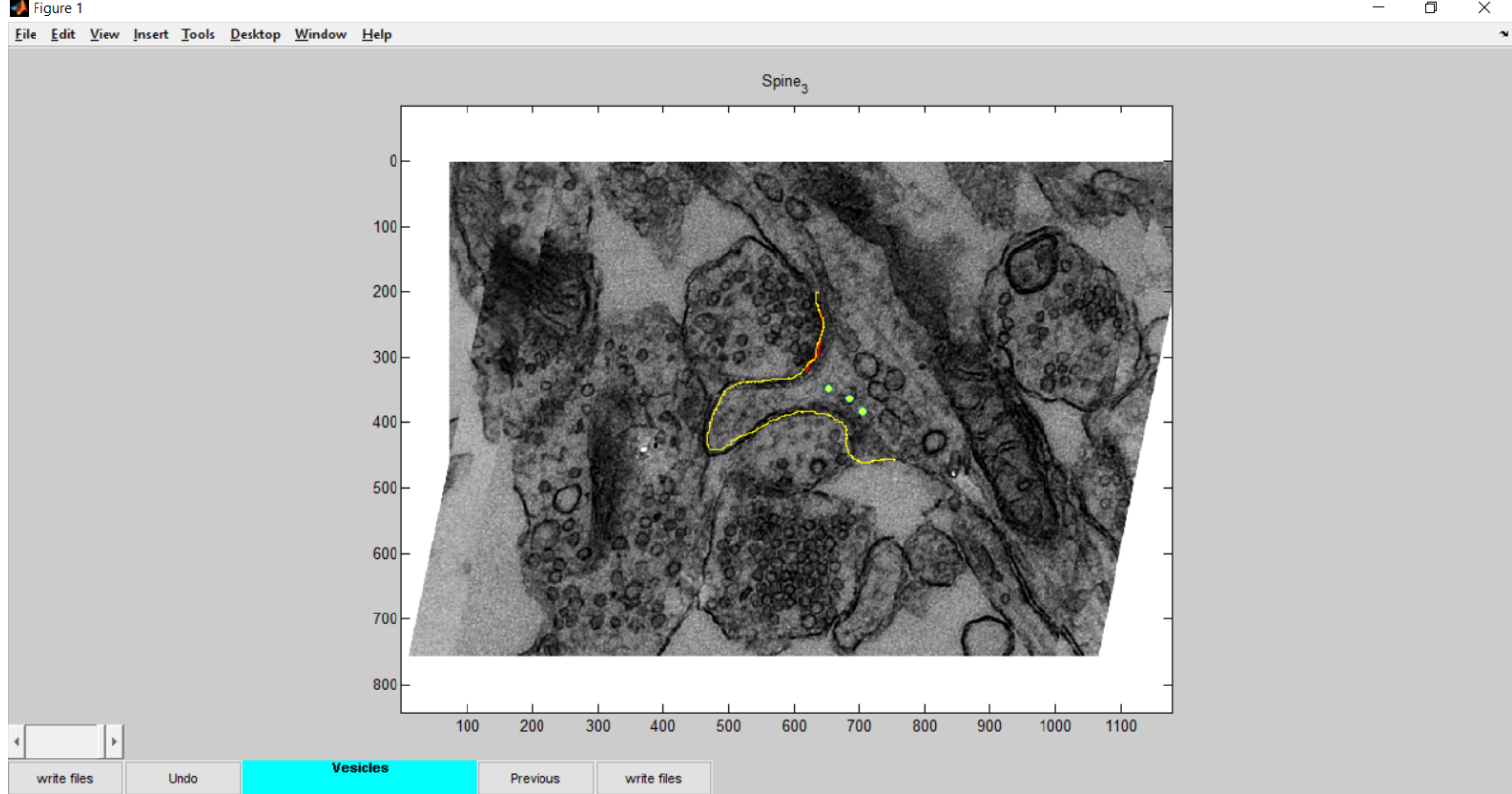

Abbildung 2.6: Matlab 3 - dritter Schnitt des dendritischen Dornfortsatzes (Abb. 2.3(c)). Umrandung der Membran der Postsynapse (gelb), Markierung der aktiven Zone (rot), Markierung der Vesikel (türkis/gelb). 


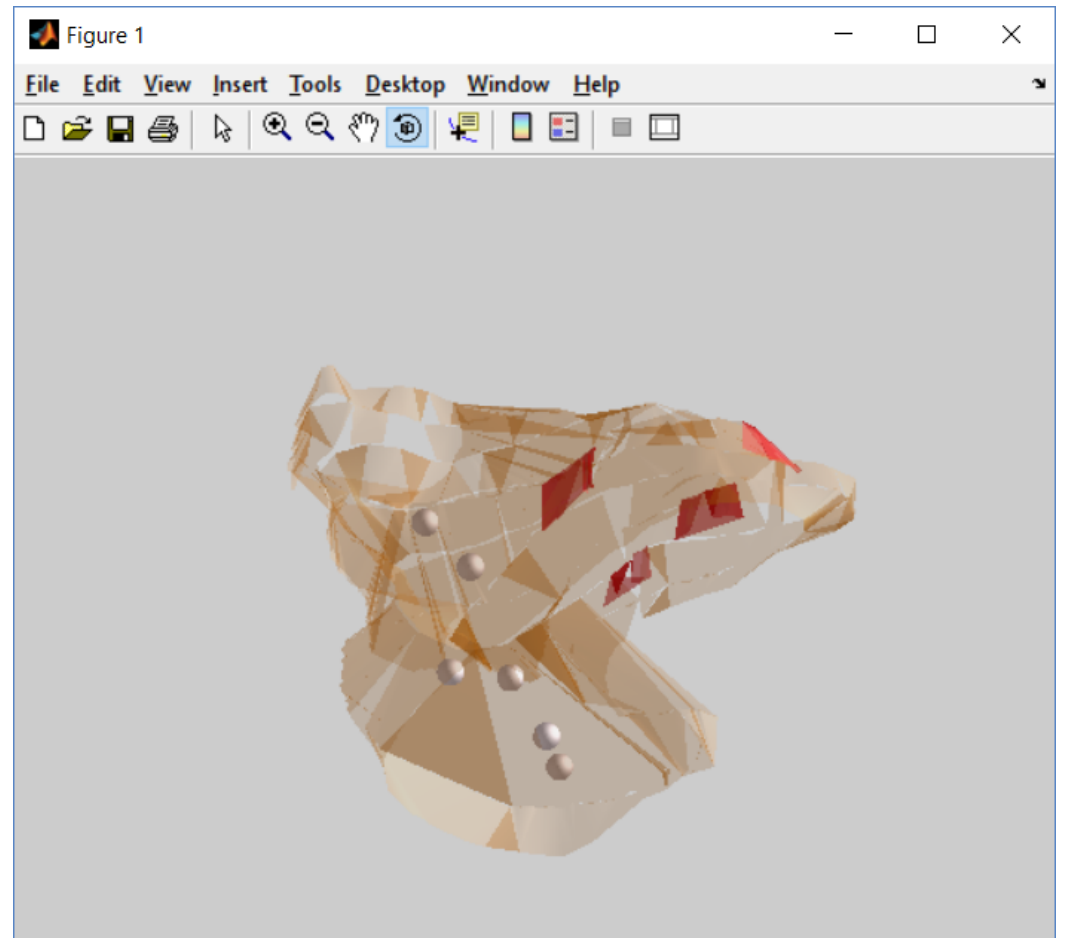

Abbildung 2.7: 3D-Modell einer Postsynapse. Die äußere Membran des dendritischen Dornfortsatzes wurde hellbraun dargestellt, die Vesikel waren hellgrau, die aktive Zone wurde rot eingezeichnet.

\subsubsection{Statistik}

Die in dieser Arbeit verwendeten Grafiken und Streudiagramme (scatterplots) wurden mithilfe von SigmaPlot erstellt. Die statistischen Untersuchungen wurden mit dem gleichen Programm durchgeführt.

\subsubsection{Pearson-Korrelation}

Die Pearson-Korrelation (Korrelationskoeffizient) ist ein dimensionsloses Maß. Es zeigt den Grad des ungerichteten linearen Zusammenhangs zwischen zwei intervallskalierten Merkmalen auf.

Der p-Wert gibt an, ob eine signifikante Korrelation zwischen zwei Merkmalen vorhanden ist. Das Signifikanzniveau wurde auf 0,05 (5\%) festgelegt, was bedeutet, dass eine signifikante Korrelation zwischen ihnen besteht, sobald $\mathrm{p} \leq 0,05$. Bei $\mathrm{p}=0,05$ bedeutet dies, dass mit einer Wahrscheinlichkeit von $95 \%$ die Merkmale miteinander korrelieren. Bei einem p-Wert zwischen 0,1 und 0,05 wird von einem statistischen Trend gesprochen.

Der sogenannte r-Wert bestimmt die Tendenz von zwei Merkmalen linear miteinander zu korrelieren. Er kann zwischen -1 und +1 liegen. Bei einem Korrelationskoeffizienten 
von null besteht kein bivariater Zusammenhang. Bei einem negativen Wert wird von einer gegenläufigen oder negativen Korrelation gesprochen.

So konnte in dieser Arbeit die Korrelation zwischen zwei verschiedenen Merkmalen einer dendritischen Dornfortsatzform untersucht werden.

\subsubsection{2 t-Test}

Um die Mittelwerte eines bestimmten Merkmals (zum Beispiel der Distanzen von der aktiven Zone zum Zentrum des Dornfortsatzes) zwischen den beiden dendritischen Dornfortsatzformen zu untersuchen, wurde der Zweistichproben-t-Test genutzt. Er überprüft zwei unabhängige Stichproben darauf, ob sich die Mittelwerte zweier Grundgesamtheiten signifikat voneinander unterscheiden. Beide Stichproben sollten aus Grundgesamtheiten mit gleicher Varianz entstammen.

Auch hier wurde das Signifikanzniveau auf 0,05 festgelegt.

Insgesamt wurden lediglich zwei t-Tests durchgeführt die eine leichte Signifikanz bei dem Vergleich der Unterschiede zwischen den zwei Formen zeigten. Hier lag der p-Wert bei 0,0456 bzw. bei 0,0276. Bei weniger als zehn t-Tests, für verschiedene Elemente, ist es in unsererem Forschungsfeld nicht üblich eine Bonferroni-Korrektur durchzuführen (p-Wert/Anzahl der Tests). Nach Durchführung der Bonferroni-Korrektur würden dennoch die Ergebnisse dieser Arbeit weiterhin bestärkt werden. Die signifikanten Unterschiede im Aufbau der beiden Formen würden dadurch eliminiert werden.

Der notwendige Nachweis der Normalverteilung wurde bei den entsprechenden Datensätzen (z.B. Oberfläche der Aktiven Zone und Volumina der dendritischen Dornfortsätze) mithilfe des Jarque-Bera-Tests mittels Matlab durchgeführt. 


\section{Ergebnisse}

\subsection{D-Modelle der stumpfartigen dendritischen Dornfortsätze}

Insgesamt wurden 34 stumpfartige dendritische Dornfortsätze analysiert. Von jedem Dornfortsatz wurde ein 3D-Modell erstellt (Abbildung 3.1). Wie oben bereits beschrieben (Abschnitt 2.3.2), erscheinen die äußeren Membranen in einer hellen, bräunlichen Farbe. Die aktiven Zonen sind rot gekennzeichnet, die Vesikel sind grau dargestellt und die Mitochondrien erscheinen in einem kräftigen lila.

\subsection{D-Modelle der pilzförmigen dendritischen Dornfortsätze}

Es wurden insgesamt 30 pilzförmige dendritische Dornfortsätze analysiert und von jedem Dornfortsatz ein 3D-Modell angefertigt (Abbildung 3.2). Die Modelle sind in den gleichen Farben dargestellt wie bei den stumpfartigen dendritischen Dornfortsätzen (Abschnitt 3.1). 


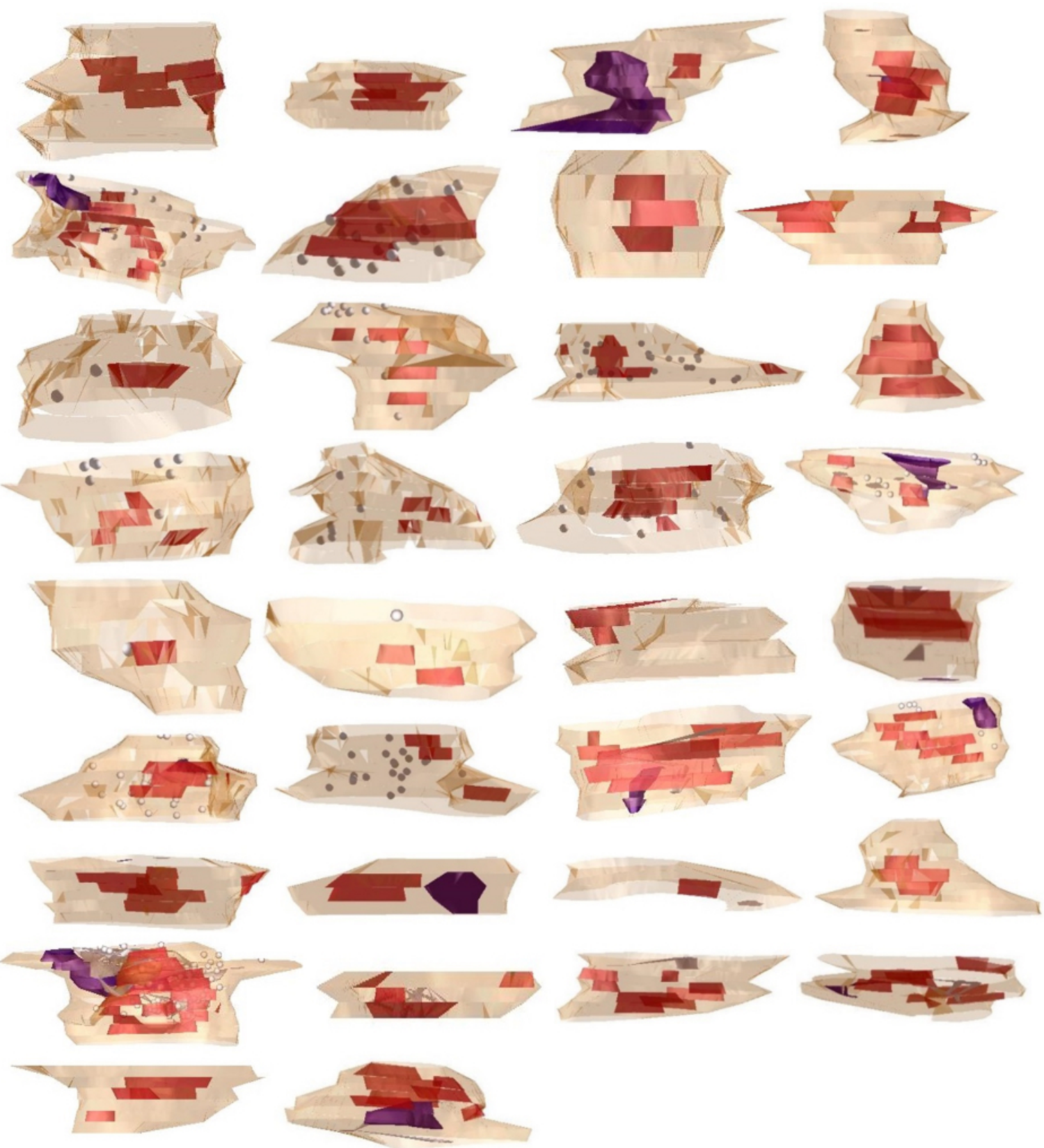

Abbildung 3.1: 3D-Modelle der stumpfartigen dendritischen Dornfortsätze 

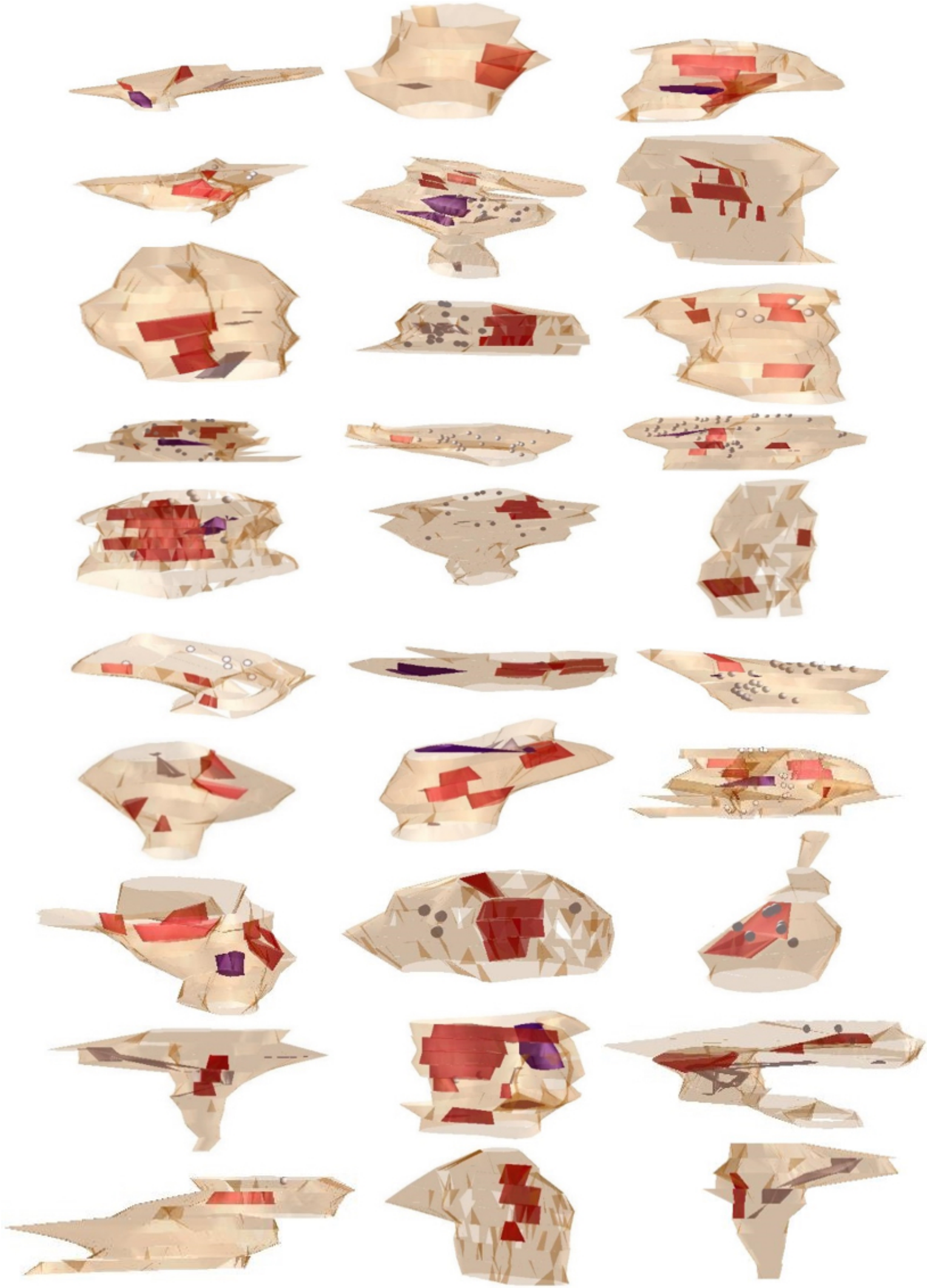

Abbildung 3.2: 3D-Modelle der pilzförmigen dendritischen Dornfortsätze 


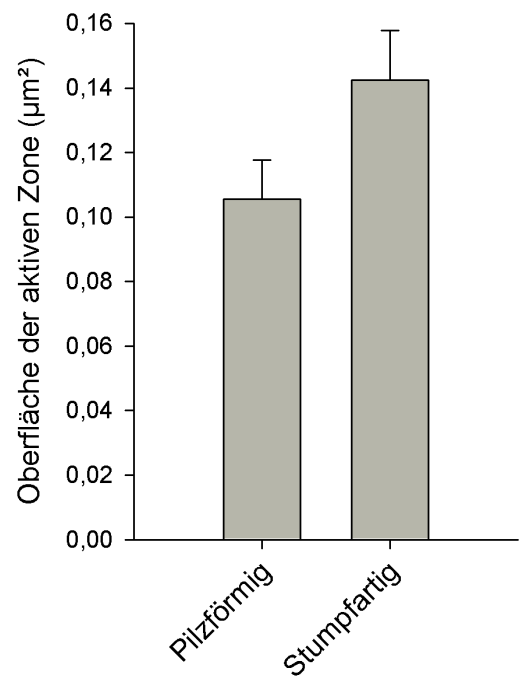

Abbildung 3.3: Durchschnittliche Oberfläche der aktiven Zonen von pilzförmigen und stumpfartigen dendritischen Dornfortsätze mit Standardfehler

\subsection{Aktive Zone}

Zunächst wurden die Oberflächen der aktiven Zonen untersucht und verglichen.

Die Oberflächen der aktiven Zonen der stumpfartigen und der pilzförmigen dendritischen Dornfortsätze unterschieden sich geringfügig voneinander. Die Oberflächen der aktiven Zonen lagen bei den stumpfartigen dendritischen Dornfortsätzen zwischen $0,0161 \mu \mathrm{m}^{2}$ und 0,3077 $\mu \mathrm{m}^{2}$. Bei den Pilzförmigen lagen sie zwischen 0,0271 $\mu \mathrm{m}^{2}$ und $0,2888 \mu \mathrm{m}^{2}$. Sowohl die kleinste als auch die größte Oberfläche der aktiven Zone war bei den stumpfartigen dendritischen Dornfortsätzen zu finden. Bei dieser Form der Dornfortsätze betrug die Differenz zwischen der größten und der kleinsten Oberfläche der aktiven Zone 0,2916 $\mu^{2}$, während der Unterschied bei den Pilzförmigen 0,2617 $\mu^{2}$ betrug. Das bedeutet, dass die Stumpfartigen eine größere Variabilität in der Oberflächengröße der aktiven Zone besaßen als die Pilzförmigen. Die einzelnen Größen der aktiven Zonen der beiden unterschiedlichen Formen sind aufsteigend sortiert in Tabelle 6.1 im Anhang aufgeführt. Beim Größenvergleich der aktiven Zonen der beiden Dornfortsatzformen zeigte sich auch hier, dass die stumpfartigen dendritischen Dornfortsätze im Durchschnitt mit 0,132 $\mu \mathrm{m}^{2}$ eine etwas größere aktive Zone besaßen als die Pilzförmigen mit 0,106 $\mu^{2}$. Abbildung 3.3 zeigt die durchschnittlichen Oberflächen der aktiven Zone der beiden Formen im Vergleich.

Die meisten pilzförmigen dendritischen Dornfortsätze besaßen eine kleine aktive Zone. Von den 30 Dornfortsätzen die vermessen wurden, besaßen 19 eine aktive Zone, die nicht größer als 0,1 $\mathrm{m}^{2}$ war. Es bedeutet, dass in diesem Bereich (Oberfläche der 
aktiven Zone $=0,01$ bis $0,1 \mu \mathrm{m}^{2}$ ) 63,3\% der pilzförmigen dendritischen Dornfortsätze zu finden waren. Bei größer werdender Oberfläche der aktiven Zone nahm die Anzahl der pilzförmigen dendritischen Dornfortsätze kontinuierlich ab.

Anders als bei den pilzförmigen dendritischen Dornfortsätzen waren bei den Stumpfartigen viele mit einer etwas größeren aktiven Zone zu finden. Zwölf Dornfortsätze wiesen eine aktive Zone mit einer Oberfläche von $0,2 \mu \mathrm{m}^{2}$ bis $0,325 \mu \mathrm{m}^{2}$ auf. Das bedeutet, dass sich in diesem Bereich (Oberfläche der aktiven Zone $=0,2$ bis 0,325 $\mu^{2}$ ) $35 \%$ aller stumpfartigen Dornfortsätze befanden. Vergleicht man diesen Wert mit dem der pilzförmigen dendritischen Dornfortsätze, der bei 13,3\% lag, so wird deutlich, dass die stumpfartigen Dornfortsätze häufiger eine größere Oberfläche der aktiven Zone aufwiesen als die Pilzförmigen. Bei den stumpfartigen Dornfortsätzen besaßen, wie bereits bei den Pilzförmigen, viele eine kleine aktive Zone (bis zu $0,1 \mu \mathrm{m}^{2}$ ). Von den 34 vermessenen stumpfartigen Dornfortsätzen besaßen 16 eine aktive Zone, die eine Oberfläche von $0,1 \mu \mathrm{m}^{2}$ nicht überschritten hatten. In diesem Bereich waren demnach 47,1\% der stumpfartigen dendritischen Dornfortsätze zu finden. Zwölf weitere Fortsätze wiesen eine aktive Zone mit einer Oberfläche von 0,2 bis $0,325 \mu^{2}$ auf. Das bedeutet, dass sich in diesem Bereich (Oberfläche der aktiven Zone $=0,2$ bis $0,325 \mu^{2}$ ) $35 \%$ aller stumpfartigen Dornfortsätze befanden. Im Vergleich mit dem Wert der pilzförmigen dendritischen Dornfortsätze, der bei 13,3\% lag, wurde deutlich, dass die stumpfartigen Dornfortsätze häufiger eine größere Oberfläche der aktiven Zone aufwiesen als Pilzförmige. Abbildung 3.4 zeigt die Verteilung der pilzförmigen und stumpfartigen dendritischen Dornfortsätze anhand ihrer Oberflächengrößen der aktiven Zonen. Um eine bessere Vergleichbarkeit zu erreichen, wurden Intervalle von $0,322 \mu \mathrm{m}^{2}$ gebildet, was 150 Pixeln in den 3D-Modellen entsprach. Die Größen der aktiven Zonen wurden entweder auf- oder abgerundet. 


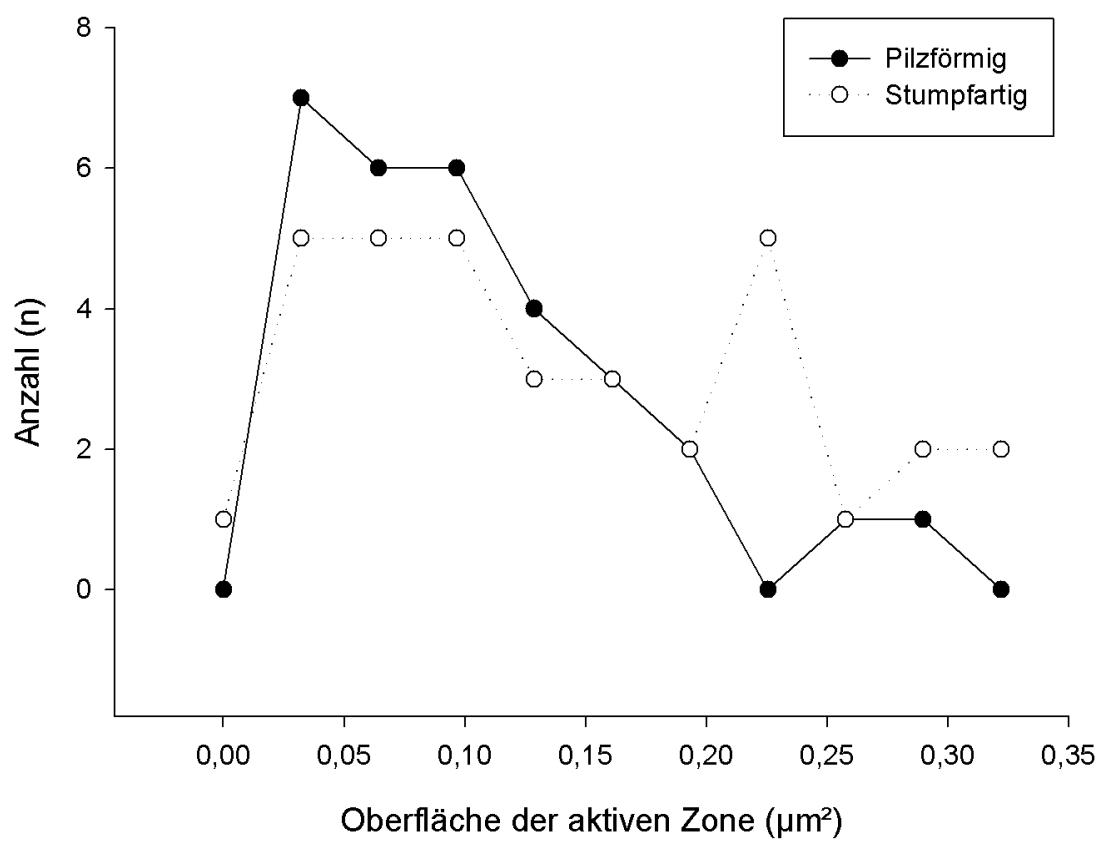

Abbildung 3.4: Anzahl der pilzförmigen und stumpfartigen dendritischen Dornfortsätze in Relation zu festgelegten Größen der aktiven Zone. Es wurden Intervalle von $0,322 \mu \mathrm{m}^{2}$ gebildet.

Beim Vergleich der Korrelationen der Oberflächengröße der aktiven Zone zu dem Gesamtvolumen der dendritischen Dornfortsätze gab es Unterschiede zwischen den zwei Formen. Die lineare Korrelation zwischen diesen beiden Merkmalen schien bei den Stumpfartigen höher und signifikanter zu sein als bei den pilzförmigen Dornfortsätzen. Ein Pearson-Test bestätigte eine lineare Korrelation bei den stumpfartigen dendritischen Dornfortsätzen $(\mathrm{r}=0,5016 ; \mathrm{p}=0,0025)$. Diese signifikante lineare Korrelation, die bei den stumpfartigen Dornfortsätzen eindeutig nachzuweisen war, fehlte bei den pilzförmigen dendritischen Dornfortsätzen $(\mathrm{r}=0,3 ; \mathrm{p}=0,173)$. Abbildung 3.5 zeigt die Verteilung der pilzförmigen und der stumpfartigen dendritischen Dornfortsätze in Bezug auf die Oberfläche der aktiven Zone und dem Gesamtvolumen des Dornfortsatzes. Es wurde für jede der beiden Formen eine Regressionsgerade (FIT) angelegt. So war gut zu erkennen, dass das Volumen der pilzförmigen dendritischen Dornfortsätze größer war als das der Stumpfartigen. Die Oberfläche der aktiven Zone hingegen schien bei den Stumpfartigen größer gewesen zu sein. Aufgrund der weiten Streuung der pilzförmigen dendritischen Dornfortsätze in dem Streudiagramm (scatterplot) war bereits zu erkennen, dass die Korrelation zwischen den beiden Merkmalen bei den stumpfartigen dendritischen Dornfortsätzen, die enger gestreut waren, größer sein könnte. 


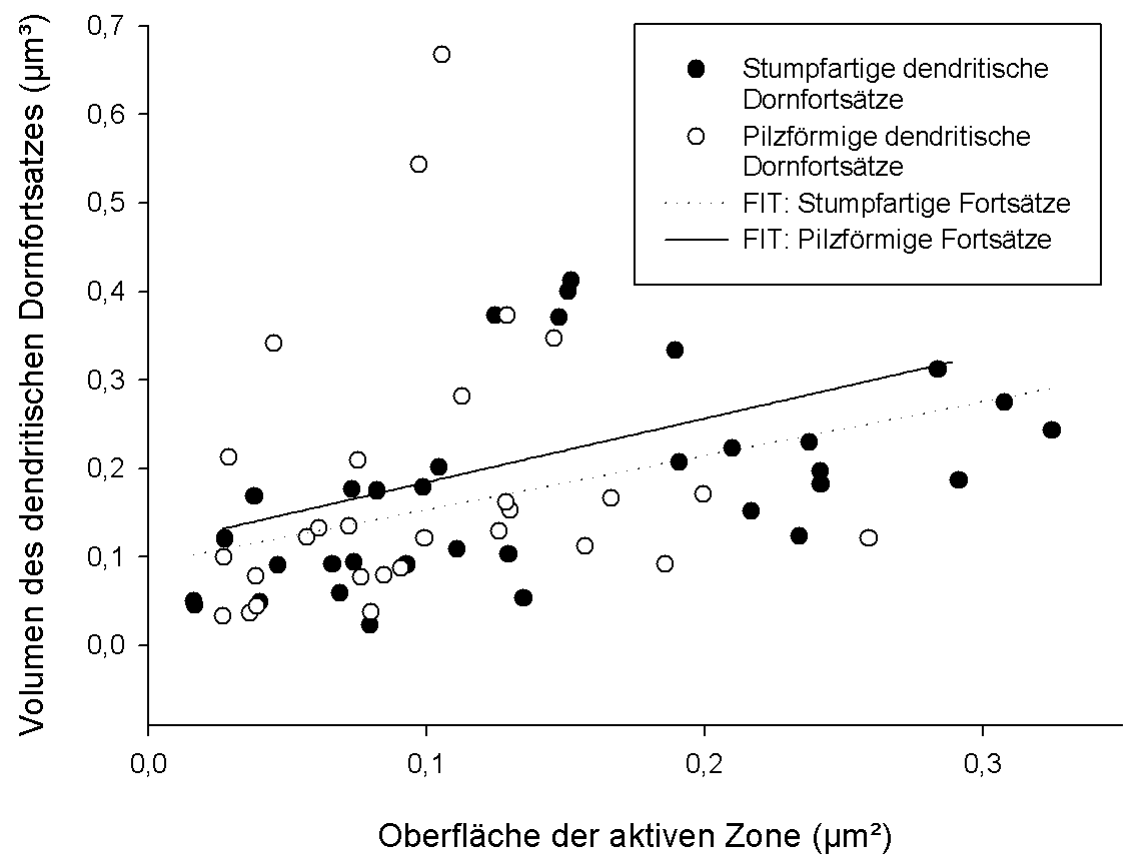

Abbildung 3.5: Vergleich zwischen der Oberfläche der aktiven Zone und dem Gesamtvolumen (von pilzförmigen und stumpfartigen dendritischen Dornfortsätzen) mit Regressionsgeraden

Ein ähnliches Ergebnis zeigte sich beim Vergleich der Oberfläche der aktiven Zone mit der Gesamtoberfläche der dendritischen Dornfortsätze.

Bei den stumpfartigen Dornfortsätzen ließ sich mithilfe der Pearson-Korrelation ein signifikanter Zusammenhang nachweisen $(\mathrm{r}=0,6055 ; \mathrm{p}=0,0001)$. Es bestand somit eine noch eindeutigere Korrelation der Oberflächengröße der aktiven Zone zur Gesamtoberfläche als zum Gesamtvolumen.

Die Korrelation der pilzförmigen dendritischen Dornfortsätze $(\mathrm{r}=0,4008 ; \mathrm{p}=0,282)$ unterschied sich bei diesen beiden Merkmalen erneut von der Korrelation der Stumpfartigen. Sie war etwas größer als bei dem Vergleich der Oberfläche der aktiven Zone mit dem Gesamtvolumen $(\mathrm{r}=0,3)$. Es reichte jedoch nicht aus, um eine signifikante lineare Korrelation zwischen der Oberfläche der aktiven Zone und der Gesamtoberfläche der pilzförmigen dendritischen Dornfortsätze nachzuweisen.

In Abbildung 3.6 ist die Verteilung der pilzförmigen und der stumpfartigen dendritischen Dornfortsätze in Bezug auf die Oberfläche der aktiven Zone und der Gesamtoberfläche dargestellt. Um eine bessere Vergleichbarkeit der beiden Formen miteinander zu erreichen, wurden zwei Regressionsgeraden (FIT), eine für die stumpfartigen und eine für die pilzförmigen dendritischen Dornfortsätze eingefügt. Es zeigte sich, dass die 


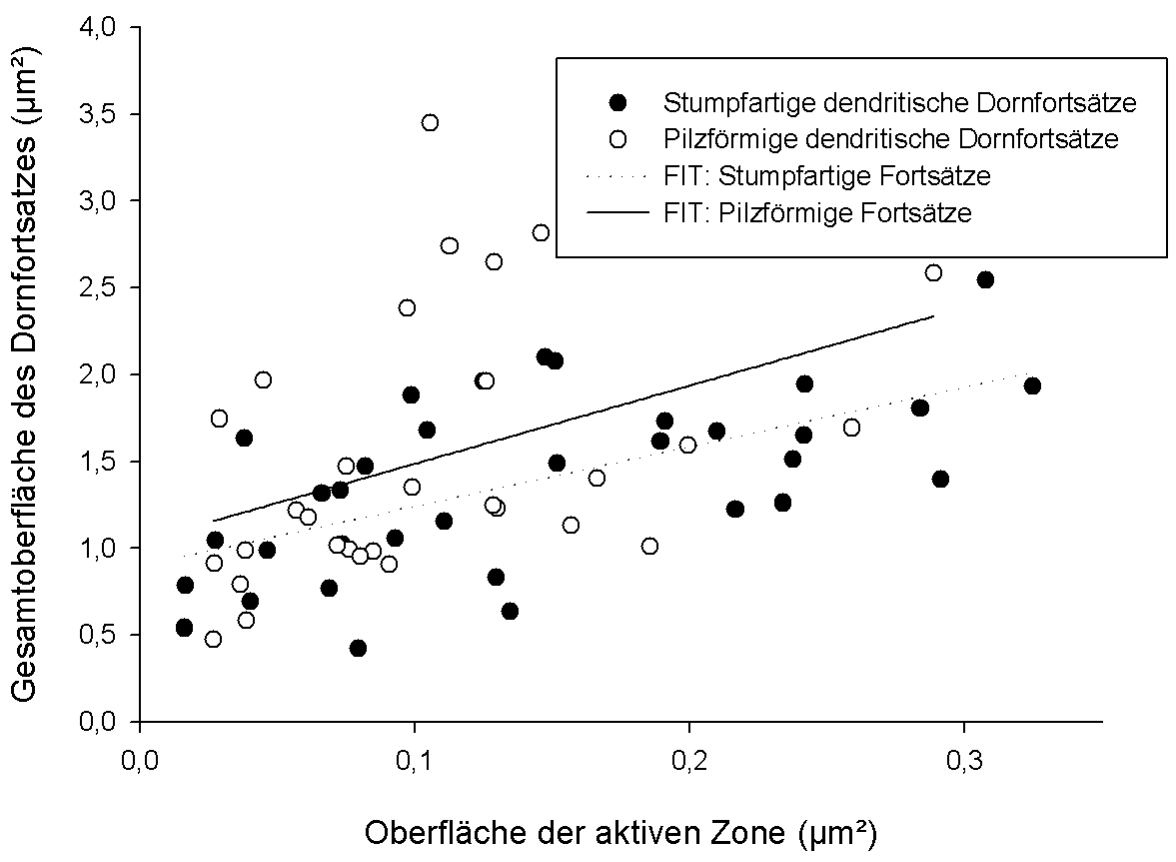

Abbildung 3.6: Vergleich zwischen der Oberfläche der aktiven Zone und der Gesamtober-
fläche (von pilzförmigen und stumpfartigen dendritischen Dornfortsätzen)
mit Regressionsgeraden

Gesamtoberfläche bei den pilzförmigen dendritischen Dornfortsätzen größer war als bei den Stumpfartigen.

Die größeren aktiven Zonen besaßen jedoch die Stumpfartigen. Die Werte der pilzförmigen dendritischen Dornfortsätze wiesen eine deutlich größere Streuung auf als die der Stumpfartigen, was bereits darauf schließen ließ, dass die lineare Korrelation zwischen den beiden Merkmalen bei den Stumpfartigen höher war als bei den Pilzförmigen.

Beim Vergleich der relativen Anteile der Oberfläche der aktiven Zone zu der Gesamtoberfläche der dendritischen Dornfortsätze, zeigte sich, dass die Oberflächen der stumpfartigen dendritischen Dornfortsätze prozentual mehr aktive Zone aufwiesen als die Pilzförmigen. Das Säulendiagramm (Abbildung 3.7) zeigt den durchschnittlichen relativen Anteil der aktiven Zone an der Gesamtoberfläche der dendritischen Dornfortsätze.

Die Oberflächen der aktiven Zone der stumpfartigen dendritischen Dornfortsätze wiesen im Durchschnitt etwa 10\% der gesamten Dornfortsatzoberfläche auf, während es bei den Pilzförmigen nur etwas mehr als $7 \%$ waren. Um nachzuweisen, dass dies ein signifikanter Unterschied zwischen den beiden Formen war, wurde der t-Test durchgeführt. Der Unterschied zwischen den stumpfartigen und den pilzförmigen dendritischen 


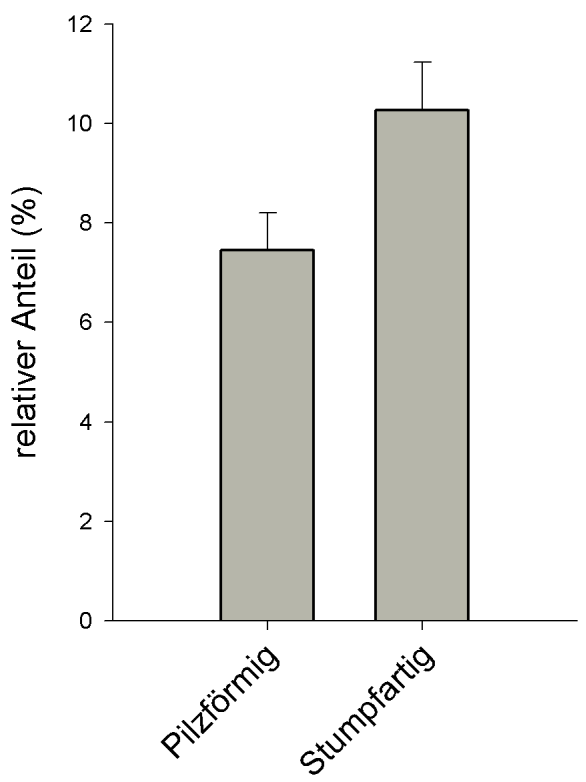

Abbildung 3.7: Durchschnittlicher relativer Anteil der Oberfläche der aktiven Zone an der Gesamtoberfläche mit Standardfehler

Dornfortsätzen in Bezug auf den relativen Anteil der aktiven Zone von der Gesamtoberfläche war nach Durchführung eines t-Tests als signifikant anzusehen ( $p=0,0276)$.

Untersucht wurden ebenfalls die Abhängigkeiten zwischen der Größe der aktiven Zone und den zwei Achsenlängen der dendritischen Dornfortsätze. Die Hauptachse war der jeweils größte Durchmesser eines Schnitts, die Nebenachse der jeweils kleinste (Abschnitt 3.6).

Zur Hauptachse zeigte sich bei den stumpfartigen dendritischen Dornfortsätzen eine schwache und dennoch signifikante lineare Abhängigkeit ( $\mathrm{r}=0,4718 ; \mathrm{p}=0,0049)$. Bei den pilzförmigen dendritischen Dornfortsätzen bestand hingegen weder eine starke lineare $(\mathrm{r}=0,3015)$, noch eine signifikante Korrelation $(\mathrm{p}=0,1054)$ zwischen der Hauptachse und der Oberfläche der aktiven Zone. In Abbildung 3.8 wurde die Verteilung der stumpfartigen und der pilzförmigen dendritischen Dornfortsätze in Bezug auf die Oberfläche der aktiven Zone und der Länge der Hauptachse dargestellt. Es wurde jeweils eine Regressionsgerade für jede Form eingezeichnet, um den Vergleich zu erleichtern. Es ist eine große Streuung bei beiden Formen der dendritischen Dornfortsätze zu erkennen, was auf eine geringe Abhängigkeit von den zwei Merkmalen schließen lässt.

Bei der Oberfläche der aktiven Zone und der Nebenachse konnte keine Korrelation bei beiden Formen erkannt werden (stumpfartige Dornfortsätze: $\mathrm{r}=0,3 ; \mathrm{p}=0,07$; pilzförmige Dornfortsätze: $\mathrm{r}=0,3 ; \mathrm{p}=0,1)$. 


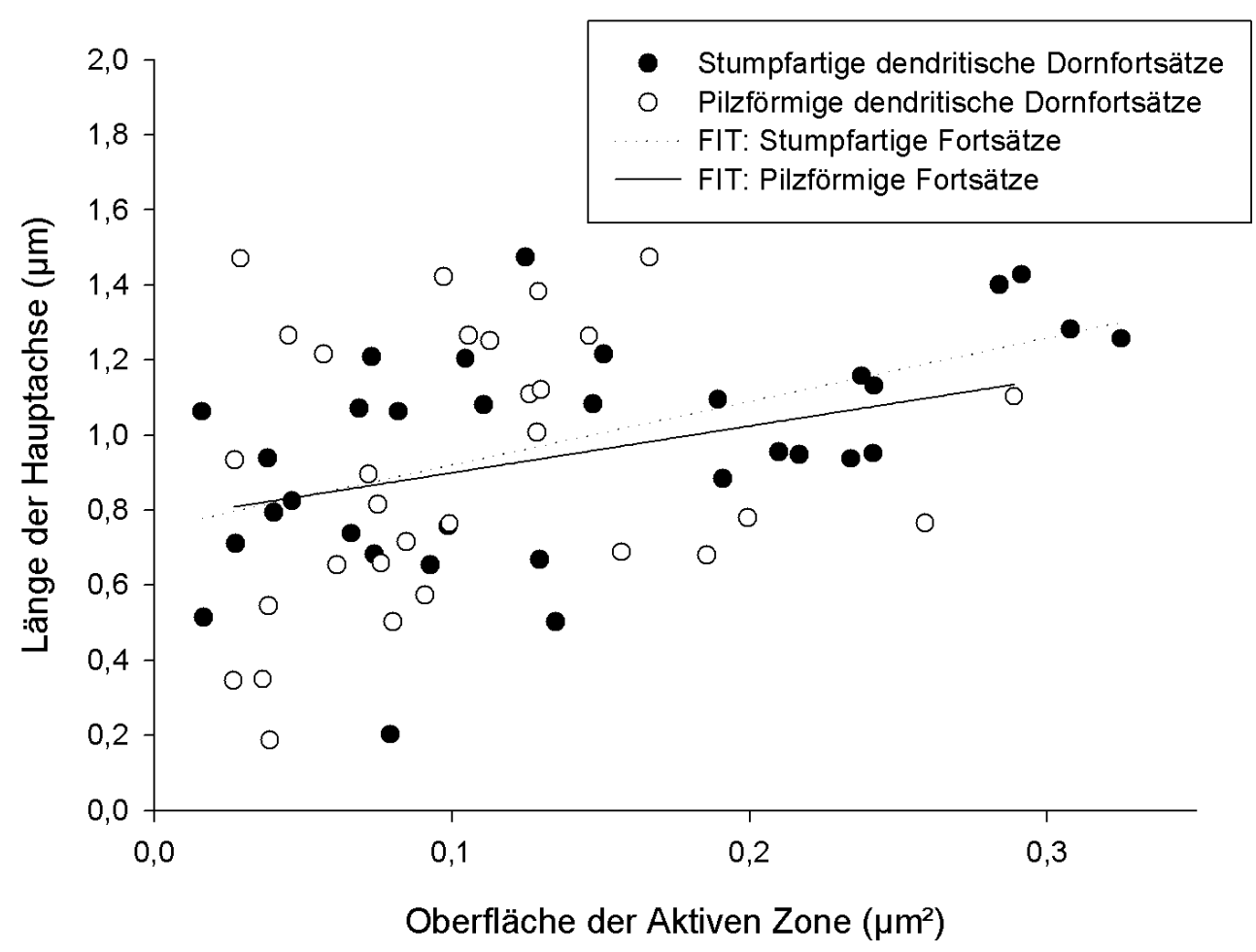

Abbildung 3.8: Vergleich zwischen der Hauptachse und der Größe der aktiven Zone (von pilzförmigen und stumpfartigen dendritischen Dornfortsätzen) mit Regressionsgeraden 


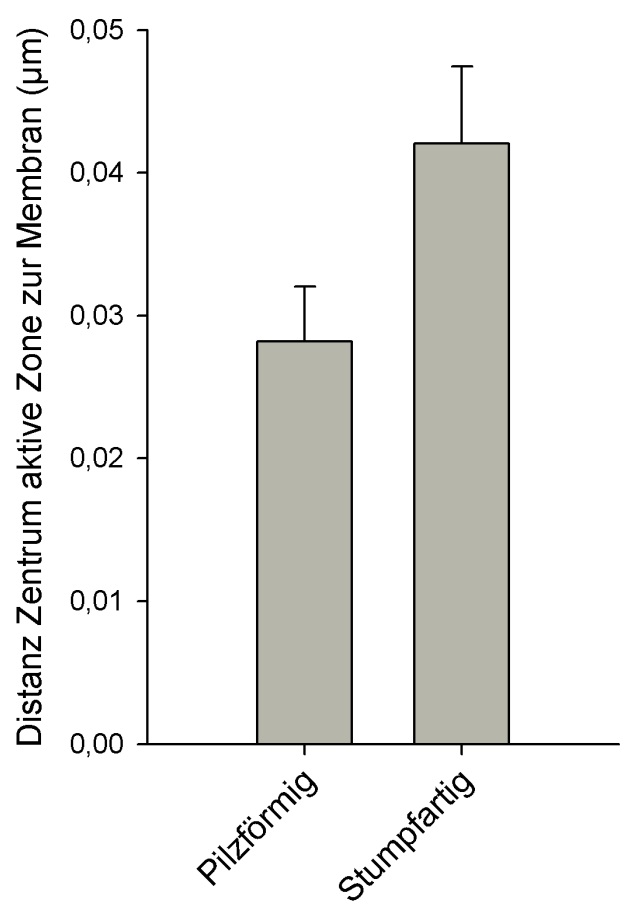

Abbildung 3.9: Durchschnittliche Distanzen der Pilzförmigen und der stumpfartigen dendritischen Dornfortsätze vom Zentrum der aktiven Zone zu der Membran mit Standardfehler

Bei der durchschnittlichen Distanz vom Zentrum der aktiven Zone zur Membran war auffällig, dass diese bei den stumpfartigen dendritischen Dornfortsätzen merklich größer war als bei den Pilzförmigen. Bei den Stumpfartigen betrug sie 0,0421 $\mu \mathrm{m}$, während sie bei den Pilzförmigen 0,0282 $\mu \mathrm{m}$ betrug. Das bedeutete, dass diese Distanz bei den Pilzförmigen im Durchschnitt knapp $31 \%$ geringer war als bei den Stumpfartigen. Ein daraufhin durchgeführter t-Test zeigte, dass der Unterschied zwischen den beiden Formen signifikant war (p: 0,0456 = 4,56\%). Das Säulendiagramm (Abbildung 3.9) zeigt den Unterschied der Distanzen.

Beim Vergleich der Distanzen vom Zentrum der aktiven Zone zum Zentrum des gesamten dendritischen Dornfortsatzes zeigte sich eine geringfügig größere Distanz bei den pilzförmigen Dornfortsätzen. Bei ihnen lag die durchschnittliche Distanz bei etwa $0,19 \mu \mathrm{m}$, während sie bei den Stumpfartigen bei 0,18 $\mu \mathrm{m}$ lag (Abbildung 3.10). Der durchgeführte t-Test zeigte keinen signifikanten Unterschied zwischen den Distanzen der beiden Dornfortsatzformen. 


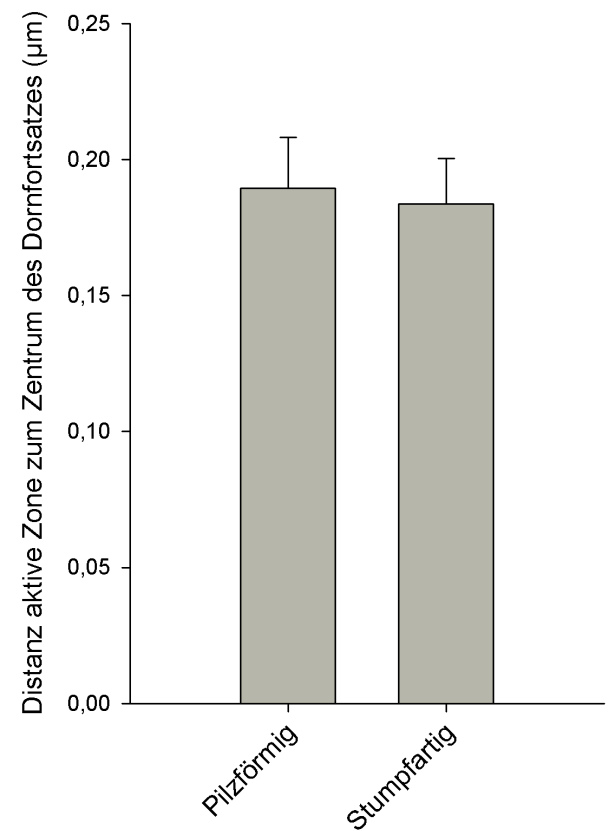

Abbildung 3.10: Durchschnittliche Distanzen der pilzförmigen und stumpfartigen dendritischen Dornfortsätze vom Zentrum der aktiven Zone bis zum Zentrum des Dornfortsatzes mit Standardfehler

\subsection{Gesamtoberfläche}

Die gesamte Oberfläche schien bei den pilzförmigen dendritischen Dornfortsätzen größer zu sein als bei den Stumpfartigen. Die Gesamtoberfläche nahm bei den Pilzförmigen Werte zwischen $0,4755 \mu \mathrm{m}^{2}$ und 3,4409 $\mu^{2}$ an. Bei den stumpfartigen dendritischen Dornfortsätzen lagen sie zwischen $0,4208 \mu \mathrm{m}^{2}$ und 2,5443 $\mu \mathrm{m}^{2}$. Im Durchschnitt betrug das Gesamtvolumen der pilzförmigen Dornfortsätze etwa $1,5 \mu \mathrm{m}^{2}$, während es bei den Stumpfartigen bei knapp 1,4 $\mu \mathrm{m}^{2}$ lag. Das Säulendiagramm (Abbildung 3.11) zeigt die durchschnittliche Gesamtoberfläche der pilzförmigen und der stumpfartigen dendritischen Dornfortsätze im Vergleich.

Die einzelnen Oberflächen der pilzförmigen und der stumpfartigen dendritischen Dornfortsätze sind im Anhang in Tabelle 6.2 aufgelistet.

Wie oben bereits beschrieben, korrelierte die gesamte Oberfläche der dendritischen Dornfortsätze nur bei den Stumpfartigen signifikant mit der Oberfläche der aktiven Zone. Diese signifikante lineare Korrelation schien bei den pilzförmigen Dornfortsätzen nicht vorhanden zu sein. 


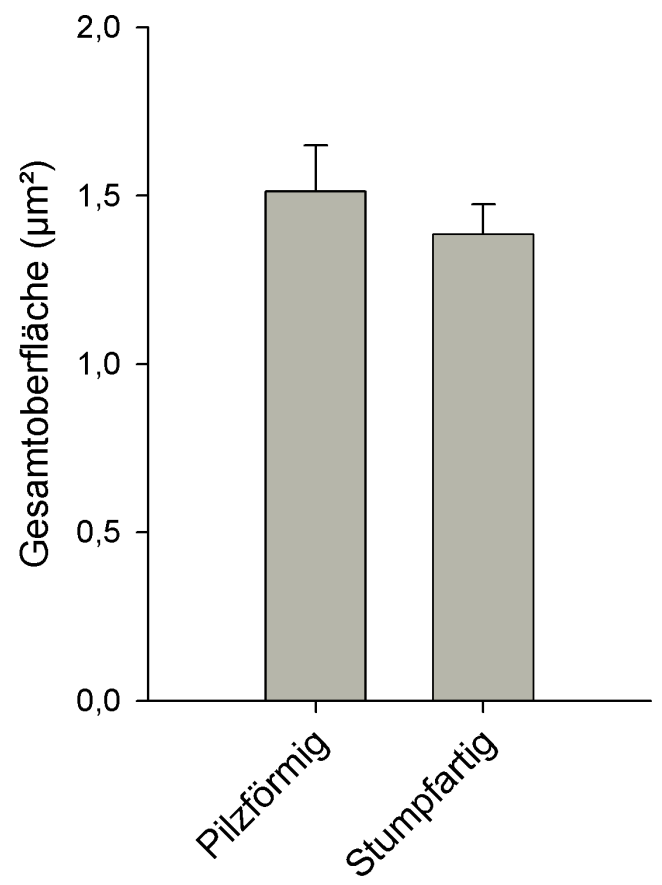

Abbildung 3.11: Durchschnittliche Gesamtoberfläche der pilzförmigen und stumpfartigen dendritischen Dornfortsätze mit Standardfehler

Wie zu erwarten war, zeigte sich eine sehr starke Korrelation zwischen der Gesamtoberfläche und dem Gesamtvolumen bei beiden Formen der dendritischen Dornfortsätze (Stumpfartig: $\mathrm{r}=0,8130 ; \mathrm{p}=0,0001$; Pilzförmig: $\mathrm{r}=0,9024 ; \mathrm{p}<0,0001$ ).

Die Korrelationen zu der Haupt- und der Nebenachse waren ebenfalls wie erwartet sehr stark. (Hauptachse Stumpfartig: $\mathrm{r}=0,6022 \mathrm{p}<0,0001$; Hauptachse Pilzförmig: $\mathrm{r}=0,7353 ; \mathrm{p}<0,0001 ;$ Nebenachse Stumpfartig: $\mathrm{r}=0,8821 ; \mathrm{p}<0,0001$; Nebenachse Pilzförmig: $\mathrm{r}=0,7770 ; \mathrm{p}<0,0001)$.

\subsection{Volumen}

Das Volumen der pilzförmigen dendritischen Dornfortsätze war im Durchschnitt größer als das der Stumpfartigen. Die Oberfläche der aktiven Zone verhielt sich genau entgegengesetzt: Die stumpfartigen dendritischen Fortsätze besaßen durchschnittlich die größeren aktiven Zonen.

Im Säulendiagramm (Abbildung 3.12) sind die durchschnittlichen Volumina der pilzförmigen und der stumpfartigen dendritischen Dornfortsätze gegeneinander aufgestellt. Der geringe Unterschied der Volumengrößen wird so deutlich. 


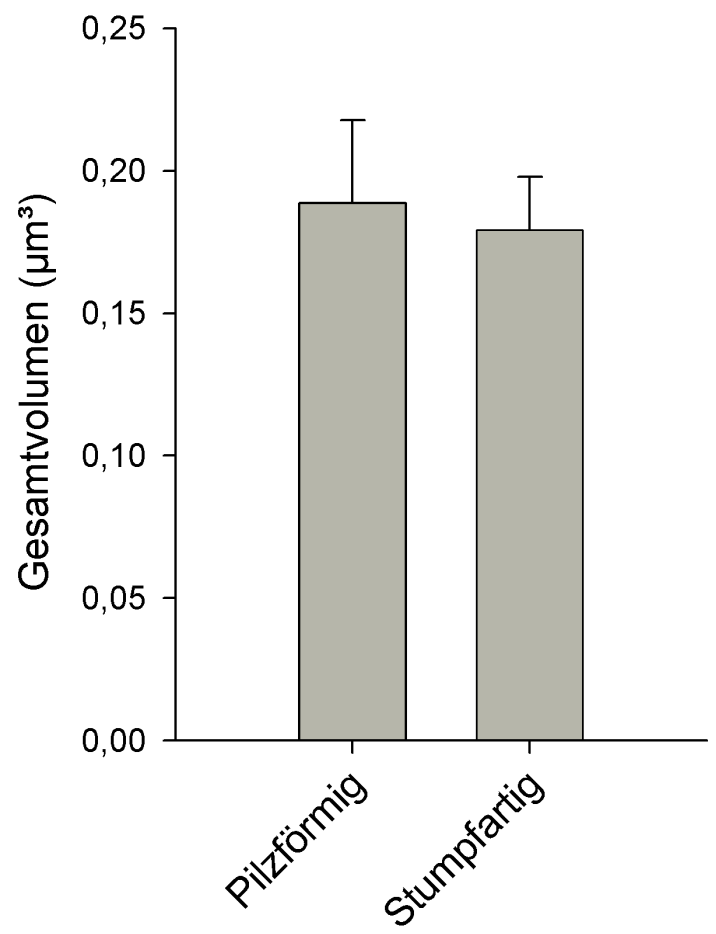

Abbildung 3.12: Durchschnittliches Volumen der pilzförmigen und stumpfartigen dendritischen Dornfortsätze mit Standardfehler 
Die gesamten Volumina werden im Anhang in der Tabelle 6.3 aufsteigend sortiert dargestellt. Das durchschnittliche Volumen der stumpfartigen dendritischen Dornfortsätze betrug 0,1793 $\mu^{3}$, das der Pilzförmigen $0,1888 \mu \mathrm{m}^{3}$.

Das Volumen der meisten stumpfartigen dendritischen Dornfortsätze lag zwischen $0,01 \mu \mathrm{m}^{3}$ und $0,2 \mu \mathrm{m}^{3}$. In diesem Bereich waren $76,6 \%$ der stumpfartigen dendritischen Dornfortsätze zu finden. Viele stumpfartige Dornfortsätze $(33,3 \%)$ besaßen ein Volumen um $0,1 \mu^{3}$, nur 23,3\% besaßen ein größeres $\left(0,25-0,45 \mu \mathrm{m}^{3}\right)$. Bei den pilzförmigen dendritischen Dornfortsätzen lagen ebenfalls mit 70,6\% die meisten bei einer Größe von $0,01 \mu \mathrm{m}^{3}$ bis $0,2 \mu \mathrm{m}^{3}$. Auffällig war hier im Vergleich zu den Stumpfartigen, dass $29,4 \%$ ein Volumen von $0,25-0,45 \mu \mathrm{m}^{3}$ besaßen. Das bedeutet, dass bei den pilzförmigen dendritischen Dornfortsätzen 6,1\% mehr Dornfortsätze ein großes Volumen besaßen. Bei etwa 0,4 $\mu \mathrm{m}^{3}$ lagen 11,8\% der pilzartigen dendritischen Dornfortsätze. Bei den stumpfartigen dendritischen Dornfortsätzen gab es mit 3,3\% deutlich weniger Dornfortsätze mit einem Volumen von etwa $0,04 \mu^{3}$. Diese Volumina wurden aufgrund der besseren Übersicht in Tabelle 3.1 aufgelistet und in Intervalle von 0,0494 $\mu \mathrm{m}^{3}$ (aufgerundet 0,05 $\mathrm{mm}^{3}$ ) unterteilt. Abbildung 3.13 zeigt die Volumina beider Formen der dendritischen Dornfortsätze, ebenfalls in Intervalle von 0,0494 $\mu^{3}$ (entsprach 75.000 Pixeln in den 3D-Modellen) unterteilt.

Tabelle 3.1: Auflistung der Volumina der pilzförmigen und der stumpfartigen dendritischen Dornfortsätze, eingeteilt in Intervalle von $0,0494 \mu \mathrm{m}^{3}$ (gerundet auf $0,05 \mu \mathrm{m}^{3}$ )

\begin{tabular}{lll}
\hline Volumen & Stumpfartig [\%] & Pilzförmig [\%] \\
\hline $0,01 \mu \mathrm{m}^{3}-0,2 \mu \mathrm{m}^{3}$ & 76,6 & 70,6 \\
$0,25 \mu \mathrm{m}^{3}-0,45 \mu \mathrm{m}^{3}$ & 23,3 & 29,4 \\
$0,1 \mu \mathrm{m}^{3}$ & 33,3 & 23,5 \\
$0,2 \mu \mathrm{m}^{3}$ & 6,6 & 23,5 \\
$0,3 \mu \mathrm{m}^{3}$ & 3,3 & 5,9 \\
$0,4 \mu \mathrm{m}^{3}$ & 3,3 & 11,8 \\
\hline
\end{tabular}

Das Volumen der dendritischen Dornfortsätze korrelierte sowohl bei den Stumpfartigen (Hauptachse: $\mathrm{r}=0,7560$; Nebenachse: $\mathrm{r}=0,8821$ ) als auch bei den Pilzförmigen (Haupt-achse: $\mathrm{r}=0,6868$; Nebenachse: $\mathrm{r}=0,7770$ ) linear mit der Haupt- und Nebenachse. 


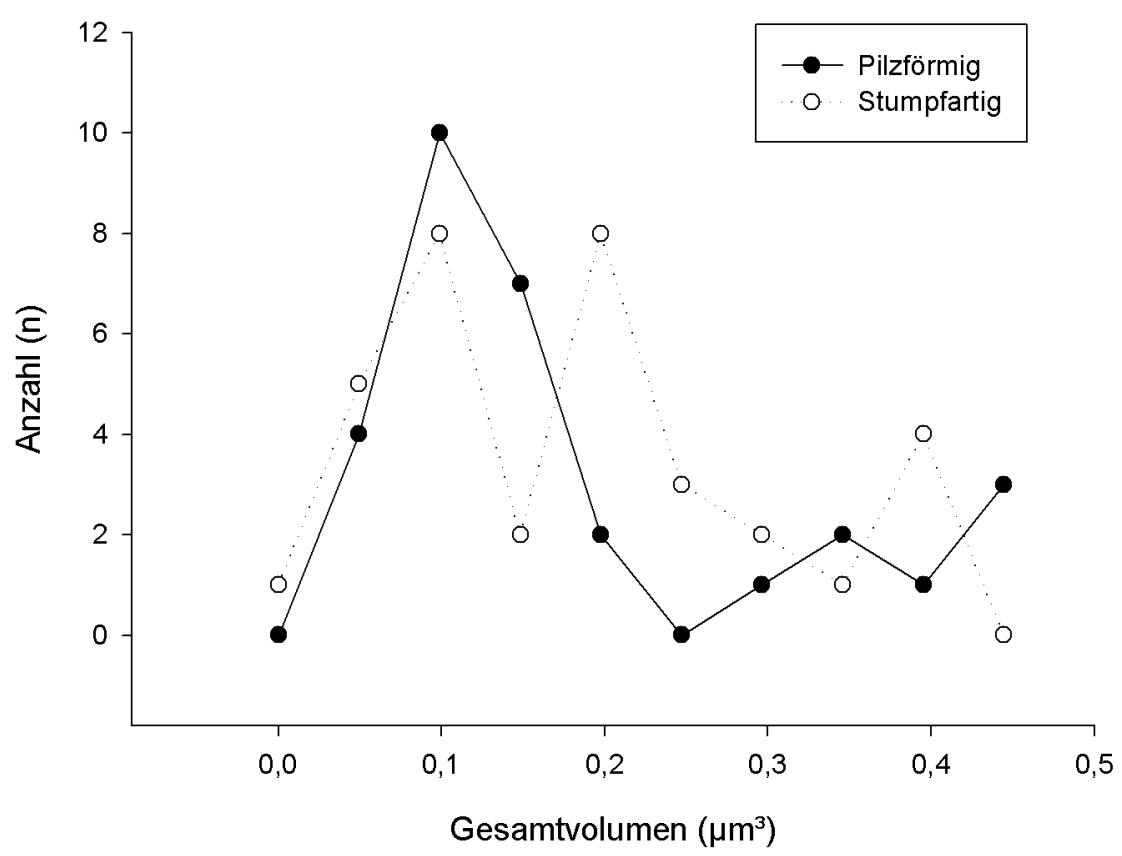

Abbildung 3.13: Verteilung der Volumina der pilzförmigen und stumpfartigen dendritischen Dornfortsätze, eingeteilt in Intervalle $\left(0,0494 \mu \mathrm{m}^{3}\right)$

\subsection{Achsenverhältnis}

Eine Haupt- und eine Nebenachse wurden bestimmt und miteinander ins Verhältnis gesetzt. Die Hauptachse war definiert als der größte Durchmesser des jeweiligen Schnittes, die Nebenachse als der kleinste Durchmesser. Der Quotient aus der Länge der Nebenachse und der Länge der Hauptachse ergibt das Achsenverhältnis. Dementsprechend sind Werte zwischen 0 (ungleiche Längen) und 1 (ähnliche Längen) möglich. Je größer die Zahl, desto runder ist der dendritische Dornfortsatz in diesem Schnitt. Um das Achsenverhältnis eines dendritischen Dornfortsatzes zu bestimmen, wurde der Durchschnitt aller Achsenverhältnisse (aus jedem Schnitt eines Dornfortsatzes) ermittelt. Abbildung 3.14 zeigt an einem Bespiel schematisch die Bestimmung der Haupt- und Nebenachse.

Das Achsenverhältnis zeigte bei beiden dendritischen Dornfortsätzen eine leichte Tendenz zur runden Form. Ausgeprägter war sie bei den pilzförmigen dendritischen Dornfortsätzen. Im Durchschnitt betrug das Achsenverhältnis bei den Stumpfartigen 0,4995 und bei den Pilzförmigen 0,5616. In dem Säulendiagramm (Abbildung 3.15) sind die durchschnittlichen Achsenverhältnisse zu sehen. Dadurch wird deutlich, dass die pilzförmigen dendritischen Dornfortsätze eine rundere Form aufwiesen.

Bei Betrachtung der Standardfehler der Achsenverhältnisse beider Formen zeigte sich, dass die pilzförmigen dendritischen Dornfortsätze eine größere Variabilität in ih- 


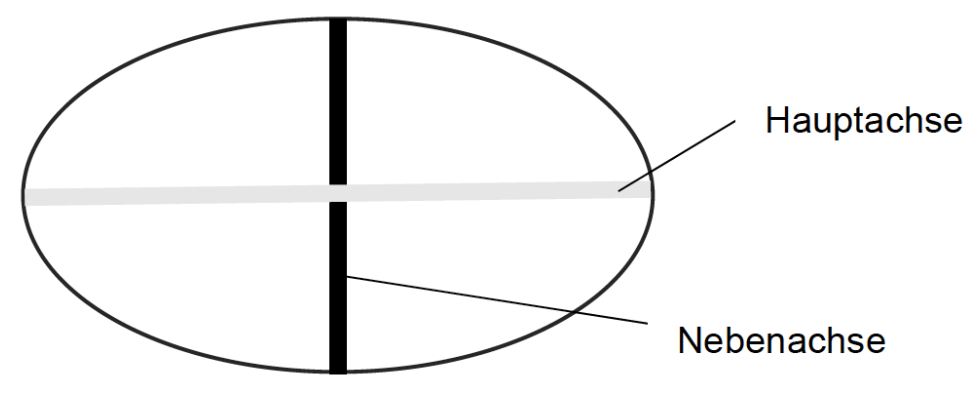

Abbildung 3.14: Schematisches Beispiel für die Ermittlung der Achsenverhältnisse

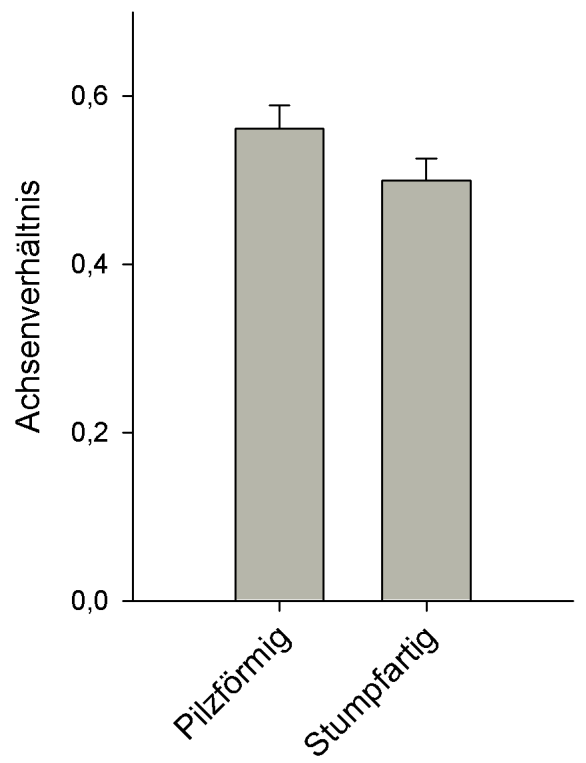

Abbildung 3.15: Durchschnittliches Achsenverhältnis der pilzförmigen und der stumpfartigen dendritischen Dornfortsätze mit Standardfehler 


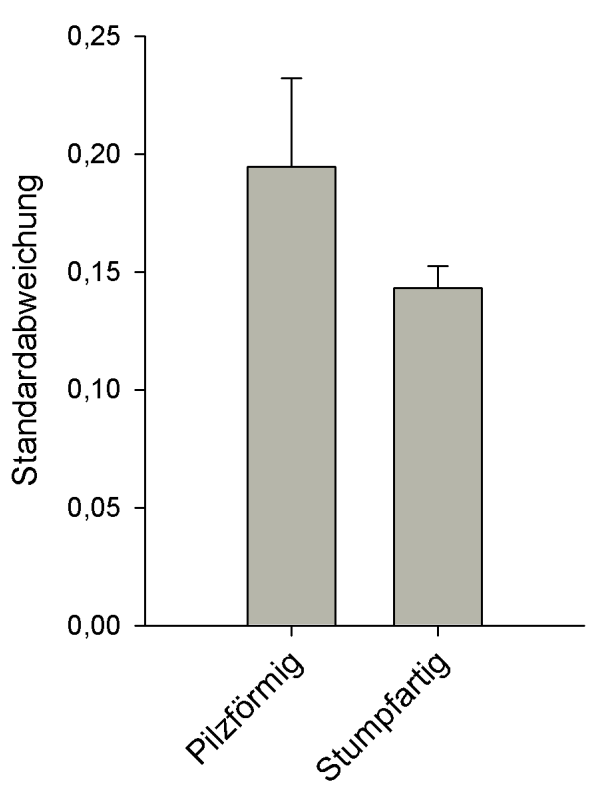

Abbildung 3.16: Durchschnittliche Standardfehler der Achsenverhältnisse bei pilzförmigen und bei stumpfartigen dendritischen Dornfortsätzen

rer Form aufwiesen. In dem Säulendiagramm (Abbildung 3.16) wird dies ersichtlich, da der Standardfehler bei den pilzförmigen größer war als bei den stumpfartigen Dornfortsätzen.

Tabelle 6.4 im Anhang zeigt alle Werte der Achsenverhältnisse der pilzförmigen und der stumpfartigen dendritischen Dornfortsätze aufsteigend sortiert.

Bei beiden Formen der dendritischen Dornfortsätze gab es eine lineare Korrelation zwischen der Größe der Haupt- und der Nebenachse. Das zeigt, dass die Fortsätze eine eher runde als ovale Form besaßen, da bei einer großen Hauptachse die Nebenachse ebenfalls groß war. Bei einer kleinen Hauptachse war die Nebenachse dementsprechend ebenfalls klein. Die lineare Korrelation war bei den Pilzförmigen etwas größer $(\mathrm{r}=0,6686)$ als bei den Stumpfartigen $(\mathrm{r}=0,7086)$, was bedeutet, dass sie eine geringfügig größere Tendenz zu einer runderen Form aufwiesen. In Abbildung 3.17 sind die Verteilungen sowohl von den pilzförmigen, als auch von den stumpfartigen dendritischen Dornfortsätzen in Bezug auf die beiden Achsen dargestellt. Es war auffällig, dass ein stumpfartiger dendritischer Dornfortsatz eine sehr große Haupt- und auch eine sehr große Nebenachse aufwies, die Relation zwischen ihnen jedoch im Vergleich zu den anderen dendritischen Dornfortsätzen ähnlich waren. Das bedeutet, dass dieser Dornfortsatz keinen übermäßigen Einfluss auf das Gesamtergebnis besaß, obwohl er extreme Werte aufwies. 


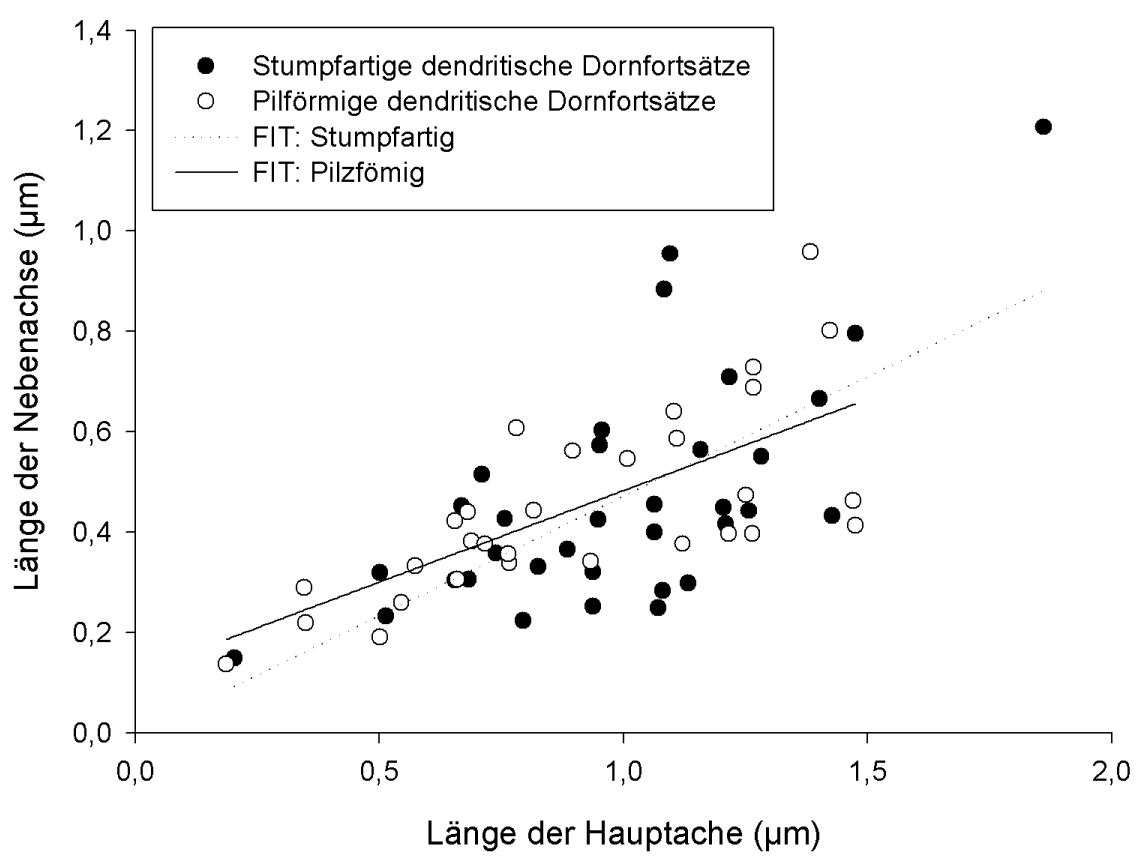

Abbildung 3.17: Vergleich zwischen der Haupt- und der Nebenachse (von pilzförmigen und stumpfartigen dendritischen Dornfortsätzen) mit Regressionsgeraden

Die einzelnen Werte der Haupt- und der Nebenachse beider Formen der dendritischen Dornfortsätze sind im Anhang in Tabelle 6.5 aufgeführt. Die Durchschnitte beider Achsen sind bei den stumpfartigen dendritischen Dornfortsätzen (Hauptachse $=0,992 \mu \mathrm{m}$, Nebenachse $=0,4679 \mu \mathrm{m})$ größer als bei den Pilzförmigen (Hauptachse $=0,9069 \mu \mathrm{m}$, Nebenachse $=0,4488 \mu \mathrm{m})$.

\subsection{Schnittvolumen}

Um das arithmetische Mittel des Schnittvolumens zu erhalten, musste zunächst der Mittelwert des Schnittvolumens jeder Synapse berechnet werden. Anschließend wurde der Durchschnitt all dieser Mittelwerte bestimmt. Dies ermöglichte es, dass die großen Dornfortsätze nicht überdurchschnittlich viel und die kleinen Dornfortsätze nicht unterdurchschnittlich wenig Einfluss auf das Schnittvolumen ausübten.

Das durchschnittliche Schnittvolumen der pilzförmigen dendritischen Dornfortsätze war mit $0,0215 \mu \mathrm{m}^{3}$ kleiner als das der Stumpfartigen mit $0,0258 \mu \mathrm{m}^{3}$, während die Pilzförmigen gleichzeitig das größere Gesamtvolumen besaßen. Im Anhang in Tabelle 6.6 sind alle Schnittvolumina der pilzförmigen und der stumpfartigen dendritischen 


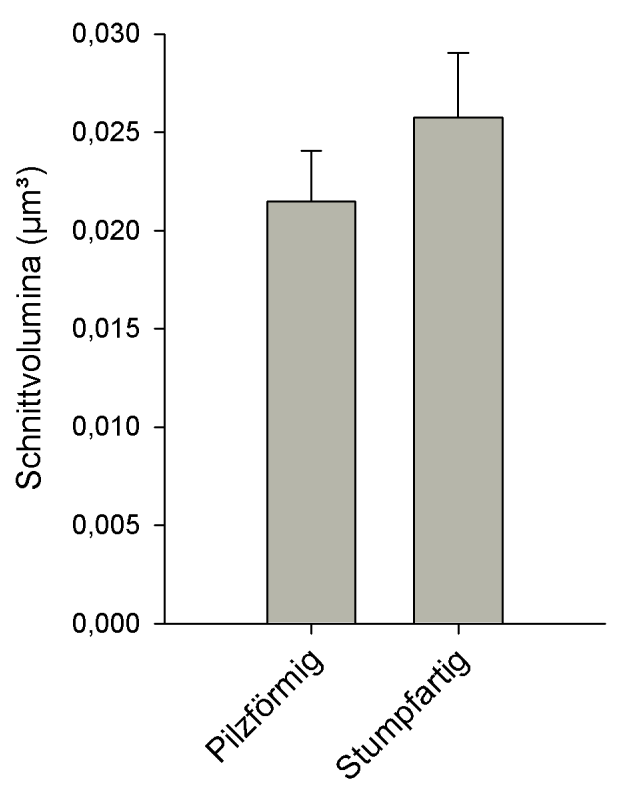

Abbildung 3.18: Durchschnittliche Schnittvolumina der pilzförmigen und der stumpfartigen dendritischen Dornfortsätze

Dornfortsätze aufgelistet. Abbildung 3.18 zeigt den unterschiedlichen Durchschnitt der Schnittvolumina beider Formen.

Auch die Schnittvolumina wurden auf mögliche Korrelationen zu anderen Merkmalen der dendritischen Dornfortsätze überprüft. Es bestand keine signifikante Korrelation zwischen den Schnittvolumina und der Oberfläche der aktiven Zone ( $p>0,05)$. Eine starke lineare Korrelation konnte sowohl bei den stumpfartigen dendritischen Dornfortsätzen $(\mathrm{r}=0,3228)$ wie auch bei den pilzförmigen $(\mathrm{r}=0,2110)$ ausgeschlossen werden. Abbildung 3.19 zeigt die Verteilung der pilzförmigen und stumpfartigen dendritischen Dornfortsätze in Bezug auf die Oberfläche der aktiven Zone und das Schnittvolumen. Die weite Streuung der Werte für beide dendritischen Dornfortsätze deutet darauf hin, dass keine Korrelationen vorhanden waren. Besonders auffällig war ein stumpfartiger dendritischer Dornfortsatz mit einem sehr großen Schnittvolumen $\left(0,1029 \mu \mathrm{m}^{3}\right)$ und einer nur durchschnittlich großen aktiven Zone.

Die selbstverständlich starke Korrelation des Schnittvolumens zu dem Gesamtvolumen, zu der Gesamtoberfläche und zu den Haupt- und Nebenachsen wurde durch die Pearson-Korrelation bestätigt $(\mathrm{r}<0,5 ; \mathrm{p}<0,05)$. 


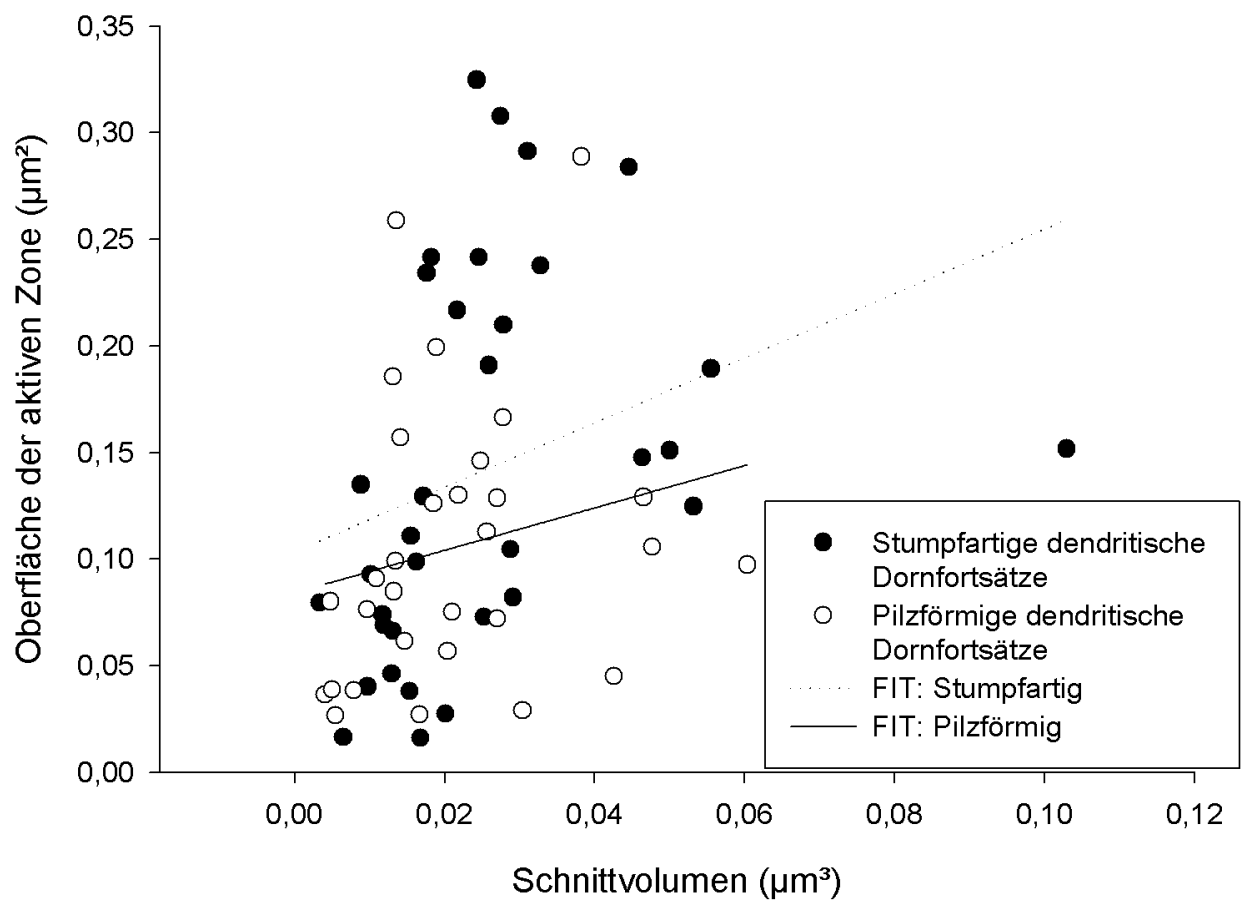

Abbildung 3.19: Vergleich zwischen der Oberfläche der aktiven Zone und dem Schnittvolumen (von pilzförmigen und stumpfartigen dendritischen Dornfortsätzen) mit Regressionsgeraden 


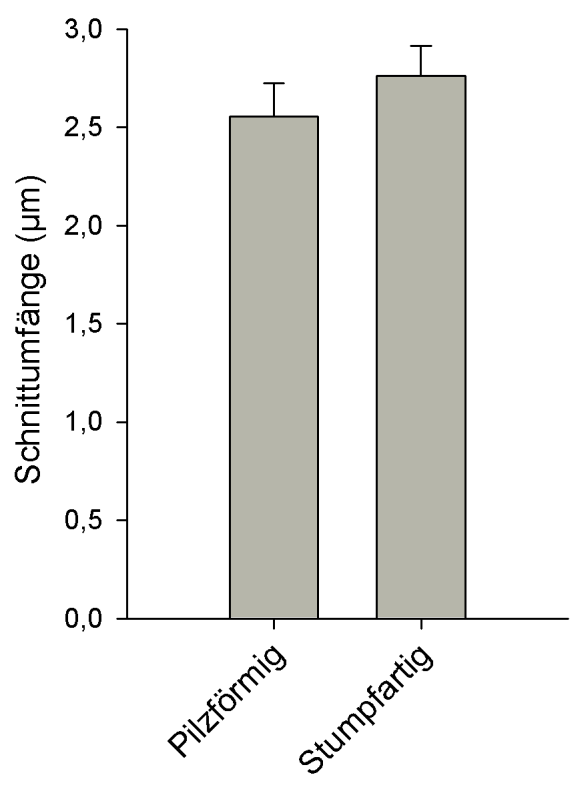

Abbildung 3.20: Durchschnittliche Schnittumfänge der pilzförmigen und der stumpfartigen dendritischen Dornfortsätze

\subsection{Schnittumfang}

Der Schnittumfang war im Durchschnitt bei den pilzförmigen dendritischen Dornfortsätzen mit 2,557 $\mu^{3}$ geringer als bei den stumpfartigen dendritischen Dornfortsätzen mit 2,737 $\mu^{3}$. Tabelle 6.7 im Anhang zeigt die einzelnen Werte der Schnittumfänge der pilzförmigen und der stumpfartigen dendritischen Dornfortsätze. Das Säulendiagramm (Abbildung 3.20) vergleicht noch einmal die Schnittumfänge beider Formen der dendritischen Dornfortsätze miteinander.

Wie bei dem Schnittvolumen bestand auch beim Schnittumfang keinerlei Korrelation zu der Oberfläche der aktiven Zone $(\mathrm{r}=0,4394 ; \mathrm{p}=0,0093)$. Auch eine nichtlineare Korrelation kann somit ausgeschlossen werden. Bei den pilzförmigen dendritischen Dornfortsätzen konnten ebenfalls Korrelationen ausgeschlossen werden ( $\mathrm{r}=0,2894$; $\mathrm{p}=0,1209)$. Abbildung 3.21 zeigt die Verteilung der pilzförmigen und der stumpfartigen dendritischen Dornfortsätze in Bezug auf die aktive Zone und den Schnittumfang. Die Streuung war bei beiden Formen der dendritischen Dornfortsätze sehr hoch und deutete bereits auf keinen signifikanten Zusammenhang der beiden Merkmale hin. 


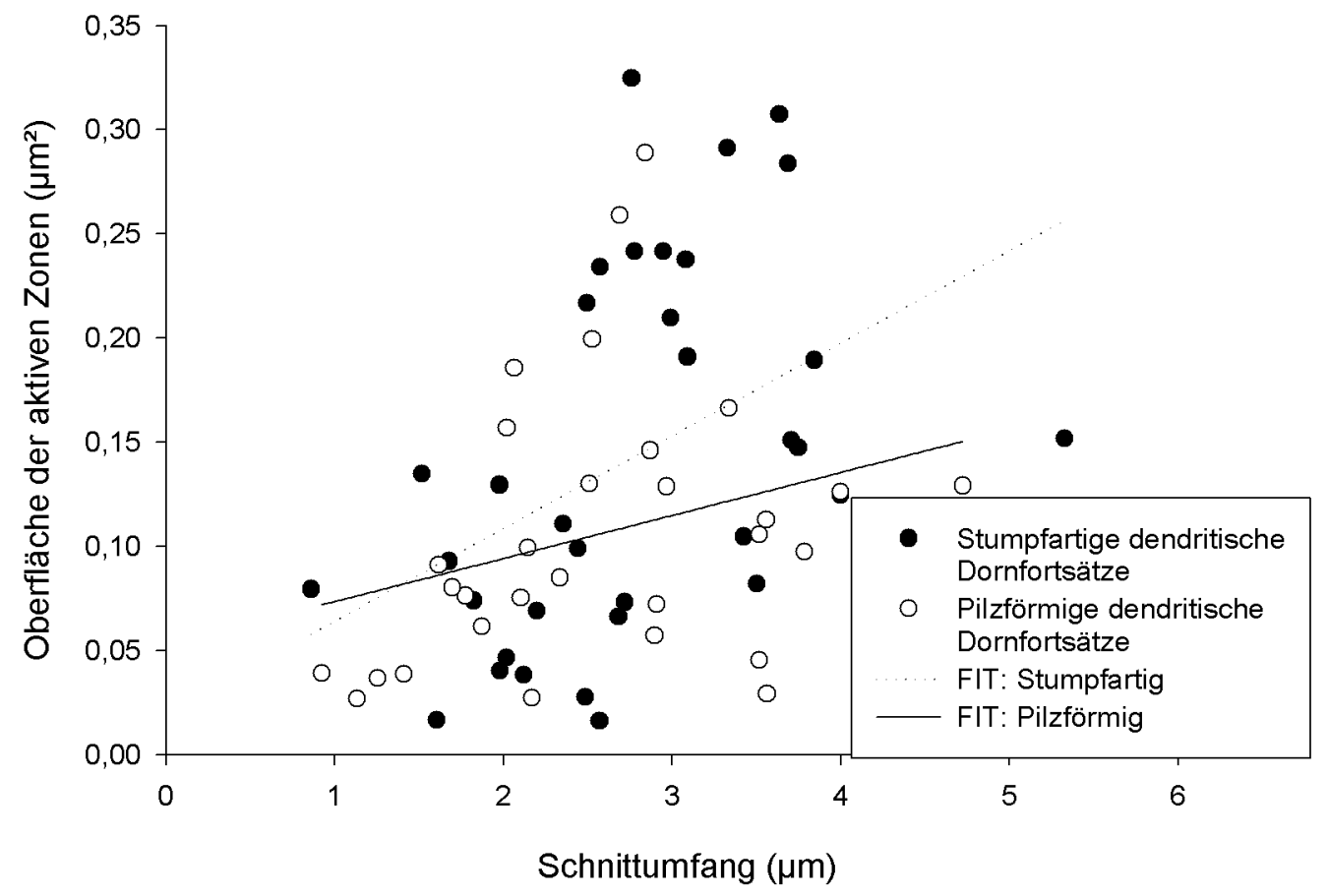

Abbildung 3.21: Vergleich zwischen der Oberfläche der aktiven Zone und dem Schnittumfang (von pilzförmigen und stumpfartigen dendritischen Dornfortsätzen) mit Regressionsgeraden 


\section{Diskussion}

In dieser Arbeit wurden hippocampale Pyramidenzellen von konventionellen Neuronenkulturen untersucht, um eine detaillierte Darstellung der Anatomie zu erreichen. Die Ergebnisse zeigen im Allgemeinen, dass die beiden unterschiedlichen dendritischen Dornfortsätze, abgesehen vom Hals der pilzförmigen Dornfortsätze, einen sehr ähnlichen Aufbau und eine sehr ähnliche Form aufweisen. Es scheint, als würden die Veränderungen der Form aufgrund unterschiedlich starker Stimulation Auswirkungen darauf haben, ob die jeweiligen Dornfortsätze eine vornehmlich runde oder flache Form besitzen, nicht jedoch, ob der dendritische Dornfortsatz eine stumpfartige oder eine pilzförmige Anatomie aufweist. Die Ergebnisse deuten demnach darauf hin, dass die grundlegende Form von der Position der dendritischen Dornfortsätze während der Entwicklung abhängig sein kann, also von dem Abstand zwischen Dendriten und Präsynapse. In den letzten Monaten wurde die Struktur der Synasen mittels super-auflösender stimulated emission depletion (STED) Mikroskopie untersucht (Wegner et al. 2017; Wegner et al. 2018). Dies wurde mit Hilfe von fluorezierenden Proteinen, welche zum einen an das Aktin (LifeAct) oder zum anderen an die PSD95 (PSD Färbung) binden dargestellt. Jedoch ist die Auflösung mit 40-80 nm deutlich schlechter als die EM-Auflösung in dieser Arbeit (3 nm), weshalb wir die Möglichkeit haben deutlich mehr Informationen zu gewinnen. Dennoch ist die STED Mikroskopie interessant um lebendige Zellen untersuchen zu können. Dies könnte langfristig Informationen über die Veränderungen an Synapsen über längere Zeit bei unterschiedlich starker Stimulation geben.

\subsection{Zusammenhang zwischen Form und Funktion}

In anderen Studien wird diskutiert, ob die einzelnen Formen der dendritischen Dornfortsätze mit einem unterschiedlichen Aufbau und folglich mit einer unterschiedlichen Funktion der Dornfortsätze einhergehen. Aufgrund der LTP können sich Form und Größe, ebenso wie die Zusammensetzung der PSD ändern, unabhängig davon, ob die Dornfortsätze sich noch im Wachstum befinden (Lang et al. 2004; Matsuzaki et al. 2004; Kopec et al. 2006; Nägerl et al. 2007) oder bereits ausgereift sind (Popov et al. 2004; Stewart et al. 2005; Bourne et al. 2007). Die meisten Formveränderungen finden jedoch 
während der Entwicklung statt (Holtmaat et al. 2005). Auch die Langzeitdepression wirkt sich auf die Morphologie der dendritischen Dornfortsätze aus und lässt sie kleiner werden oder sogar ganz verschwinden (Chen et al. 2004; Nägerl et al. 2004; Zhou et al. 2004). Für die Formveränderungen sind neben dem Aktingerüst ebenfalls verschiedenste Proteine erforderlich (Yasuda 2017). So wurde nachgewiesen, dass beispielsweise das aktinbindende Protein Drebrin (Grintsevich 2017; Hayashi 2017) ebenso wie das Amyloid-Vorläuferprotein (APP) (Montagna et al. 2017) maßgeblich an der Formveränderung und der synaptischen Plastizität beteiligt zu sein scheinen.

Der überwiegende Teil der Studien, die die Anatomie der dendritischen Dornfortsätze untersucht haben, wurde anhand von Gewebeschnitten und nicht an Neuronenkulturen durchgeführt (Parnass et al. 2000; Bourne und Harris 2007). Die Veränderungen der Morphologie wurden mithilfe eines Zwei-Photonen-Zeitraffers ebenfalls anhand von Gewebeschnitten des Hippocampus bereits in einer vergangenen Studie untersucht (Parnass et al. 2000). Die Pyramidenzellen wurden dabei in die charakteristischen vier Formen der dendritischen Dornfortsätze eingeteilt (Harris et al. 1992), wohingegen in dieser Studie lediglich die Pilzförmigen und die Stumpfartigen betrachtet wurden, da diese mit etwa 80 Prozent den größten Teil der dendritischen Dornfortsätze in den verwendeten Neuronenkulturen darstellten. Es zeigte sich, dass sich vor allem die Filopodien in ihrer Form änderten und dann anderen Formen der Dornfortsätze zugeordnet werden konnten. Die Filopodien waren zahlreich vertreten, da die Gewebeschnitte in einem frühen Entwicklungsstadium entnommen wurden. In späteren Stadien waren nur noch wenige dieser langen und dünnen dendritischen Dornfortsätze vorhanden. Die stumpfartigen und die pilzförmigen dendritischen Dornfortsätze zeigten in den Studien, die Gewebeschnitte nutzten, keine häufigen und grundlegenden Veränderungen ihrer Morphologie (Parnass et al. 2000). Das bestätigt, dass sich die grundlegenden Veränderungen der Anatomie vor allem während der Entwicklung abspielen und die einzelnen Formen nicht notwendigerweise eine unterschiedliche Funktion aufweisen. Neuere Studien zeigen, dass die Varianz der Formen ebenfalls von der Anwesenheit bestimmter Proteine abhängig ist (Burk et al. 2017; Yasuda 2017).

\subsection{Aktive Zone}

Betrachtet man die Größe der aktiven Zone der beiden unterschiedlichen Formen fallen kleine Differenzen zwischen ihnen auf. In der Vergangenheit wurde bereits anhand von Gewebeschnitten beschrieben, dass die pilzförmigen dendritischen Dornfortsätze eine größere und komplexere PSD aufweisen als andere Formen der dendritischen Dornfortsätze (Bourne und Harris 2007). Außerdem wurde nachgewiesen, dass die pilzförmigen 
dendritischen Dornfortsätze eine höhere Anzahl an Glutamat-Rezeptoren in der PSD aufweisen (Matsuzaki et al. 2001). In dieser Studie, die auf Neuronenkulturen basiert, können die Ergebnisse anderer Studien, bezogen auf die Ausprägung der aktiven Zone, nicht bestätigt werden. Die stumpfartigen dendritischen Dornfortsätze weisen eine etwas größere Oberfläche der aktiven Zone auf als die der Pilzförmigen. Wie komplex der Aufbau der PSD ist und welche Rezeptoren vorhanden sind, sollte mit den hier vorgenommenen Untersuchungen jedoch nicht nachvollzogen werden. Die aktive Zone besitzt bei den pilzförmigen dendritischen Dornfortsätzen eine durchschnittliche Oberfläche von $\sim 0,10 \mu \mathrm{m}^{2}$, während sie bei den Stumpfartigen $\sim 0,14 \mu \mathrm{m}^{2}$ beträgt. Die pilzförmigen dendritischen Dornfortsätze besitzen dementsprechend eine um etwa $25 \%$ kleinere aktive Zone als die Stumpfartigen (Differenz 0,04 $\mu \mathrm{m}^{2}$ ). Aufgrund der Ergebnisse der unterschiedlichen Studien wäre es möglich, dass nicht jede Erhöhung der PSD mit einer Vergrößerung der aktiven Zone einhergeht. Es muss auch berücksichtigt werden, dass die Methoden der Studien unterschiedlich sind, da sie in der hier beschriebenen Studie auf Neuronenkulturen und in den vorangegangenen Studien auf Gewebeschnitten basieren. Eine weitere komplexe Untersuchung der PSD mit Zellkulturen wäre erforderlich, um diesen Unterschied abschließend klären zu können.

Sowohl die kleinste als auch die größte Oberfläche der aktiven Zone ist bei den stumpfartigen dendritischen Dornfortsätzen zu finden. Bei den Stumpfartigen liegt der Unterschied zwischen der größten und der kleinsten Oberfläche der aktiven Zone bei $\sim 0,29 \mu^{2}$, während der Unterschied bei den Pilzförmigen $\sim 0,26 \mu \mathrm{m}^{2}$ beträgt. Das bedeutet, dass die Stumpfartigen eine größere Variabilität in der Oberflächengröße der aktiven Zone aufweisen als die Pilzförmigen.

Da die Größe der aktiven Zone davon abhängt, wie stark die Synapse stimuliert wird (Matsuzaki et al. 2004; Kopec et al. 2006), bedeutet es, dass die stumpfartigen dendritischen Dornfortsätze fortbestehen, wenn sie wenig stimuliert werden, sie aber ebenfalls in der Lage sind, stärkere Stimuli zu verarbeiten. Bei den pilzförmigen dendritischen Dornfortsätzen scheint hingegen eine minimal gleichmäßigere Stimulation vorzuliegen. Die pilzförmigen dendritischen Dornfortsätze gelten als die stabileren in Bezug auf ihre Form, weshalb ihnen eine Gedächtnisfunktion zugeschrieben wird (Bourne und Harris 2007). Die etwas gleichmäßigere Größenverteilung der aktiven Zone bei dieser Form weist ebenfalls auf eine stabile aktive Zone hin, welche weniger Veränderungen unterliegt als die der stumpfartigen dendritischen Dornfortsätze. 


\subsubsection{Vergleich zwischen der aktiven Zone und der Gesamtoberfläche}

Der relative Anteil der aktiven Zone an der Gesamtoberfläche der stumpfartigen dendritischen Dornfortsätze liegt mit durchschnittlich etwa $10 \%$ knapp $3 \%$ über dem der Pilzförmigen. Dies ist ein signifikanter Unterschied $(\mathrm{p}=0,0276)$, der sich aufgrund der zwei unterschiedlichen Formen gut erklären lässt und somit keinen Hinweis darauf gibt, dass die beiden Dornfortsatzformen grundlegend anders strukturiert sein müssen. Bei den pilzförmigen dendritischen Dornfortsätzen zählt die Oberfläche des Halses mit zu der Gesamtoberfläche des Fortsatzes, während in dieser Region jedoch keine aktive Zone zu finden ist, da sich dieser nicht in der Nähe der Präsynapse befindet. Dies bedeutet, dass der prozentuale Anteil der aktiven Zone an der Gesamtoberfläche geringer sein muss, wenn der Aufbau des Köpfchens vergleichbar mit dem Körper der stumpfartigen dendritischen Dornfortsätze sein soll. Dementsprechend zeigt sich eine signifikante lineare Korrelation zwischen der Größe der aktiven Zone und der Gesamtoberfläche bei den stumpfartigen dendritischen Dornfortsätzen $(\mathrm{r}=0,6055 ; \mathrm{p}=0,0001)$, die bei den Pilzförmigen ( $\mathrm{r}=0,4008 ; \mathrm{p}=0,0282)$ deutlich schwacher ausgeprägt ist. Dieses Ergebnis lässt sich demnach ebenfalls auf die Hälse der pilzförmigen dendritischen Dornfortsätze zurückführen, da sie viele verschiedene Größen aufweisen, die unabhängig von den Größen der Gesamtoberfläche und der aktiven Zone des dendritischen Dornfortsatzes sind.

\subsubsection{Vergleich zwischen der aktiven Zone und des Gesamtvolumens}

Das gleiche Ergebnis wird bestätigt durch die Korrelation der Größe der aktiven Zone zum Gesamtvolumen des dendritischen Dornfortsatzes. Auch hier fällt eine signifikante lineare Korrelation der stumpfartigen Dornfortsätze auf ( $r=0,5016 ; \mathrm{p}=0,0025)$, während es keinen signifikanten Zusammenhang bei den pilzförmigen Dornfortsätzen zu geben scheint $(r=0,3000 ; p=0,1730)$. Eine andere Studie, die anhand von hippocampalen Gewebeschnitten durchgeführt wurde, bestätigt, dass die Korrelation zwischen der PSD und dem Volumen des Kopfs des pilzförmigen dendritischen Dornfortsatzes deutlich größer ist, als die zum Hals des Dornfortsatzes (Harris und Stevens 1989).

\subsubsection{Formen und Lage der aktiven Zone}

Nicht nur die Größen, sondern auch die Formen der aktiven Zonen der pilzförmigen und der stumpfartigen dendritischen Dornfortsätze scheinen sich zu unterscheiden. Auffällig 


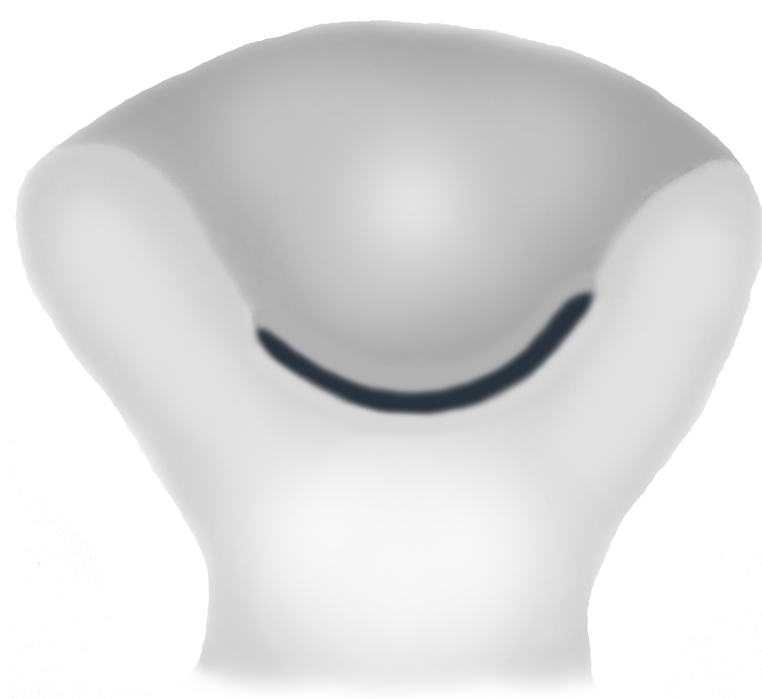

(a) Stumpfartig

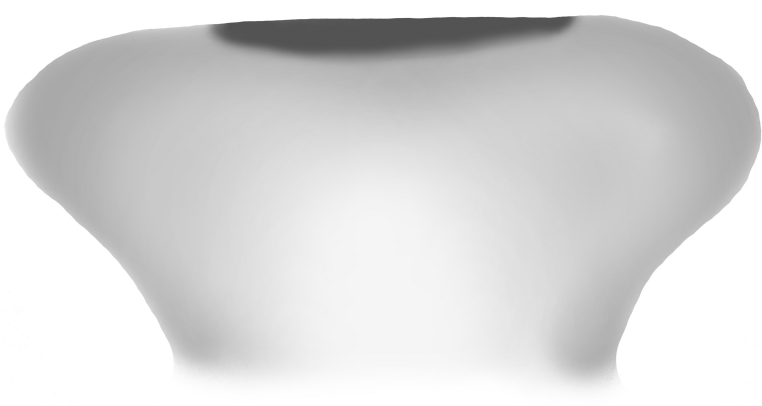

(b) Pilzförmig

Abbildung 4.1: Form der aktiven Zone der stumpfartigen (a) und der pilzförmigen dendritischen Dornortsätze (b)

ist, dass die stumpfartigen dendritischen Dornfortsätze im Durchschnitt eine längere Distanz vom Zentrum der aktiven Zone zur Membran aufweisen $(\sim 0,04 \mu \mathrm{m})$ als die Pilzförmigen $(\sim 0,03 \mu \mathrm{m})$. Dieser Unterschied von etwa $0,01 \mu \mathrm{m}$ ist nicht nur durch die minimal größere Oberfläche der aktiven Zone bei den stumpfartigen dendritischen Dornfortsätzen zu erklären. Dass dieser Unterschied signifikant ist, wurde durch einen t-test $(p=0,0456)$ bestätigt. Demnach scheint die aktive Zone bei den stumpfartigen dendritischen Dornfortsätzen häufiger eine gekrümmte Form aufzuweisen (Abbildung 4.1) als bei den Pilzförmigen, da es so zu einer Verlängerung der Distanz vom Zentrum der aktiven Zone zu der Membran kommt.

Die Distanz vom Zentrum der aktiven Zone zum Zentrum der dendritischen Dornfortsätze ist bei den Pilzförmigen $(\sim 0,189 \mu \mathrm{m})$ um $\sim 0,005 \mu \mathrm{m}$ größer als bei den Stumpfartigen $(\sim 0,184 \mu \mathrm{m})$. Dieser geringe und nicht signifikante Unterschied $(\mathrm{p}=0,9264)$ lässt sich gut auf die Anatomie der beiden Dornfortsätze zurückführen, da der Hals der pilzförmigen dendritischen Dornfortsätze das Zentrum weiter in Richtung Dendrit und damit weiter entfernt von der aktiven Zone verschiebt. Aufgrund der geringen Differenz der Distanzen zwischen den beiden Formen, liegt es nahe, dass wenn der Hals wegfällt, die Distanzen sehr ähnlich sind. Somit ähnelt der Aufbau des Köpfchens der pilzförmigen dendritischen Dornfortsätze sehr dem des Körpers der Stumpfartigen. Durch den längeren Hals ist es den pilzförmigen dendritischen Dornfortsätzen jedoch möglich im Rahmen ihrer Entwicklung weiter entfernte Präsynapsen zu erreichen. 


\subsection{Abhängigkeit zwischen der Form der dendritischen Dornfortsätze und der Oberfläche der aktiven Zone}

Vergleicht man die beiden Achsenlängen mit der Größe der Oberfläche der aktiven Zone, so fällt nur eine leichte, aber dennoch signifikante lineare Korrelation bei den stumpfartigen dendritischen Dornfortsätzen zu der Länge der Hauptachsen auf ( $\mathrm{r}=0,4718 ; \mathrm{p}=$ 0,0049). Diese signifikante Korrelation ist bei den pilzförmigen Dornfortsätzen nicht zu erkennen $(\mathrm{r}=0,3015 ; \mathrm{p}=0,1054)$. Der Unterschied entsteht ebenfalls durch den Hals der pilzförmigen dendritischen Dornfortsätze. Die Hauptachsen des Halses verkleinern den Durchschnitt aller Hauptachsen unterschiedlich stark, je nach Größe und Form des Halses. Dadurch ist eine Korrelation bei den pilzförmigen dendritischen Dornfortsätzen zwischen der Größe der aktiven Zone und der Länge der Hauptachse nicht zu erwarten. Zu der Länge der Nebenachse steht die Größe der aktiven Zone bei keiner der beiden Formen der dendritischen Dornfortsätze in signifikanter Korrelation (Stumpfartig: $\mathrm{r}=$ $0,3 ; \mathrm{p}=0,07$; Pilzförmig: $\mathrm{r}=0,3 ; \mathrm{p}=0,1)$. Somit scheinen die Formen des dendritischen Dornfortsatzes irrelevant für die Größe der aktiven Zone zu sein. Die Ergebnisse einer anderen Studie zeigten, dass durch eine Aktivierung der Synapsen im Rahmen einer LTP eine Stärkung des Aktingerüsts und eine rundere Form der Dornfortsätze die Folge waren (Matsuzaki et al. 2004). Des Weiteren wurde beschrieben, dass auch die aktive Zone bei häufig stimulierten Synapsen wächst und sich dadurch an die vermehrte Aktivität anpasst (Hering und Sheng 2001). Aufgrund dessen war zu erwarten, dass die Größe der aktiven Zone der dendritischen Dornfortsätze auch mit deren Form korreliert. Die Ergebnisse dieser Arbeit zeigen jedoch, dass dies nicht der Fall ist. Es ist möglich, dass sich die aktive Zone und die Form der dendritischen Dornfortsätze unterschiedlich schnell und unterschiedlich stark an eine neue Stimulationsrate anpassen. Ein Grund kann sein, dass nicht jede Erhöhung der PSD mit einer dauerhaften Vergrößerung der aktiven Zone einhergeht. Einen weiteren Grund könnte die begrenzte Anpassungsmöglichkeit der dendritischen Dornfortsätze im Vergleich zur ursprünglichen Form darstellen. Das bedeutet, dass ein von Beginn an eher runder und kleiner dendritischer Dornfortsatz mit einer kleinen aktiven Zone bei einer anhaltenden Stimulation eine Zunahme der aktiven Zone aufweist, diese jedoch kleiner bleibt als die aktive Zone bei einem eher abgeflachten dendritischen Dornfortsatz, der jedoch ein größeres Gesamtvolumen besitzt.

Auch die durchschnittlichen Achsenverhältnisse der Hauptachse zur Nebenachse zeigen in diesen Untersuchungen, dass die pilzförmigen dendritischen Dornfortsätze mit 0,5616 eine rundere Form besitzen als die Stumpfartigen mit 0,4994. Beachtet man hierbei, dass die stumpfartigen dendritischen Dornfortsätze eine größere Oberfläche 
der aktiven Zone aufweisen, weist dies erneut auf eine fehlende Korrelation zwischen der runden Form der dendritischen Dornfortsätze und der Größe der Oberfläche der aktiven Zone hin. Denkbar ist ebenfalls, dass die Form der pilzförmigen dendritischen Dornfortsätze zu einer runderen Form beeinflusst wird, indem der Hals der Fortsätze eine überdurchschnittlich runde Form aufweist. Die Standardabweichung der pilzförmigen dendritischen Dornfortsätze $(\sim 0,19)$ ist merklich höher als die der Stumpfartigen $(\sim 0,14)$. Dies bedeutet, dass bei den Formen der pilzförmigen Dornfortsätze eine größere Variabilität vorzufinden ist. Dass beide Formen der dendritischen Dornfortsätze $\mathrm{zu}$ einer eher runden Form tendieren, zeigt sich auch in der nachgewiesenen linearen Korrelation zwischen Haupt- und Nebenachse. Bei den pilzförmigen dendritischen Dornfortsätzen $(r=0,7086)$ ist eine stärkere lineare Korrelation nachzuweisen als bei den sumpfartigen $(r=0,6686)$. Dennoch ist bei beiden Formen die Korrelation zwischen diesen beiden Merkmalen signifikant $(\mathrm{p}<0,0001)$. Dadurch bestärkt das Ergebnis der Berechnung der Achsenverhältnisse, dass die pilzförmigen dendritischen Dornfortsätze zu einer etwas runderen Form tendieren als die Stumpfartigen.

\subsection{Gesamtvolumen}

Die pilzförmigen dendritischen Dornfortsätze besitzen durchschnittlich ein größeres Gesamtvolumen als die Stumpfartigen. Bei beiden Formen weisen jedoch die meisten dendritischen Dornfortsätze ein Volumen zwischen 0,01-0,2 $\mathrm{\mu m}^{2}$ auf. Bei den stumpfartigen Dornfortsätzen lagen $6 \%$ mehr im Bereich der kleinen Synapsen (bis zu 0,2 $\mu^{2}$ ) als bei den Pilzförmigen. Da kleine Dornfortsätze sich schneller anpassen können (Bourne und Harris 2007), scheinen die stumpfartigen dendritischen Dornfortsätze aufgrund der geringeren Größe mehr Anpassungsmöglichkeiten zu besitzen. Die Theorie, dass die voluminöseren pilzförmigen dendritischen Dornfortsätze von der Anatomie weniger anpassungsfähig sind und sie für die Gedächtnisfunktion in Frage kommen (Zuo et al. 2005; Bourne und Harris 2007; Bello-Medina et al. 2016), wird daher bestärkt. Sie können bis zu einigen Monaten existieren, wobei stumpfartige dendritische Dornfortsätze meist nach wenigen Tagen verschwinden (Holtmaat et al. 2005; Zuo et al. 2005).

Obwohl das Gesamtvolumen der pilzförmigen dendritischen Dornfortsätze größer ist als das der Stumpfartigen, ist das durchschnittliche Schnittvolumen der Pilzförmigen kleiner. Da die pilzförmigen Dornfortsätze auch eine rundere Form besitzen, wird deutlich, dass sie mehr kleinere und rundere Schnitte besitzen als die Stumpfartigen. Dies wiederum heißt, dass die pilzförmigen dendritischen Dornfortsätze eine längere und dünnere Grundform besitzen müssen als die Stumpfartigen. Dieses Ergebnis ist erneut 
auf den vorhandenen Hals zurückzuführen, der die Form der pilzförmigen dendritischen Dornfortsätze streckt.

Die verständlicherweise enge Korrelation des Schnittvolumens zum Gesamtvolumen der dendritischen Dornfortsätze, der Haupt- und Nebenachsen sowie zu der Gesamtoberfläche werden durch die Pearson-Korrelation bestätigt. Die Korrelation zum Schnittumfang ist ebenso gegeben, wobei dieser Zusammenhang bei den pilzförmigen dendritischen Dornfortsätzen geringer und weniger signifikant ist als bei den Stumpfartigen.

\subsection{Technische Aspekte und Modellkritik}

Eine Zellkultur wurde genutzt, da zusätzlich zu dieser Untersuchung innerhalb der Arbeitsgruppe Rizzoli ebenfalls Immunofärbungen durchgeführt wurden, bei denen Gliazellen und weitere Strukturen störend sind. Das gemeinsame Ziel der Arbeitsgruppe besteht darin ein detailiertes Modell einer Synapse zu entwerfen und somit die Grundlagen für ein funktionelles Modell zu schaffen, mit welchem die Funktion und Arbeitsweise ermittelt werden kann.

Da die geplante Hochdruckgefrierung der Neuronenkulturen qualitativ nicht ausreichende Ergebnisse geliefert hat, musste mit einer chemische Fixierung gearbeitet werden. Hierdurch können im Vergleich zum Vorgang des Hochdruckgefrierens kleine Ungenauigkeiten vorkommen, da diese mehrere Minuten in Anspruch nimmt. Aufgrund der Vielzahl der untersuchten dendritischen Dornfortsätze war eine EM-Tomographie, mit welcher man geringere Schnittdicken (wenige nm) erreicht nicht möglich. Der zusätzliche Nutzen im Vergleich zu der Untersuchung mit dem Transmissionselektronenmikroskop würde zu gering sein. Auch mit dieser Technik und den $70 \mathrm{~nm}$ dicken Schnitten konnte eine genaue Analyse der quantitativen Anatomie durchgeführt werden. Jedoch können anhand der bloßen Morphologie die Vakuolen und Vesikel nicht weiter biochemisch klassifiziert werden. Eine Immunomarkierung war für die Fragestellung dieser Untersuchung nicht notwendig und wurde nicht durchgeführt auch um die Morphologie der Zelle möglichst gut zu erhalten. Wenn eine Immunofärbung in Kombination mit einem Elektronenmikroskop durchgeführt werden, kommt es häufig zu einem Qualitätsverlust der Morphologie.

\subsection{Schlussfolgerung}

Zusammenfassend kann gesagt werden, dass sich die beiden Formen der dendritischen Dornfortsätze im Aufbau ähneln. Die unterschiedlichen Korrelationen einzelner Merkmale bei den zwei Dornfortsatzformen sind meist durch den vorhandenen Hals der 
pilzförmigen dendritischen Dornfortsätze zu erklären. Lässt man diesen unbeachtet, so gleicht die Anatomie des Endköpfchens sehr der Anatomie der stumpfartigen Dornfortsätze. Dies deutet auf eine ähnliche Arbeitsweise der zwei Formen hin. Jedoch erscheinen die Pilzförmigen etwas konstanter in ihrer Größe und Form zu sein. Deshalb sind die Ergebnisse anderer Studien naheliegend, dass sie bei der Gedächtnisfunktion eine größere Rolle spielen als die Stumpfartigen (Bourne und Harris 2007). Nach dieser genauen Untersuchung der quantitativen Anatomie der zwei Formen der dendritischen Dornfortsätze sollten weitere Untersuchungen angestellt werden, um einen ausführlicheren Vergleich des molekularen Aufbaus und der Arbeitsweise, insbesondere auch der Kalziumkompartimentierung zu erhalten. 


\section{Zusammenfassung}

Das Verstehen der Funktionsweise von dendritischen Dornfortsätzen ist nur möglich nach einer genauen Untersuchung ihrer Anatomie. Ziel dieser Arbeit war es, die Unterschiede und Gemeinsamkeiten der Morphologie der stumpfartigen und der pilzförmigen dendritischen Dornfortsätze herauszustellen, um somit einen Hinweis darauf zu bekommen, ob die beiden Formen unterschiedliche oder ähnliche Funktionen besitzen. Untersucht wurden insgesamt 64 dendritische Dornfortsätze, 30 pilzförmige und 34 stumpfartige.

Die Studie wurde mit hippocampalen Neuronenkulturen (Pyramidenzellen) durchgeführt. Es wurden nach der Präparation der Nervenzellen und dem Anlegen der konventionellen Neuronenkulturen Resinblöcke hergestellt, von welchen $70 \mathrm{~nm}$ dicke Querschnitte genommen wurden, um die darin enthaltenen Neurone mithilfe eines Elektronenmikroskops darzustellen.

Es stellte sich heraus, dass der Aufbau des Endköpfchens der pilzförmigen dendritischen Dornfortsätze sehr dem Aufbau der Stumpfartigen ähnelt, trotz einiger Unterschiede die zwischen beiden Formen festgestellt werden konnten. Einer dieser Unterschiede zeigte sich bei der Größe der aktiven Zone, welche bei den stumpfartigen Dornfortsätzen größer ausfiel und variabler war als bei den Pilzförmigen. Da die Größe von der Häufigkeit und Stärke der Stimulation beeinflusst wird, kann auf eine gleichmäßigere Erregung der pilzförmigen dendritischen Dornfortsätze geschlossen werden. Diese konstante Stimulation spricht ebenfalls für eine erhöhte Stabilität. Damit kann ihnen eine wichtige Rolle bei der Gedächtnisfunktion zukommen. Des Weiteren ist die Distanz zwischen dem Zentrum der aktiven Zone und der Membran bei den stumpfartigen deutlich größer als bei den pilzförmigen dendritischen Dornfortsätzen, was auf eine gekrümmte Form der aktiven Zone bei den Stumpfartigen schließen lässt.

Während die durchschnittliche aktive Zone bei den stumpfartigen dendritischen Dornfortätzen größer ist, ist die Gesamtoberfläche und das Gesamtvolumen der pilzförmigen Dornfortsätze größer. Grund hierfür ist der Hals der pilzförmigen Dornfortsätze. Dieser erhöht das Gesamtvolumen und den Gesamtumfang im unbestimmten Maße, während die aktive Zone ausschließlich am Endköpfchen zu finden ist. Auch die Korrelationen zwischen bestimmten Variablen fallen aus diesem Grund bei den beiden 
Formen unterschiedlich groß aus. Während der unregelmäßig geformte Hals bei den pilzförmigen dendritischen Dornfortsätzen die lineare Korrelation zwischen der Größe der aktiven Zone und dem Gesamtvolumen (und der Gesamtoberfläche) abschwächt, ist diese Korrelation bei den Stumpfartigen ausgeprägter.

Die Tendenz zur runderen Form ist bei den pilzförmigen dendritischen Dornfortsätzen stärker als bei den Stumpfartigen. Sie zeigt sich bei den Pilzförmigen sowohl in der höheren Korrelation zwischen der Haupt- und der Nebenachse als auch in dem größeren Achsenverhältnis. Die Hauptachse ist definiert als der größte Durchmesser des Dornfortsatzes in einem Schnitt, während die Nebenachse der kleinste ist. Das größere Achsenverhältnis der Pilzförmigen weist ebenfalls eine höhere Variabilität auf. Diese rundere und variablere Form kann ebenfalls aufgrund des Halses entstehen, da dieser je nach Länge unterschiedlich starken Einfluss ausüben kann.

Die pilzförmigen dendritischen Dornfortsätze haben eine etwas längere und gestreckte Form als die Stumpfartigen, da sie kleinere Schnittumfänge und Schnittvolumina besitzen bei gleichzeitig höherem Gesamtvolumen und größerem Gesamtumfang. Das bedeutet, dass bei den Pilzförmigen deutlich mehr, aber dafür kleine Schnitte vorhanden sein müssen.

Nahezu alle Unterschiede, die bei der Analyse der Daten ermittelt werden konnten, lassen sich durch das Vorhandensein des Halses bei den pilzförmigen dendritischen Dornfortsätzen erklären. Lediglich die konstantere Größe der aktiven Zone der pilzförmigen dendritischen Dornfortsätze weist auf eine erhöhte Stabilität dieser Form hin. Dennoch zeigen die Ergebnisse, dass das Endköpfchen der Pilzförmigen dem Aufbau der stumpfartigen dendritischen Dornfortsätze entspricht. Die Form scheint eher eine Frage der Entwicklung zu sein. Bei großem Abstand zwischen Präsynapse und Dendrit ist es notwendig, diese Distanz mit einem Hals zu überbrücken, was zur Entwicklung von pilzförmigen dendritischen Dornfortsätzen führt. Bei einem kleinen Abstand bilden sich überwiegend stumpfartige Dornfortsätze aus. Ob sie funktionell dennoch unterschiedliche Funktionen und Arbeitsweisen aufweisen, muss mit Studien nachgewiesen werden, die sich ausdrücklich auf die Funktion und nicht auf die reine Morphologie der dendritischen Dornfortsätze konzentrieren. 


\section{Anhang}

Tabelle 6.1: Oberflächen der aktiven Zonen der einzelnen Postsynapsen unterteilt in stumpfartige und pilzförmige dendritische Dornfortsätze

\begin{tabular}{llll}
\hline \multicolumn{2}{l}{ Stumpfartig $\left[\mathrm{\mu m}^{2}\right]$} & \multicolumn{2}{l}{ Pilzförmig $\left[\mu \mathrm{m}^{2}\right]$} \\
\hline 0,0161 & 0,1509 & 0,0266 & 0,1286 \\
0,0165 & 0,1518 & 0,0271 & 0,129 \\
0,0275 & 0,1894 & 0,029 & 0,1299 \\
0,038 & 0,1909 & 0,0365 & 0,146 \\
0,0401 & 0,2098 & 0,0384 & 0,1569 \\
0,0464 & 0,2166 & 0,0389 & 0,1664 \\
0,0661 & 0,234 & 0,0451 & 0,1857 \\
0,0689 & 0,2377 & 0,0569 & 0,1994 \\
0,073 & 0,2415 & 0,0614 & 0,2589 \\
0,0739 & 0,2417 & 0,0719 & 0,2888 \\
0,0794 & 0,2838 & 0,0751 & \\
0,082 & 0,2913 & 0,0762 & \\
0,0927 & 0,3077 & 0,0801 & \\
0,0988 & 0,3248 & 0,0848 & \\
0,1046 & & 0,0908 & \\
0,1108 & & 0,0973 & \\
0,1247 & & 0,0992 & \\
0,1295 & & 0,1056 & \\
0,1348 & & 0,1127 & \\
0,1475 & & 0,126 & \\
\hline$\sum$ & 4,48432 & \multicolumn{3}{c}{$\sum 3,1693$} \\
$\varnothing$ & 0,1319 & \multicolumn{3}{c}{$\varnothing 0,1056$}
\end{tabular}


Tabelle 6.2: Gesamtoberflächen aller dendritischer Dornfortsätze unterteilt in stumpfartige und pilzförmige Dornfortsätze

\begin{tabular}{ll}
\hline Stumpfartig $\left[\mu \mathrm{m}^{2}\right]$ & Pilzförmig $\left[\mu \mathrm{m}^{2}\right]$ \\
\hline 0,4208 & 0,4755 \\
0,5395 & 0,5818 \\
0,6366 & 0,7896 \\
0,6926 & 0,9053 \\
0,7688 & 0,9109 \\
0,7866 & 0,9509 \\
0,8304 & 0,9801 \\
0,9897 & 0,9865 \\
1,0213 & 0,9944 \\
1,0427 & 1,0118 \\
1,0558 & 1,0174 \\
1,1529 & 1,1312 \\
1,2218 & 1,1789 \\
1,2604 & 1,2162 \\
1,3143 & 1,2287 \\
1,3315 & 1,2456 \\
1,3966 & 1,3515 \\
1,4706 & 1,4017 \\
1,4915 & 1,4713 \\
1,5095 & 1,5911 \\
1,614 & 1,6939 \\
1,634 & 1,7456 \\
1,6505 & 1,9586 \\
1,6739 & 1,9681 \\
1,678 & 2,3824 \\
1,7306 & 2,5838 \\
1,8066 & 2,645 \\
1,8798 & 2,7388 \\
1,9311 & 2,8124 \\
1,9432 & 3,446 \\
1,959 & \\
2,0745 & \\
2,0986 & \\
\hline$\sum 47,152$ & \\
$\varnothing 1,3868$ & \\
& \\
& \\
&
\end{tabular}


Tabelle 6.3: Volumina aller dendritischer Dornfortsätze unterteilt in stumpfartige und pilzförmige Dornfortsätze

\begin{tabular}{ll}
\hline Stumpfartig $\left[\mu \mathrm{m}^{2}\right]$ & Pilzförmig $\left[\mu \mathrm{m}^{2}\right]$ \\
\hline 0,0232 & 0,0325 \\
0,0455 & 0,0365 \\
0,0486 & 0,0382 \\
0,0503 & 0,0449 \\
0,0529 & 0,0772 \\
0,0592 & 0,0786 \\
0,0906 & 0,0796 \\
0,0913 & 0,0868 \\
0,0918 & 0,0916 \\
0,0938 & 0,0999 \\
0,1028 & 0,1126 \\
0,1084 & 0,1212 \\
0,1207 & 0,1215 \\
0,1233 & 0,1223 \\
0,1518 & 0,1295 \\
0,1686 & 0,132 \\
0,1748 & 0,135 \\
0,1766 & 0,1526 \\
0,1788 & 0,162 \\
0,1821 & 0,1668 \\
0,1864 & 0,1704 \\
0,1963 & 0,2097 \\
0,2015 & 0,2126 \\
0,2072 & 0,2817 \\
0,2226 & 0,3407 \\
0,2295 & 0,3472 \\
0,2428 & 0,3723 \\
0,2741 & 0,4967 \\
0,3119 & 0,5429 \\
0,3331 & 0,6675 \\
0,3708 & \\
0,3723 & \\
0,4 & \\
0,4118 & \\
\hline$\sum 6,0954$ & \\
$\varnothing 0,1793$ & \\
& \\
\hline & \\
0 & \\
0 &
\end{tabular}


Tabelle 6.4: Alle Werte des Achsenverhältnisses der pilzförmigen und stumpfartigen dendritischen Dornfortsätze

\begin{tabular}{|c|c|}
\hline $\begin{array}{l}\text { Achsenverhältnis } \\
\text { Stumpfartig }\end{array}$ & $\begin{array}{l}\text { Achsenverhältnis } \\
\text { Pilzförmig }\end{array}$ \\
\hline 0,2537 & 0,2969 \\
\hline 0,2629 & 0,3203 \\
\hline 0,2998 & 0,3718 \\
\hline 0,3075 & 0,377 \\
\hline 0,321 & 0,3948 \\
\hline 0,322 & 0,4054 \\
\hline 0,3565 & 0,4381 \\
\hline 0,3731 & 0,4441 \\
\hline 0,3779 & 0,4456 \\
\hline 0,3826 & 0,4827 \\
\hline 0,4089 & 0,519 \\
\hline 0,4133 & 0,5487 \\
\hline 0,4446 & 0,556 \\
\hline 0,4544 & 0,5581 \\
\hline 0,4563 & 0,559 \\
\hline 0,476 & 0,5777 \\
\hline 0,4762 & 0,5878 \\
\hline 0,4767 & 0,5932 \\
\hline 0,4947 & 0,612 \\
\hline 0,5125 & 0,625 \\
\hline 0,5148 & 0,6315 \\
\hline 0,5301 & 0,6359 \\
\hline 0,5783 & 0,6405 \\
\hline 0,5998 & 0,6447 \\
\hline 0,6063 & 0,6447 \\
\hline 0,6068 & 0,674 \\
\hline 0,6164 & 0,6944 \\
\hline 0,6387 & 0,7851 \\
\hline 0,6469 & 0,8465 \\
\hline 0,6573 & 0,938 \\
\hline \multicolumn{2}{|l|}{0,7049} \\
\hline \multicolumn{2}{|l|}{0,7264} \\
\hline \multicolumn{2}{|l|}{0,8121} \\
\hline \multicolumn{2}{|l|}{0,8722} \\
\hline$\sum 16,9816$ & $\sum 16,8485$ \\
\hline$\varnothing 0,4995$ & $\varnothing 0,5616$ \\
\hline
\end{tabular}


Tabelle 6.5: Werte der Haupt- und Nebenachse eingeteilt in pilzförmige und in stumpfartige dendritische Dornfortsätze, aufsteigend sortiert

\begin{tabular}{|c|c|c|c|}
\hline $\begin{array}{l}\text { Hauptachse } \\
\text { Stumpfartig }[\mu \mathrm{m}]\end{array}$ & $\begin{array}{l}\text { Nebenachse } \\
\text { Stumpfartig }[\mu \mathrm{m}]\end{array}$ & $\begin{array}{l}\text { Hauptachse } \\
\text { Pilzförmig }[\mu \mathrm{m}]\end{array}$ & $\begin{array}{l}\text { Nebenachse } \\
\text { Pilzförmig }[\mu \mathrm{m}]\end{array}$ \\
\hline 0,2024 & 0,148 & 0,1867 & 0,1359 \\
\hline 0,5017 & 0,2233 & 0,346 & 0,1901 \\
\hline 0,5141 & 0,2319 & 0,3496 & 0,2182 \\
\hline 0,6542 & 0,2486 & 0,5014 & 0,2593 \\
\hline 0,6683 & 0,252 & 0,5447 & 0,289 \\
\hline 0,683 & 0,2834 & 0,574 & 0,3061 \\
\hline 0,7101 & 0,2981 & 0,6543 & 0,3324 \\
\hline 0,7383 & 0,3037 & 0,6587 & 0,3383 \\
\hline 0,7569 & 0,3062 & 0,6804 & 0,3411 \\
\hline 0,7944 & 0,3191 & 0,6884 & 0,3563 \\
\hline 0,8247 & 0,3202 & 0,7158 & 0,3763 \\
\hline 0,8844 & 0,331 & 0,764 & 0,3765 \\
\hline 0,9368 & 0,3578 & 0,7659 & 0,3821 \\
\hline 0,938 & 0,3654 & 0,7803 & 0,396 \\
\hline 0,9483 & 0,3992 & 0,8155 & 0,3966 \\
\hline 0,9512 & 0,416 & 0,8956 & 0,4127 \\
\hline 0,9557 & 0,4249 & 0,9325 & 0,4216 \\
\hline 1,0629 & 0,4269 & 1,0076 & 0,44 \\
\hline 1,0631 & 0,4328 & 1,103 & 0,4428 \\
\hline 1,071 & 0,4422 & 1,1093 & 0,4628 \\
\hline 1,0797 & 0,4485 & 1,1207 & 0,4733 \\
\hline 1,0833 & 0,4526 & 1,2148 & 0,5462 \\
\hline 1,0949 & 0,4544 & 1,2511 & 0,5616 \\
\hline 1,1315 & 0,5142 & 1,2638 & 0,5864 \\
\hline 1,1577 & 0,5511 & 1,2652 & 0,6073 \\
\hline 1,2039 & 0,5636 & 1,2663 & 0,6404 \\
\hline 1,2089 & 0,5722 & 1,3826 & 0,6882 \\
\hline 1,2167 & 0,6032 & 1,4228 & 0,7276 \\
\hline 1,2571 & 0,6658 & 1,4705 & 0,8017 \\
\hline 1,2822 & 0,7091 & 1,4743 & 0,9581 \\
\hline 1,4006 & 0,7958 & & \\
\hline 1,4277 & 0,8842 & & \\
\hline 1,4742 & 0,9547 & & \\
\hline 1,8597 & 1,2072 & & \\
\hline$\sum 33,7376$ & $\sum 15,9073$ & $\sum 27,205$ & $\sum 13,4649$ \\
\hline$\varnothing 0,9922$ & $\varnothing 0,4679$ & $\varnothing 0,9069$ & $\varnothing 0,4488$ \\
\hline
\end{tabular}


Tabelle 6.6: Werte aller Schnittvolumina aufgeteilt in pilzförmige und stumpfartige dendritische Dornfortsätze, aufsteigend sortiert

\begin{tabular}{ll}
\hline Stumpfartig $\left[\mu \mathrm{m}^{3}\right]$ & Pilzförmig $\left[\mu \mathrm{m}^{3}\right]$ \\
\hline 0,00331 & 0,00405 \\
0,00665 & 0,00477 \\
0,00882 & 0,00498 \\
0,00971 & 0,00542 \\
0,0101 & 0,00786 \\
0,0117 & 0,00965 \\
0,0118 & 0,0109 \\
0,0129 & 0,0131 \\
0,0131 & 0,0133 \\
0,0153 & 0,0135 \\
0,0155 & 0,0135 \\
0,0163 & 0,0141 \\
0,0168 & 0,0147 \\
0,0171 & 0,0167 \\
0,0176 & 0,0185 \\
0,0182 & 0,0189 \\
0,0201 & 0,0204 \\
0,0217 & 0,021 \\
0,0243 & 0,0218 \\
0,0245 & 0,0248 \\
0,0252 & 0,0256 \\
0,0259 & 0,027 \\
0,0274 & 0,027 \\
0,0278 & 0,0278 \\
0,0288 & 0,0304 \\
0,0291 & 0,0382 \\
0,0311 & 0,0426 \\
0,0328 & 0,0465 \\
0,0446 & 0,0477 \\
0,0463 & 0,0603 \\
0,05 & \\
0,0532 & \\
0,0555 & \\
0,1029 & \\
\hline$\sum 0,8761$ & 0,0450215 \\
&
\end{tabular}


Tabelle 6.7: Werte aller Schnittumfänge aufgeteilt in stumpfartige und pilzförmige dendritische Dornfortsätze, aufsteigend sortiert

\begin{tabular}{ll}
\hline Stumpfartig $[\mu \mathrm{m}]$ & Pilzförmig $[\mu \mathrm{m}]$ \\
\hline 0,8588 & 0,9235 \\
1,5156 & 1,1322 \\
1,6054 & 1,2534 \\
1,6759 & 1,4093 \\
1,8237 & 1,6167 \\
1,9772 & 1,698 \\
1,9788 & 1,7758 \\
2,0198 & 1,8712 \\
2,1221 & 2,02 \\
2,1966 & 2,065 \\
2,3528 & 2,1018 \\
2,4413 & 2,1452 \\
2,4827 & 2,1689 \\
2,4935 & 2,3335 \\
2,5691 & 2,5075 \\
2,5723 & 2,5255 \\
2,6823 & 2,6887 \\
2,7174 & 2,8393 \\
2,7588 & 2,8698 \\
2,7759 & 2,8958 \\
2,9474 & 2,9069 \\
2,9892 & 2,9658 \\
3,0805 & 3,3375 \\
3,0903 & 3,5145 \\
3,3252 & 3,5163 \\
3,4246 & 3,5568 \\
3,5016 & 3,5626 \\
3,6347 & 3,7816 \\
3,6868 & 3,9972 \\
3,7046 & 4,7232 \\
3,7476 & \\
3,843 & \\
3,9981 & \\
5,3268 & \\
\hline$\sum 93,0616$ & \\
$\varnothing 2,7371$ & \\
& \\
\hline & \\
& \\
&
\end{tabular}




\section{Materialverzeichnis}

CMF-HBSS

Gliamedium

N2-Medium

HBSS Puffer
Kalzium, Magnesium- und Bikarbonatfreie Hanks gepufferte Salzlösung (BSS) mit $10 \mathrm{mM}$ 4-(2-Hydroxyethyl)-1-Piperazin-Ethansulfonsäure (HEPES)

Komponenten:

10x Hanks-BSS (Invitrogen \#14175-095)

1 M HEPES-Puffer, pH 7,3 (Invitrogen \#15630-056)

Minimal essential medium (MEM) mit $10 \%$ Vol Pferdeserum ergänzt mit Glukose $(0,6 \%$ wt/vol $)$, Penicillin (100 U/ml), Streptomycin $(100 \mu \mathrm{m} / \mathrm{ml})$

Komponenten:

MEM mit Earles-Salz und L-Glutamin (Life

Technologies \#51200046)

D-Glukose (Sigma \#G8769)

Penicillin-Streptomycin (Biozym \#882082)

Pferdeserum (Biochrom \#S9135)

Komponenten:

10 mM Natriumpyruvat

$1 \mathrm{mM}$ Putrescin

$0,2 \mu \mathrm{M}$ Progesteron

$0,3 \mu \mathrm{M}$ Silendioxid

$1 \mathrm{mg} / \mathrm{ml}$ Rindertransferrin

$50 \mu \mathrm{g} / \mathrm{ml}$ Insulin

(Life Technlogies \#17502-048)

4-(2-Hydroxyethyl)-1-Piperazinethansulfonsäure(HEPES) mit Hanks gepufferter Salzlösung (BSS) (Invitrogen \#14175-095) 
Trypsin-Inhibitor

L-Cystein

HBSS

Neurobasal-A-Medium

B27 - Supplement

Glutamax-I Supplement

Poly-L-Lysin

Hydrochlorid

5-Fluoro-2'-Deoxyuridin

Uridin

DMEM

Pen/Strep

FCS Superior

10\% FCS-Medium

FUDR-STOCK
Sigma-Aldrich Cat.\#T-9253

Sigma-Aldrich Cat.\# C7352

Hanks Balanced Salt GIBCO BRL Cat.\#

24020-091, ThermoFisherScientific

$500 \mathrm{ml}$ Neurobasal- A (GIBCO Cat.\# 10888-022)

+10 ml B-27-Supplement (GIBCO Cat.\#

17504-044)

$+5 \mathrm{ml}$ Glutamax l-Stock

$+1000 \mathrm{U} / \mathrm{ml}$ Penicillin/Streptomycin (Biozym

\#882082)

GIBCO BRL Cat.\# 17504-044,

ThermoFisherScientific

GIBCO BRL Cat.\#35050-038,

ThermoFisherScientific

Sigma-Aldrich Cat.\#P2658

Sigms-Aldrich Cat.\#F-0503

Sigma-Aldrich Cat.\#U-3003

Lonza, Biozym Cat.\#880026

Lonza, Biozym Cat.\#882082

Biochrom Cat.\#S0615

437 ml DMEM (Biozym \#880026-12)

50 ml FCS (Biochrom \#S0415)

$10 \mathrm{ml}$ Glutamin (Biozym \#882027)

$3 \mathrm{ml}$ Pen/Strep (Biozym \#882082)

$25 \mathrm{mg}$ 5-Fluoro-2'-Deoxyuridin (8,1 mM) (Sigma \#F-0503)

62,5 mg Uridin (20,4 mM) (Sigma \#U-3003)

12,5 ml DMEM (Biozym \#880026-12) 
Sorgfältig mischen. Im Kühlschrank in $500 \mu \mathrm{l}$

Aliquots lagern.

$0,02 \mathrm{ml} /$ well wurden hinzugefügt

Inaktivierungslösung $\quad 25$ mg Albumin (Applichem \#A1391 0250)

$25 \mathrm{mg}$ Trypsin-Inhibitor (Sigma \#T9253)

$5 \mathrm{ml} 10$ \% FCS-Medium (Biochrom \#S0415)

Enzymlösung

2 mg Cystein (Sigma \#30090)

10 ml DMEM (Biozym \#880026-12)

$0,1 \mathrm{ml} \mathrm{CaCl}{ }_{2}(100 \mathrm{mM})$ (Merck \#1.02382.1000)

0,1 ml EDTA (50 mM) (Merck \#1.08418.1000)

20-25 U/ml Papain/Enzymlösung (Cell Systems \#LS003124)

Für 10-20 Minuten mit Carbogen-Gas begasen

Lösung im Wasserbad lagern, bis sie genutzt wird

Borat-Puffer (pH 8,5; $\quad$ Lösung 1 - 500 ml Base (Sigma \#S9640) $100 \mathrm{mM})$

Lösung 2 - 500 ml Säure (Sigma \#B0252)

Lösung 2 (Säure) wird in einen Becher gegeben,

Lösung 1 (Base) wird titriert, bis pH 8,5 erreicht ist

Plating-Medium

111 ml MEM (Gibco Cat.\#51200-046)

$66 \mathrm{mg}$ Glucose (3,3 mM) (Sigma \#G8769)

$11 \mathrm{ml}$ Pferdeserum (10 \%) (Biochrom \#S9135)

1,1 ml Glutamin (2 mM) (Biozym \#882027)

Salpetersäure

Sigma \#695033-2.5L

DNase

Roche \#10104159001

Paraffin

Merck \#1.071581000

Trypsin

Lonza \#3147

Saphirscheiben $(6 \mathrm{~mm} \quad 6 \mathrm{~mm} \times 0.1 \mathrm{~mm}, \# 616$, Engineering Office M.

Durchmesser)

Wohlwend GmbH, Sennwald, Switzerland

Deckgläser

TH Geyer \#9161062 


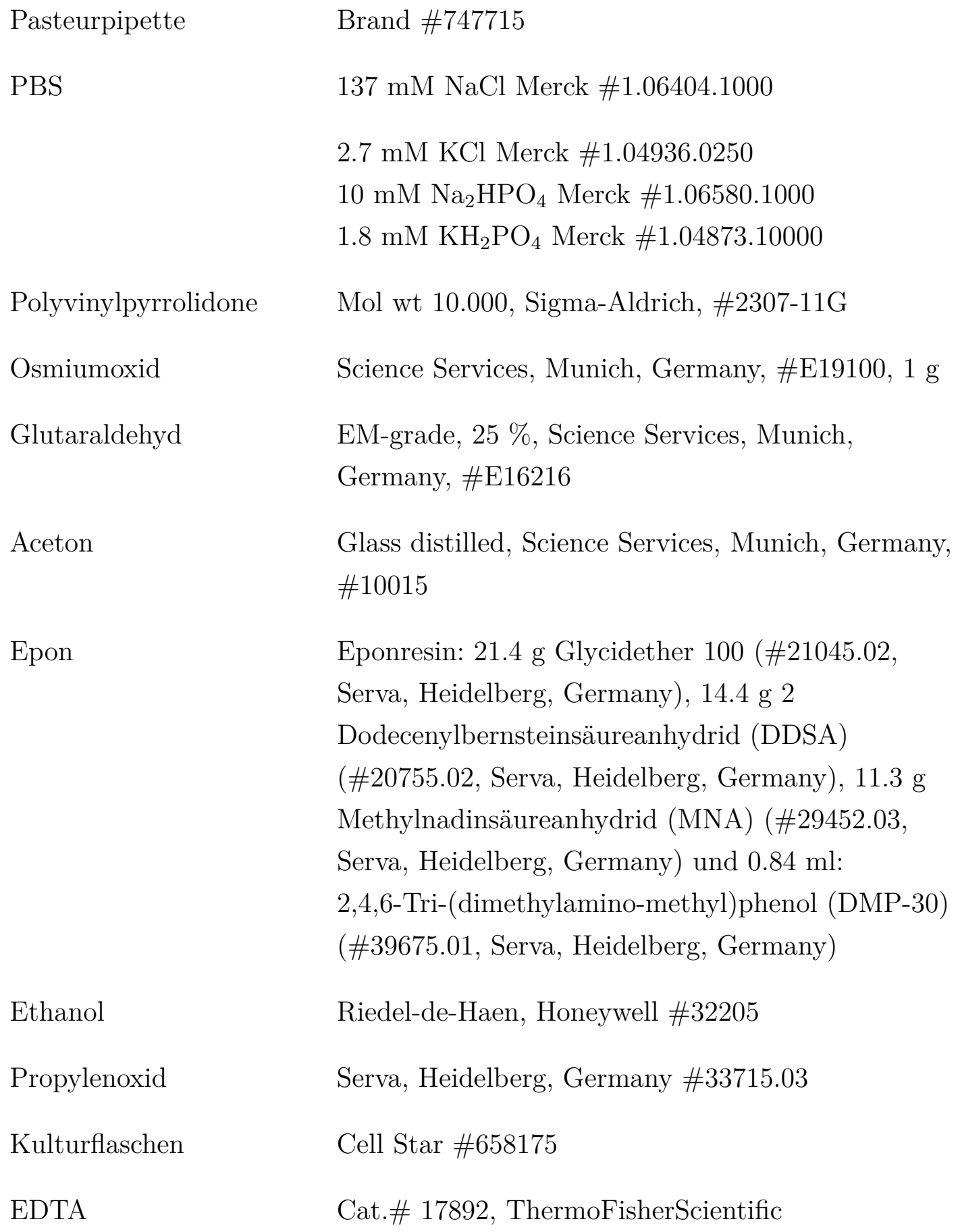




\section{Literaturverzeichnis}

[1]Azevedo FAC, Carvalho LRB, Grinberg LT, Farfel JM, Ferretti REL, Leite REP, Jacob Filho W, Lent R, Herculano-Houzel S (2009): Equal numbers of neuronal and nonneuronal cells make the human brain an isometrically scaled-up primate brain. J Comp Neurol $\underline{513}, 532-541$

[2]Bello-Medina PC, Flores G, Quirarte GL, McGaugh JL, Prado Alcala RA (2016): Mushroom spine dynamics in medium spiny neurons of dorsal striatum associated with memory of moderate and intense training. Proc Natl Acad Sci USA $\underline{113}$, E6516-E6525

[3]Bisbal M, Quassollo G, Caceres A (2016): Imaging Golgi Outposts in Fixed and Living Neurons. Methods Mol Biol 1496, 31-39

[4]Bourne J, Harris KM (2007): Do thin spines learn to be mushroom spines that remember? Curr Opin Neurobiol 17, 381-386

[5]Bourne JN, Harris KM (2008): Balancing structure and function at hippocampal dendritic spines. Annu Rev Neurosci 31, 47-67

[6]Bourne JN, Sorra KE, Hurlburt J, Harris KM (2007): Polyribosomes are increased in spines of CA1 dendrites $2 \mathrm{~h}$ after the induction of LTP in mature rat hippocampal slices. Hippocampus $\underline{17}, 1-4$

[7]Bredt DS, Nicoll RA (2003): AMPA Receptor Trafficking at Excitatory Synapses. Neuron 40, 361-379

[8]Buchs PA, Stoppini L, Parducz A, Siklos L, Muller D (1994): A new cytochemical method for the ultrastructural localization of calcium in the central nervous system. J Neurosci Methods $\underline{54}, 83-93$

[9]Burk K, Ramachandran B, Ahmed S, Hurtado-Zavala JI, Awasthi A, Benito E, Faram R, Ahmad H, Swaminathan A, McIlhinney J (2017): Regulation of Dendritic Spine Morphology in Hippocampal Neurons by Copine-6. (Cereb Cortex, im Druck) 
[10]Cajigas IJ, Tushev G, Will TJ, tom Dieck S, Fuerst N, Schuman EM (2012): The local transcriptome in the synaptic neuropil revealed by deep sequencing and highresolution imaging. Neuron $\underline{74}$, 453-466

[11]Caldwell JH, Schaller KL, Lasher RS, Peles E, Levison SR (2000): Sodium channel Nav1. 6 is localized at nodes of Ranvier, dendrites, and synapses. Proc Natl Acad Sci U S A $\underline{97}, 5616-5620$

[12]Chang FL, Greenough WT (1984): Transient and enduring morphological correlates of synaptic activity and efficacy change in the rat hippocampal slice. Brain res $\underline{309}$, $35-46$

[13]Chen Y, Bourne J, Pieribone VA, Fitzsimonds RM (2004): The role of actin in the regulation of dendritic spine morphology and bidirectional synaptic plasticity. NeuroReport $\underline{15}, 829-832$

[14]Chevaleyre V, Takahashi KA, Castillo PC (2006): Endocannabinoid-mediated synaptic plasticity in the CNS. Annu Rev Neurosci 29, 37-76

[15]Chicurel ME, Harris KM (1992): Three-dimensional analysis of the structure and composition of CA3 branched dendritic spines and thei synaptic relationships with mossy fiber boutons in the rat hippocampus. J Comp Neurol $\underline{325}$, 169-182

[16]Cho KO, Hunt CA, Kennedy MB (1992): The rat brain postsynaptic density fraction contains a homolog of Drosophila discs-large tumor suppressor protein. Neuron $\underline{9}, 929-942$

[17]Choquet D, Triller A (2013): The dynamic synapse. Neuron 무, 691-703

[18]Citri A, Malenka RC (2008): Synaptic plasticity: multiple forms, functions, and mechanisms. Neuropsychopharmacology $\underline{33}, 18-41$

[19]Constals A, Penn AC, Compans B, Toulmé E, Phillipat A, Marais S, Retailleau N, Hafner AS, Coussen F, Hosy E (2015): Glutamate-induced AMPA receptor desensitization increases their mobility and modulates short-term plasticity through unbinding from Stargazin. Neuron $\underline{85}$, 787-803

[20]Deller T, Mundel P, Frotscher M (2000): Potential role of synaptopodin in spine motility by coupling actin to the spine apparatus. Hippocampus 10, 569-581

[21]Deller T, Korte M, Chabanis S, Drakew A, Schwegler H, Stefani GG, Zuniga A, Schwarz K, Bonhoeffer T, Zeller R (2003): Synaptopodin-deficient mice lack a spine 
apparatus and show deficits in synaptic plasticity. Proc Natl Acad Sci U S A 100, 10494-10499

[22]Denker A, Bethani I, Kröhnert K, Körber C, Horstmann H, Wilhelm BG, Barysch SV, Kuner T, Neher E, Rizzoli SO (2011): A small pool of vesicles maintains synaptic activity in vivo. Proc Natl Acad Sci U S A $\underline{108}, 17177-17182$

[23]Engert F, Bonhoeffer T (1999): Dendritic spine changes associated with hippocampal long-term synaptic plasticity. Nature $\underline{399}, 66-70$

[24]Fifková E, Anderson CA (1981): Stimulation-induced changes in dimensions of stalks of dendritic spines in the dentate molecular layer. Exp Neurol 74, 621-627

[25]Fischer M, Kaech S, Wagner U, Brinkhaus H, Matus A (2000): Glutamate receptors regulate actin-based plasticity in dendritic spines. Nat Neurosci $\underline{3}, 887-894$

[26]Gardiol A, Racca C, Triller A (1999): Dendritic and postsynaptic protein synthetic machinery. Eur J Neurosci 19, 168-179

[27]Gray EG (1959): Axo-somatic and axo-dendritic synapses of the cerebral cortex: an electron microscope study. J Anat $\underline{93}$, 420-433

[28]Grintsevich EE (2017): Remodeling of Actin Filaments by Drebrin A and Its Implications. Adv Exp Med Biol 1006, 61-82

[29]Harris KM (1999): Structure, development, and plasticity of dendritic spines. Curr Opin Neurobiol $\underline{9}, 343-348$

[30]Harris KM, Stevens JK (1989): Dendritic spines of CA 1 pyramidal cells in the rat hippocampus: serial electron microscopy with reference to their biophysical characteristics. J Neurosci $\underline{9}, 2982-2997$

[31]Harris KM, Frances EJ, Tsao B (1992): Three-dimensional structure of dendritic spines and synapses in rat hippocampus (CA1) at postnatal day 15 and adult ages: implication for the maturation of synaptic physiology and long-term potentiation. J Neurosci 12, 2685-2705

[32]Hayashi K (2017): Cell Shape Change by Drebrin. Adv Exp Med Biol 1006, 83-101

[33]Hebb DO: The Organization of Behavior: a neuropsychological theory. 1. Auflage; Taylor Francis Inc, New York 2002

[34]Hering H, Sheng M (2001): Dendritic spines: structure, dynamics and regulation. Nat Rev Neurosci 2, 880-888 
[35]Holtmaat AJ, Trachtenberg JT, Wilbrecht L, Shepherd GM, Zhang X, Knott GW, Svoboda K (2005): Transient and persistent dendritic spines in the neocortex in vivo. Neuron $\underline{45}, 279-291$

[36]Horton AC, Ehlers MD (2003): Dual modes of endoplasmic reticulum-to-Golgi transport in dendrites revealed by live-cell imaging. J Neurosci $\underline{23}, 6188-6199$

[37]Islam MA, Sharif SR, Lee H, Seog D, Moon IS (2015): N-acetyl-D-glucosamine kinase interacts with dynein light-chain roadblock type 1 at Golgi outposts in neuronal dendritic branch points. Exp Mol Med 푸, e177

[38]Jiménez N, Humbel B, van Donselaar E, Verkleij AJ, Burger KNJ (2006): Aclar discs: a versatile substrate for routine high-pressure freezing of mammalian cell monolayers. J Microsc 221, 216-223

[39]Kaech S, Banker G (2006): Culturing hippocampal neurons. Nat Protoc 1 , 24062415

[40]Kim DY, Kim SH, Choi HB, Min C, Gwag BJ (2001): High abundance of GluR1 mRNA and reduced Q/R editing of GluR2 mRNA in individual NADPH-diaphorase neurons. Mol Cell Neurosci 17, 1025-1033

[41]Kistner U, Wenzel BM, Veh RW, Cases-Langhoff C, Garner AM, Appeltauer U, Voss B, Gundelfinger ED, Garner CC (1993): SAP90, a rat presynaptic protein related to the product of the Drosophila tumor suppressor gene dig-A. J Biol Chem 268, 4580-4583

[42]Kopec CD, Li B, Wei W, Boehm J, Malinow R (2006): Glutamate receptor exocytosis and spine enlargement during chemically induced long-term potentiation. J Neurosci 26, 2000-2009

[43]Korkotian E, Holcman D, Segal M (2004): Dynamic regulation of spine-dendrite coupling in cultured hippocampal neurons. Eur J Neurosci 20, 2649-2663

[44]Lang C, Barco A, Zablow L, Kandel ER, Siegelbaum SA, Zakharenko SS (2004): Transient expansion of synaptically connected dendritic spines upon induction of hippocampal long-term potentiation. Proc Natl Acad Sci U S A 101, 16665-16670

[45]Lee KS, Schottler F, Oliver M, Lynch G (1980): Brief bursts of high-frequency stimulation produce two types of structural change in rat hippocampus. J Neurophysiol $\underline{44}, 247-258$ 
[46]Lendvai B, Stern EA, Chen B, Svoboda K (2000): Experience-dependent plasticity of dendritic spines in the developing rat barrel cortex in vivo. Nature $\underline{404}, 876-881$

[47]Lorincz A, Nusser Z (2010): Molecular identity of dendritic voltage-gated sodium channels. Science $\underline{328}$, 906-909

[48]Malenka RC (1991): Postsynaptic factors control the duration of synaptic enhancement in area CA1 of the hippocampus. Neuron $\underline{6}, 53-60$

[49]Malenka RC (2003): Synaptic plasticity and AMPA receptor trafficking. Ann N Y Acad Sci 1003, 1-11

[50]Malenka RC, Nicoll RA (1993): NMDA-receptor-dependent synaptic plasticity: multiple forms and mechanisms. Trends Neurosci $\underline{16}, 521-527$

[51]Maletic-Savatic M, Malinow R, Svoboda K (1999): Rapid Dendritic Morphogenesis in CA1 Hippocampal Dendrites Induced by Synaptic Activity. Science 283, 19231927

[52]Mameli M, Balland B, Luján R, Lüscher C (2007): Rapid synthesis and synaptic insertion of GluR2 for mGluR-LTD in the ventral tegmental area. Science $\underline{317}$, $530-533$

[53]Matsuzaki M, Ellis-Davies GC, Nemoto T, Miyashita Y, Iino M, Kasai H (2001): Dendritic spine geometry is critical for AMPA receptor expression in hippocampal CA1 pyramidal neurons. Nat Neurosci $\underline{4}, 1086-1092$

[54]Matsuzaki M, Honkura N, Ellis-Davies GCR, Kasai H (2004): Structural basis of long-term potentiation in single dendritic spines. Nature $\underline{429}, 761-766$

[55]Mayer ML, Westbrook GL, Guthrie PB (1984): Voltage-dependent block by Mg2+ of NMDA responses in spinal cord neurones. Nature 309, 261-263

[56]McDonald KL, Webb RI (2011): Freeze substitution in 3 hours or less. J Microsc $\underline{243}, 227-233$

[57]Montagna E, Dorostkar MM, Herms J (2017): The Role of APP in Structural Spine Plasticity. Front Mol Neurosci 10, 136

[58]Nägerl UV, Eberhorn N, Cambridge SB, Bonhoeffer T (2004): Bidirectional activity-dependent morphological plasticity in hippocampal neurons. Neuron $\underline{44}$, 759-767 
[59]Nägerl UV, Köstinger G, Anderson JC, Martin KAC, Bonhoeffer T (2007): Protracted synaptogenesis after activity-dependent spinogenesis in hippocampal neurons. J Neurosci 27, 8149-8156

[60]Nakanishi S, Masu M (1994): Molecular diversity and functions of glutamate receptors. Annu Rev Biophys Biomol Struct 23, 319-348

[61]Nikolaev MV, Magazanik LG, Tikhonov DB (2012): Influence of external magnesium ions on the NMDA receptor channel block by different types of organic cations. Neuropharmacology $\underline{62}, 2078-2085$

[62] Ostroff LE, Fiala JC, Allwardt B, Harris KM (2002): Polyribosomes redistribute from dendritic shafts into spines with enlarged synapses during LTP in developing rat hippocampal slices. Neuron $\underline{35}, 535-545$

[63]Parnass Z, Tashiro A, Yuste R (2000): Analysis of spine morphological plasticity in developing hippocampal pyramidal neurons. Hippocampus $\underline{10}, 561-568$

[64]Pierce JP, Mayer T, McCarthy JB (2001): Evidence for a satellite secretory pathway in neuronal dendritic spines. Curr Biol 11, 351-355

[65]Popov VI, Davies HA, Rogachevsky VV, Patrushev IV, Errington ML, Gabbott PLA, Bliss TVP, Stewart MG (2004): Remodelling of synaptic morphology but unchanged synaptic density during late phase long-term potentiation (LTP): a serial section electron micrograph study in the dentate gyrus in the anaesthetised rat. Neuroscience $\underline{128}, 251-262$

[66]Ramón y Cajal S (1888): Estructura de los centros nerviosos de las aves. Rev Trim Histol Norm $\underline{1}, 1-10$

[67]Rassow J, Hauser K, Netzker R, Deutzmann R: Duale Reihe-Biochemie 3. Aufl.; Thieme, Stuttgart 2012

[68]Romeis, Mikroskopische Technik. Hrsg. v. Mulish M, Welsch U, 18. Aufl.; Springer Spektrum, Heidelberg 2010

[69]Rosahl TW, Geppert M, Spillane D, Herz J, Hammer RE, Malenka RC, Südhof TC (1993): Short-term synaptic plasticity is altered in mice lacking synapsin I. Cell $\underline{75}$, $661-670$

[70]Sabatini BL, Svoboda K (2000): Analysis of calicum channels in single spines using optical fluctuation analysis. Nature $\underline{408}, 589-593$ 
[71]Sabatini BL, Maravall M, Svoboda K (2001): Ca(2+) signaling in dendritic spines. Curr Opin Neurobiol 11, 349-356

[72]Schiffelholz T, Aldenhoff JB (2002): Novel object presentation affects sleep-wake behavior in rats. Neurosci Lett $\underline{328}, 41-44$

[73]Schwarb P: Morphologische Grundlagen zur Zell-Zell Interaktion bei adulten Herzmuskelzellen in Kultur. Naturwis. Diss. ETH Zürich 1900

[74]Segal M, Vlachos A, Korkotian E (2010): The spine apparatus, synaptopodin, and dendritic spine plasticity. Neuroscientist 16, 125-131

[75]Sorra KE, Harris KM (1998): Stability in synapse number and size at $2 \mathrm{hr}$ after long-term potentiation in hippocamal area CA1. J Neurosci 18, 658-671

[76]Sorra KE, Harris KM (2000): Overview on the structure, composition, function, development, and plasticity of hippocampal dendritic spines. Hippocampus $\underline{10}, 501-$ 511

[77]Spacek J, Harris KM (1997): Three-dimensional organization of smooth endoplasmatic reticulum in hippocampal CA1 dendrites and dentritic spines of the immature and mature rats. J Neurosci $\underline{17}$, 190-203

[78]Stewart MG, Medvedev NI, Popov VI, Schoepfer R, Davies HA, Murphy K, Dallérac GM, Kraev IV, Rodríguez JJ (2005): Chemically induced long-term potentiation increases the number of perforated and complex postsynaptic densities but does not alter dendritic spine volume in CA1 of adult mouse hippocampal slices. Eur J Neurosci 21, 3368-3378

[79]Toni N, Buchs PA, Nikonenko I, Bron CR, Muller D (1999): LTP promotes formation of multiple spine synapses between a single axon terminal and a dendrite. Nature $\underline{402}, 421-425$

[80]Toni N, Buchs PA, Nikonenko I, Povilaitite P, Parisi L, Muller D (2001): Remodeling of synaptic membranes after induction of long-term potentiation. J Neurosci 21, $6245-6251$

[81]Wegner W, Mott AC, Grant SGN, Steffens H, Willig KI (2018): In vivo STED microscopy visualizes PSD95 sub-sutrctures and morphological changes over several hours in the mouse visual cortex. SciRep 8:219 
[82] Wegner W, Ilgen P, Gregor C, van Dort J, Mott AC, Steffens H, Willig KI (2018): In vivo mouse and live cell STED microscopy of neuronal actin plasticity using far-red emitting fluorescent proteins. SciRep 7:11781

[83]Wu K, Aoki C, Elste A, Rogalski-Wilk AA, Siekevitz P (1997): The synthesis of ATP by glycolytic enzymes in the postsynaptic density and the effect of endogenously generated nitric oxide. Proc Natl Acad Sci U S A 무, 13273-13278

[84]Wu Q, Sun M, Bernard LP, Zhang H (2017): Postsynaptic density 95 (PSD-95) serine 561 phosphorylation regulates a conformational switch and bidirectional dendritic spine structural plasticity. J Biol Chem 292, 16150-16160

[85]Yasuda R (2017): Biophysics of Biochemical Signaling in Dendritic Spines: Implications in Synaptic Plasticity. Biophys J 113, 2152-2159

[86]Zhou Q, Homma KJ, Poo M (2004): Shrinkage of dendritic spines associated with long-term depression of hippocampal synapses. Neuron 44, 749-757

[87]Zucker RS, Regehr WG (2002): Short-term synaptic plasticity. Annu Rev Physiol $\underline{64}, 355-405$

[88]Zuo Y, Lin A, Chang P, Gan W (2005): Development of long-term dendritic spine stability in diverse regions of cerebral cortex. Neuron $\underline{46}, 181-189$ 


\section{Danksagung}

An erster Stelle möchte ich meinem Doktorvater Herrn Prof. Dr. Silvio O. Rizzoli für die gute Betreuung während der gesamten Zeit danken. Die ständige Erreichbarkeit und die geduldige Hilfsbereitschaft habe ich nicht als selbstverständlich angesehen.

Ich danke Herrn PD Dr. Rickmann für die hilfsbereite und nette Unterstützung als Zweitbetreuer, sowie Herrn Martin Helm und Frau Christina Schäfer für die Hilfestellungen.

Besonders danken möchte ich Herrn Dr. Falko Partosch für die große Hilfe beim Formatieren der Arbeit und Frau Vanessa Salimi für die gute und nette Zusammenarbeit in der Arbeitsgruppe.

Ein weiterer Dank gilt auch Dr. Uwe Koerbs, Annegret Koerbs, Dr. Alexander Koerbs sowie Dr. Inga Könemund für ihre Hilfe und den großen Beistand. 